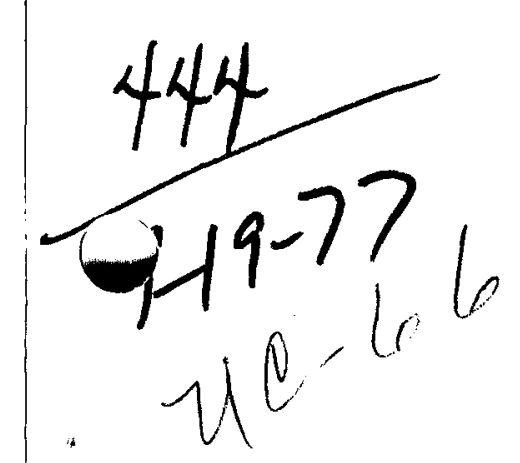

Lh. 1420

TREE-1164

\title{
FLOATING POWER OPTIMIZATION STUDIES \\ FOR THE COOLING SYSTEM OF A \\ GEOTHERMAL POWER PLANT
}

C. J. SHAFFER

August 1977

Mhotu

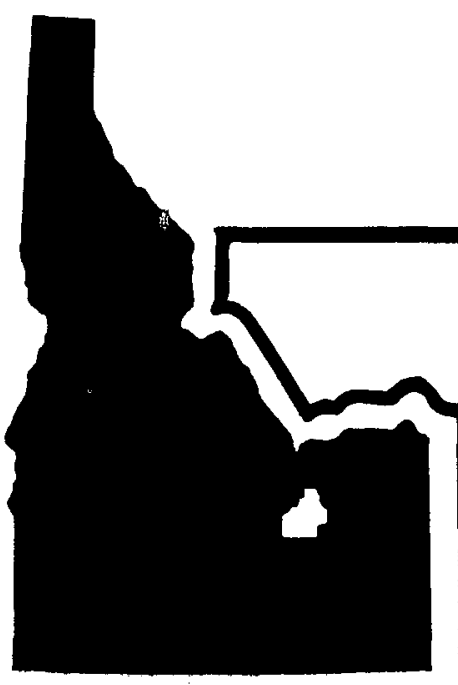

EG\&G Idaho, Inc.

IDAHO NATIONAL ENGINEERING LABORATORY

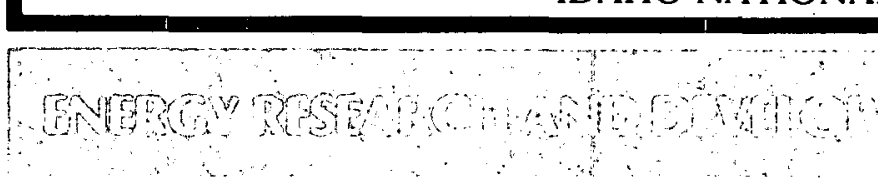

IDAHO OPERATIONS OFFICE UNDER CONTRACT EY-76-C-07-1570 


\section{DISCLAIMER}

This report was prepared as an account of work sponsored by an agency of the United States Government. Neither the United States Government nor any agency Thereof, nor any of their employees, makes any warranty, express or implied, or assumes any legal liability or responsibility for the accuracy, completeness, or usefulness of any information, apparatus, product, or process disclosed, or represents that its use would not infringe privately owned rights. Reference herein to any specific commercial product, process, or service by trade name, trademark, manufacturer, or otherwise does not necessarily constitute or imply its endorsement, recommendation, or favoring by the United States Government or any agency thereof. The views and opinions of authors expressed herein do not necessarily state or reflect those of the United States Government or any agency thereof. 


\section{DISCLAIMER}

Portions of this document may be illegible in electronic image products. Images are produced from the best available original document. 
Printed in the United States of America Available from

National Technical Information Service

U.S. Department of Commerce

5285 Port Royal Road

Springfield, Virginia 22161

Price: Printed Copy $\$ 3.00$

\section{NOT ICE}

This report was prepared as an account of work sponsored by the United States Government. Neither the United States nor the Energy Research and Development Administration, nor any of their employees, nor any of their contractors, subcontractors, or their employees, makes any warranty, express or implied, or assumes any legal liability or responsibility for the accuracy, completeness or usefulness of any information, apparatus, product or process disclosed, or represents that its use would not infringe privately owned rights. 


\section{FLOATING POWER OPTIMIZATION STUDIES \\ FOR THE COOLING SYSTEM OF A GEOTHERMAL POWER PLANT}

\section{J. Shaffer}

Physics Division

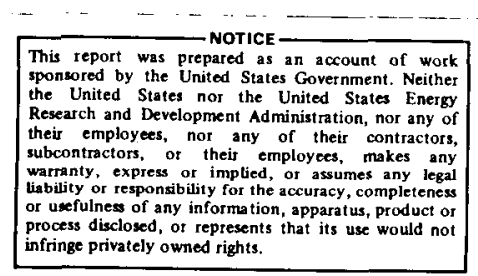

EG\&G IDAHO, INC.

Date Published - August 1977

PREPARED FOR THE ENERGY RESEARCH \& DEVELOPMENT ADMINISTRATION IDAHO OPERATIONS OFFICE

UNDER CONTRACT NO. EY-76-C-07-1570 


\section{ABSTRACT}

The floating power concept was studied for a geothermal power plant as a method of increasing the plant efficiency and decreasing the cost of geothermal power. The stored cooling concept was studied as a method of reducing the power fluctuations of the floating power concept. The studies include parametric and optimization studies for a variety of different types of cooling systems including wet and dry cooling towers, direct and indirect cooling systems, forced and natural draft cooling towers, and cooling ponds. The studies use an indirect forced draft wet cooling tower cooling system as a base case design for comparison purposes. 
The floating power concept was studied for a geothermal power plant as a method of increasing the plant efficiency and descreasing the cost of geothermal power. The floating power concept refers to the operation of an atmospheric cooled geothermal power plant such that the net power output is allowed to fluctuate with the atmospheric conditions in order to produce as much power as possible. These studies include parametric and optimization studies for a variety of different types of cooling systems centering around the base case design of an indirect forced draft wet cooling tower cooling system. The cooling system types include wet and dry cooling towers, direct and indirect cooling systems, forced and natural draft cooling towers, and cooling ponds. The floating power concept was found to be a viable method for realizing a significant power increase in power plants cooled by the atmosphere. Floating power coefficients of performance (ratio of the yearly averaged floating power to the design power) calculated were on the order of 1.2 for the wet cooling systems and on the order of 1.5 to 2.5 for the dry cooling systems. These coefficients illustrate the inefficient use of the atmospheric cooling potential by most cooling systems designs.

The major disadvantage of the floating power concept is the power fluctuations resulting from the floating power. The stored cooling concept was studied as a method of reducing these power fluctuations. This concept stores colder cooling water from times of good cooling conditions to be used during times of poor cooling conditions thereby reducing the severity of the power fluctuations. One possible system would involve inserting a volume of water into the cooling water loop between the cooling tower exit and the condenser inlet which would act as a thermal capacitor by dampening out the power fluctuations. The stored cooling concept has the capacity of dampening the floating power fluctuations but requires the use of relatively large volumes of stored water. It will for instance require a volume of water on the order of $10^{8}$ cubic feet (2300 acre $\mathrm{ft}$ ) to reduce just the greatest daily fluctuation down to about one percent 
of the yearly averaged net power. The cost effectiveness of the stored cooling concept will have to be evaluated for each individual power plant design and must trade-off the increased power production of the floating power concept with the disadvantage of either the floating power fluctuations on the power grid or the cost of dampening the fluctuations. 
CONTENTS

Page

ABSTRACT. . . . . . . . . . . . . . . . . . . . i

SUMMARY . . . . . . . . . . . . . . . . . . . . . i i

I. INTRODUCTION ........................ 1

II. FLOATING POWER CONCEPT . . . . . . . . . . . . . 2

1. Theoretical Aspects of the Floating Power Concept. . . . 2

1.1 The Average Net Power Output. . . . . . . . . . 3

1.2 The Average Energy Conversion Efficiency ...... 5

1.3 The Floating Power Coefficient of Performance . . . 6

1.4 The Plant Reduction Percentage. . . . . . . . 8

1.5 Floating Power Fluctuation Parameters . . . . . . 9

2. Atmospheric Data Base. . . . . . . . . . . 12

2.1 NOAA Data Tapes ............... 12

2.2 Temperature Statistics............. 12

2.3 Solar Insolation Data Approximation . . . . . . 15

3. Practical Aspects of the Floating Power Concept. . . . 15

3.1 Design Base Case. . . . . . . . . . . . 17

3.1.1 System Configuration. . . . . . . . . 17

3.1.2 System Mode1.............. 17

3.1.3 Design Base Case Power Plant
Characteristics............... 23

3.1.4 The Design Base Case Floating
Power Parameters. . . . . . . . . . 31

3.1.5 The Design Base Case Floating
Power Fluctuations................ 33

3.2 Base Case Sensitivity Studies . . . . . . . . 33

3.2.1 Concenser Area Sensitivity. . . . . . . 33

3.2.2 Cooling Water Flow Rate Sensitivity ... . 39

3.3 Comparison of the Design Base Case with
Other System Types....................... 39

3.3.1 Dry Cooling Towers. . . . . . . . 39

3.3.2 Direct Dry Cooling. ........... 43

3.3.3 Direct Wet Cooling and Hybrids. . . . . . 48

3.3.4 Natural Draft Cooling Systems ....... 51

3.3.5 Systems Comparison to the Atmospheric
Cooling Potential.............. 54 
CONTENTS (contd)

Page

III. STORED COOLING CONCEPT . . . . . . . . . . . 62

1. Theoretical Aspects of the Stored Cooling Concept. . . . 62

2. Practical Aspects of the Stored Cooling Concept. . . . . 64

2.1 Adiabatic Stored Water Systems. . . . . . . 64

2.2 Non-Adiabatic Stored Water Systems. . . . . . . 64

2.2.1 Closed Water Storage Systems. . . . . . 66

2.2.2 Open Water Storage Systems. . . . . . 66

2.3 Phase Stored Cooling. ............. 71

IV. CONCLUSIONS AND RECOMMENDATIONS. ........... 73

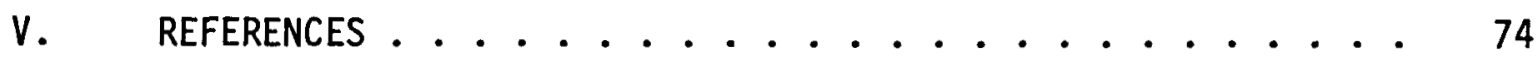

APPENDIX A: The Monthly Average Days for the Base

Case Design. . . . . . . . . . . 75 
FIGURES

Page

1. The Plant Reduction Percentage ............ 10

2. Binary Cycle Geothermal Power Plant. . . . . . . . . 18

3. Reaction Turbine Efficiency. ............ 20

4. Base Case Net Electrical Power vs. the Atmospheric

Wet Bulb Temperature ................ 24

5. Base Case Condensing Temperature vs. the

Atmospheric Wet Bulb Temperature ........... 25

6. Base Case Condensing Pressure vs. the

Atmospheric Wet Bulb Temperature ............. 26

7. Base Case Condenser Cooling Water Exit

Temperature vs. the Atmospheric Wet Bulb Temperature . . . . 27

8. Base Case Condenser Cooling Water Inlet

Temperature vs. the Atmospheric Wet Bulb Temperature . . . . . 28

9. Base Case Make-up Water Flow Rate vs. the

Atmospheric Wet Bulb Temperature ............ 29

10. Base Case Net Electrical Power vs. the Condenser

Cooling Water Inlet Temperature. . . . . . . . . 30

11. The Daily Averaged Net Electrical Floating

Power for 1959................. 35

12. The Monthly Averaged Net Electrical Floating

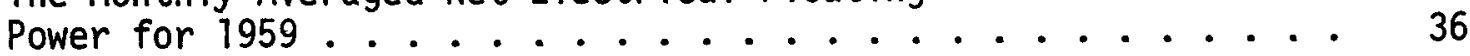

13. The Net Electrical Floating Power for the Average

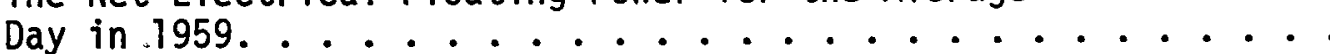

14. Sensitivity of the Yearly Averaged Net Power

to the Condenser Area. .............. 38

15. Sensitivity of the Yearly Averaged Net Power

to the Cooling Water Flow Rate............ 40

16. Dry-Wet Cooling Tower Power Plant

Characteristics Comparison .............

17. Comparison of Power Plant Characteristics for the Direct

Dry Cooling and the Wet Cooling Towers .......... 
FIGURES (contd)

18. Direct Wet Cooling and Hybrid Power

Plant Characteristics...............

19. Net Electrical Power as a Function of

Condensing Temperature ............. 55

20. Cooling Systems Comparisons on the Basis

of Power and Fluctuations. ..............

21. Cooling Systems Effective

Approach Temperature ................

22. Size Sensitivity of the Adiabatic Stored

Water System ...............

23. Heat Load Sensitivity of the Non-Adiabatic Stored

Water System (for a volume of $10^{7} \mathrm{ft}^{3}$ ) .........

24. Heat Load Sensitivity of the Non-Adiabatic Stored

Water System (for a volume of $108 \mathrm{ft} 3$ ) ......... 68

25. Storage Cooling Systems Comparisons. . . . . . . . . 70

A1. The Net Electrical Floating Power for the

Average Day in January, $1959 \ldots \ldots$

A2. The Net Electrical Floating Power for the

Average Day in February, 1959............

A3. The Net Electrical Floating Power for the

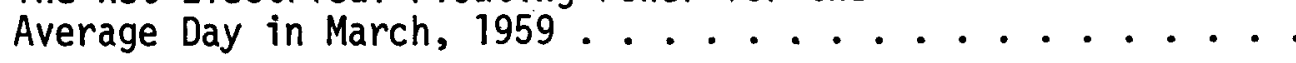

A4. The Net Electrical Floating Power for the Average Day in Apri1, 1959...........

A5. The Net Electrical Floating Power for the Average Day in May, 1959 ............

A6. The Net Electrical Floating Power for the Average Day in June, 1959.............

A7. The Net Electrical Floating Power for the Average Day in July, 1959..............

A8. The Net Electrical Floating Power for the Average Day in August, 1959.............

A9. The Net Electrical Floating Power for the Average Day in September, $1959 \ldots \ldots . . . .$. 


\section{FIGURES (contd)}

A10. The Net Electrical Floating Power for the Average Day in October 1959.................

A11. The Net Electrical Floating Power for the Average Day in November, 1959................

A12. The Net Electrical Floating Power for the Average Day in December, 1959............... 


\section{TABLES}

Page

I. Table of Temperature Integrals for Pocatello, Idaho .... 13

II. Table of Temperature Integrals for Idaho Falls, Idaho . . . 14

III. Wet and Dry Bulb Temperature Distributions for Pocatello, Idaho During 1959. . . . . . . . . . 16

IV. Base Case Parameters. . . . . . . . . . . . 22

V. Floating Turbine Efficiencies . . . . . . . . . . 32

VI. Base Case Power Fluctuation Parameters. . . . . . . . . 34

VII. Floating Power Parameter for the Dry
Cooling Tower System. . . . . . . . . . . . . . 44

VIII. Floating Power Parameters for the Direct
Dry Cooling System. . . . . . . . . . . . . 47

IX. Floating Power Parameters for the Direct Wet Cooling and Hybrid Systems. . . . . . . . . 52

X. Natural Draft Cooling Floating Power Parameters . . . . . 53

XI. Floating Power Parameters for the Idealized System. . . . . 56

XII. Cooling Systems Comparison Parameters . . . . . . . . 59 


\section{INTRODUCTION}

Floating power operation of a geothermal power plant is one possible method of increasing the plant efficiency and decreasing the cost of geothermal power. Floating power operation refers to the operation of an atmospheric cooled geothermal power plant such that the net power output is allowed to fluctuate with the atmospheric conditions in order to produce as much power as possible. That is, the turbine back pressure is reduced due to a lower condensing temperature as the atmospheric temperature drops. This operation can produce a significantly greater amount of power than the standard constant power operation from essentially the same power plant. The major disadvantage of the floating power concept is that the net power will fluctuate up and down as the atmospheric temperature varies.

The stored cooling concept was evaluated as a possible method of reducing the floating power fluctuations. This concept stores colder cooling water from times of good cooling conditions to times of poor cooling conditions thereby reducing the severity of the power fluctuations. One possible system would involve inserting a volume of water into the cooling water loop between the cooling tower exit and the condenser inlet which would act as a thermal capacitor by dampening out the power fluctuations.

Several types of cooling systems were studied including both wet and dry cooling towers of the indirect and direct types, forced and natural draft types, and cooling ponds. The studies included optimization studies for the different cooling systems but were centered around a base case design for comparison purposes. These studies were done using actual atmospheric data taken by the National Atmospheric and Oceanic Administration. 


\section{FLOATING POWER CONCEPT}

The floating power concept refers to the operating mode of the power plant in which the cooling system is allowed to operate at full capacity regardless of the atmosphere heat sink temperature. The clear advantage of this concept is the production of more power from the same power plant design than would be possible if the plant was operated at a constant design power. A wet cooling tower is usually designed such that the wet bulb temperature does not exceed the design wet bulb temperature more than a given percentage (such as $5 \%$ ) of the time during the year but during this

given percentage time, the power plant is unable to maintain constant design power. The power output is held constant during the remainder of the year by not using the full cooling potential.

The floating power concept suggests that the full cooling potential be used to produce as much power as possible from a given power plant design. The disadvantages of this concept are: (1) the plant power output varies with the heat sink temperature which translates into a variable turbine back pressure, and (2) the plant (especially the turbine-generator set) must be designed to handle the fluctuating power.

\section{THEORETICAL ASPECTS OF THE FLOATING POWER CONCEPT}

The calculation of the average power output of a particular floating power plant design requires: (1) the power plant power characteristics and, (2) adequate atmospheric heat sink data over the period of time to be evaluated. The power plant power characteristics are the data and/or relationships necessary to predict the power plant net power output as a function of the heat sink data (either the wet or the dry bulb temperature heat sinks). The atmospheric heat sink data consists of the wet and the dry bulb temperatures, the relative humidity, the wind velocity, the atmospheric pressure, and the solar insolation. This is usually taken over a one year period, and taken at one hour intervals for good results. The types of heat sink data required for a particular calculation depends upon the type and complexity of the power plant power characteristics. 


\subsection{The Average Net Power Output}

The Average net power of a floating power plant is calculated by integrating the net power over a period of time and is defined by the following expression:

$$
P_{a}=\frac{1}{\Delta t} \int_{\Delta t} P\left(T_{d}, T_{w}, \phi, V, P_{a t m}, S\right) d t
$$

where: $\mathrm{P}_{\mathrm{a}}=$ the average net power

$\mathrm{P}=$ the net power as a function of the atmospheric conditions which are a function of time.

$\Delta t=$ the time period of the average.

$T_{d} \quad=$ the dry bulb temperature

$T_{W}=$ the wet bulb temperature

$\phi \quad=$ the relative humidity

$V \quad=$ the wind velocity

$P_{\text {atm }}=$ the atmospheric pressure

$S=$ the solar insolation

Normally Equation (1) requires solution by numerical methods but in at least one simplified type of conditions, the equation can be simplified to the point that the average power can be calculated by hand. The assumptions necessary in order to perform these hand calculations are (1) the power plant net power is a function of either the wet or the dry bulb temperature only and, (2) the net power can be characterized by a polynomial equation of that temperature. Such an equation might be obtained 
by a polynomial least squares fit of power plant characteristics data as shown in Equation (2) below:

$$
P=c_{0}+c_{1} T+c_{2} T^{2}+c_{3} T^{3}+\ldots+c_{n} T^{n}
$$

where: $P=$ the net power

$$
\begin{aligned}
& T \quad=\text { either the wet or dry bulb temperature } \\
& C_{n} \quad=\text { polynomial constants }
\end{aligned}
$$

Inserting Equation (2) into Equation (1) and simplifying results in Equation (3).

$$
\begin{aligned}
P_{a}= & \frac{C_{0}}{\Delta t} \int_{\Delta t} d t+\frac{C_{1}}{\Delta t} \int_{\Delta t} T d t+\frac{C_{2}}{\Delta t} \int_{\Delta t} T^{2} d t+\frac{C_{3}}{\Delta t} \int_{\Delta t} T^{3} d t+\ldots \\
& +\frac{c_{n}}{\Delta t} \int_{\Delta t} T^{n} d t
\end{aligned}
$$

The integrals yield the average values of the quantity $T^{n}$ over the period $\Delta t$ so that Equation (3) can be rewritten as Equation (4).

$$
P_{a}=C_{0}+C_{1} I_{1}+C_{2} I_{2}+C_{3} I_{3}+\ldots+C_{n} I_{4}
$$

where: $I_{n}=$ the temperature integral of the order $n$

$$
=\frac{1}{\Delta t} \int_{\Delta t} T^{n} d t
$$

This approach to the solution of Equation (1) requires the evaluation of the $I_{n}$ temperature integrals which for a one year period of data will 
need to be evaluated by computer. However, once these integrals have been evaluated for a particular location and time period, the net power averages for a variety of power plant characteristics can be quite readily determined. Should the plant characteristics be linear (i.e., the constants $C_{n}$ for $n$ greater or equal to 2 are equal to zero) only the average temperature (first integral) is needed and that number is usualiy readily available.

\subsection{The Average Energy Conversion Efficiency}

Equations can be written for the power plant energy conversion efficiency similar to Equations (1) through (4) for the net power, i.e.,

$$
\begin{aligned}
& n_{a}=\frac{1}{\Delta t} \int_{\Delta t} \eta\left(T_{d}, T_{w}, \phi, V, P_{a t m}, S\right) d t \\
& n=C_{0}^{\prime}+C_{1}^{1} T+C_{2}^{1} T^{2}+C_{3}^{\prime} T^{3}+\ldots .+C_{n}^{\prime} T^{n} \\
& n_{a}=C_{0}^{\prime}+C_{1}^{\prime} I_{1}+C_{2}^{\prime} I_{2}+C_{3}^{\prime} I_{3}+\ldots .+C_{n}^{\prime} I_{n}
\end{aligned}
$$

where: $n_{a}=$ the effective average efficiency

$$
\begin{aligned}
& n=\text { the power plant energy conversion efficiency } \\
& C_{n}^{\prime} \quad=\text { polynomial constants }
\end{aligned}
$$

The polynomial constants $C_{n}^{\prime}$ are proportional to the polynomial constants $c_{n}$ assuming that the power source conditions are constant, i.e., the brine mass flow rate and temperature, the boiler temperature and pressure, and etc. remain constant as the heat sink temperature varies. More simply, these equations assume that the energy conversion efficiency can be expressed by $n=P / Q$ where $Q$ is equal to the energy removed from the brine and is constant (therefore, $C_{n}^{\prime}=C_{n} / Q$ ). 


\subsection{The Floating Power Coefficient of Performance}

The value of the floating power concept is reflected in the floating power coefficient of performance which is defined by the following equation.

$$
C O P=\frac{P_{a}}{P_{\text {design }}}=\frac{n_{a}}{n_{\text {design }}}
$$

where: $\quad C O P=$ the floating power coefficient of performance

$$
\begin{aligned}
P_{\text {design }}= & \text { the net power output at the design heat sink } \\
& \text { temperature } \\
{ }^{n} \text { design }= & \text { the power plant energy conversion efficiency at } \\
& \text { the design heat sink temperature }
\end{aligned}
$$

The power plant characteristics for a Carnot cycle will now be considered as an example of the coefficient of performance, i.e.,

$$
\eta_{C}=1-\frac{T_{L}}{T_{H}}
$$

where: $n_{c}=$ the efficiency of the Carnot cycle

$$
\begin{aligned}
& T_{H}=\text { the heat source temperature } \\
& T_{L}=\text { the heat sink temperature }
\end{aligned}
$$

The Carnot coefficient of performance where the average efficiency is evaluated at the average heat sink temperature and the design efficiency is evaluated at the design heat sink temperature is given by the following equation;

$$
\operatorname{COP}_{C}=\frac{T_{H}-T_{\text {ave }}}{T_{H}-T_{\text {design }}}
$$


where: $\quad{ }_{C O P}=$ the Carnot coefficient of performance

Two numerical examples of Equation (10) are offered in examples 1 and 2.

\section{Example 1.}

$$
\begin{aligned}
& T_{H}=300^{\circ} \mathrm{F} \\
& T_{\text {ave }}=39^{\circ} \mathrm{F} \text { (wet bulb average temperature) } \\
& T_{\text {design }}=65^{\circ} \mathrm{F} \\
& \mathrm{COP}_{C}=\frac{300-39}{300-65}-1.11
\end{aligned}
$$

\section{Example 2.}

$$
\begin{aligned}
& T_{H}=300^{\circ} \mathrm{F} \\
& T_{\text {ave }}=48^{\circ} \mathrm{F} \text { (dry bu1b average temperature) } \\
& T_{\text {design }}=92^{\circ} \mathrm{F} \\
& \operatorname{COP}_{C}=\frac{300-48}{300-92}=1.21
\end{aligned}
$$

More realistic examples of the power plant characteristics and the corresponding coefficients of performance are given in Examples 3 and 4. The power plant characteristics for Examples 3 and 4 are linear approximations of realistic data for a plant cooled by a wet cooling tower and a dry cooling tower, respectively. These plant characteristics yield a nominal 10,000 kW of net electrical power at the design temperatures of $65^{\circ} \mathrm{F}$ and $92^{\circ} \mathrm{F}$, respectively, and were obtained using a more complex model which is described in Section II,3.1.2. 
Example 3.

$$
\begin{aligned}
& \mathrm{P}=16500-98 \mathrm{~T}(\mathrm{~T}=\text { the wet bulb temperature }) \\
& \mathrm{P}_{\text {design }}=10,000 \mathrm{~kW}\left(\mathrm{~T}_{\text {design }}=65^{\circ} \mathrm{F}\right) \\
& \mathrm{T}_{\text {ave }}=39^{\circ} \mathrm{F} \\
& \mathrm{P}_{\mathrm{a}}=16500-98(39)=12700 \mathrm{~kW} \\
& \mathrm{COP}=\frac{12700}{10000}=1.27
\end{aligned}
$$

\section{Example 4.}

$$
\begin{aligned}
& \mathrm{P}=56,800-509 \mathrm{~T}(\mathrm{~T}=\text { the dry bulb temperature }) \\
& \mathrm{P}_{\text {design }}=10,000 \mathrm{~kW}\left(\mathrm{~T}_{\text {design }}=92^{\circ} \mathrm{F}\right) \\
& \mathrm{T}_{\text {ave }}=48 \\
& \mathrm{P}_{\mathrm{a}}=56,800-509(48)=32,400 \mathrm{~kW} \\
& \mathrm{COP}=\frac{32400}{10000}=3.24
\end{aligned}
$$

Examples 3 and 4 illustrate the sensitivity of the floating power coefficient of performance to the slope of the power characteristics curve. The slope is in general larger for a dry bulb cooling system than for a wet bulb cooling system due to low heat capacity of dry air versus the effective heat capacity of evaporative cooling.

\subsection{The Plant Reduction Percentage}

The previous theory discusses the increased power production of the floating power plant concept as the end benefit of the concept but suppose that it is more desirable to reduce the capital investment of the 
plant such that the average net power output of the plant was equal to the design power. Therefore, it is convenient to define a term which will be named the plant reduction percentage. The plant reduction percentage is that percentage of a standard constant power plant capital investment that the plant may be reduced such that the average power of the reduced floating power plant concept is equal to the design power of the original constant power plant. The plant reduction percentage can be related to the coefficient of performance by the following equation which assumes that the plant capital investment is proportional to the net power output.

$$
\delta=\left[1-\frac{1}{\mathrm{COP}}\right] \times 100
$$

where: $\delta=$ the plant reduction percentage

$$
\text { COP = the floating power coefficient of performance }
$$

A plot of Equation (11) is shown in Figure 1 which shows a sharp rise in the plant reduction percentage for a coefficient of performance increasing between 1 and 2 and shows a gradual leveling off of the percentage above a coefficient of performance of around 2 . The plant reduction percentages which correspond to the coefficients of performance $1.11,1.21,1.27$, and 3.24 in Examples 1 through 4 are 9.9, 17.4, 21.3, and 69.1 percent. These numbers clearly demonstrate the possible advantage of the floating power concept.

\subsection{Floating Power Fluctuation Parameters}

The major disadvantage of the floating power concept is that the net power output varies with the atmospheric conditions which produces seasonal power fluctuations, weather systems power fluctuations, and daily power fluctuations. Several fluctuation parameters will now be defined to provide a method of quantifying the power fluctuations for comparison purposes. These parameters are: 


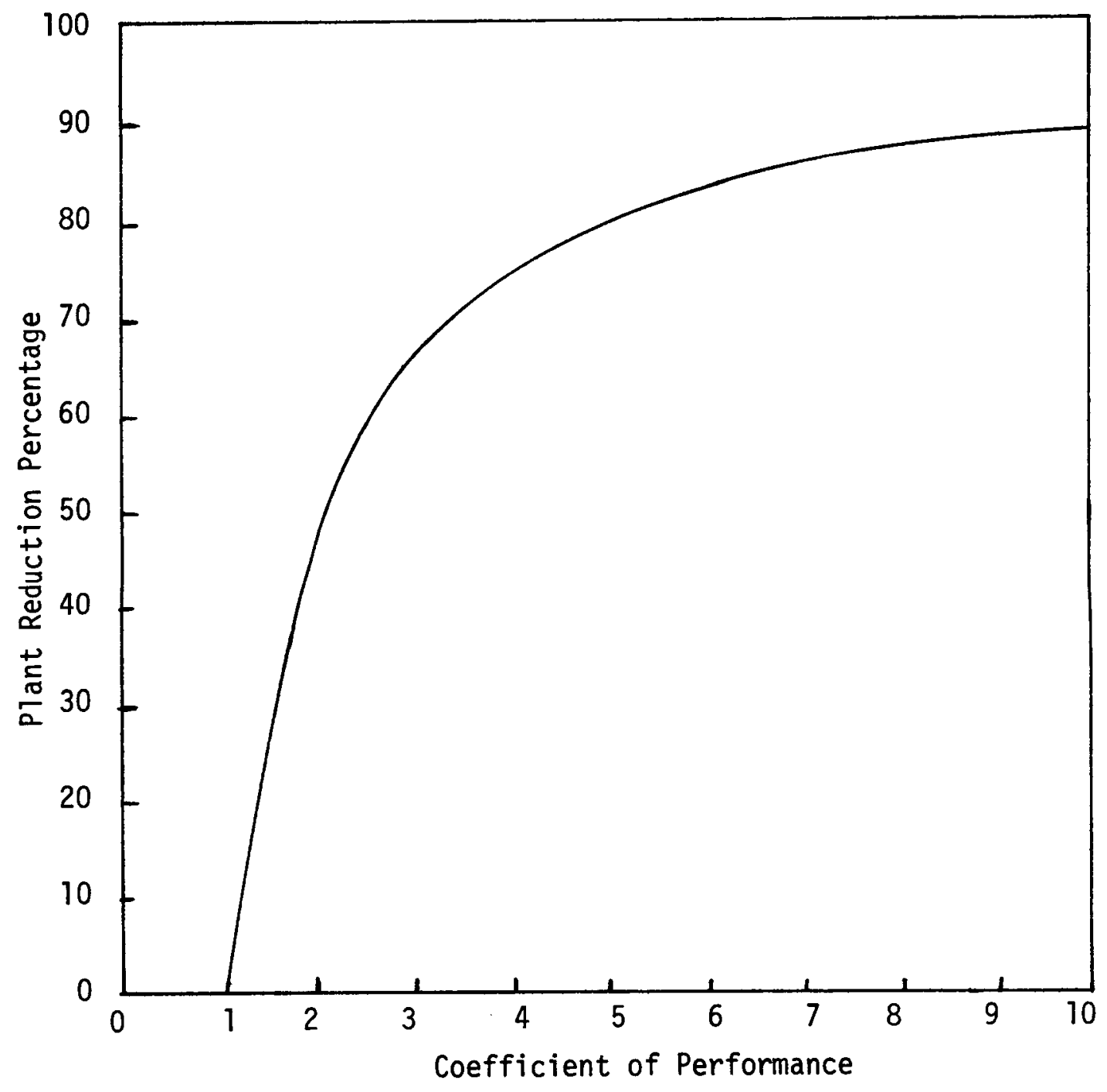

Figure 1. The Plant Reduction Percentage 
1. $\mathrm{GY}=$ the greatest yearly fluctuation defined as the difference between maximum and minimum net power output during an entire one year period.

2. $G M=$ the greatest monthly fluctuation defined as the greatest difference between maximum and minimum net power output during an entire one month period for the 12 months of the year.

3. $\mathrm{GD}=$ the greatest daily fluctuation defined as the greatest difference between maximum and minimum net power output during an entire one day period for the 365 days (or 366 for leap year) of the year.

4. $A D=$ the average daily fluctuation defined as the difference between maximum and minimum net power output during a so called average day. The average day is defined over a period of time such as a month or a year by averaging each hour of the day over that period, i.e., the first hour between midnight and 1 A.M. for each day of the period is averaged and so forth through all 24 hours.

5. $G Y \%=$ the greatest yearly fluctuation percent $\left(=G Y / P_{a} \times 100\right)$

6. $G M \%$ = the greatest monthly fluctuation percent $\left(=G M / P_{a} \times 100\right)$

7. $\mathrm{GD} \%=$ the greatest daily fluctuation percent $\left(=\mathrm{GD} / \mathrm{P}_{\mathrm{a}} \times 100\right)$

8. $A D \%=$ the average daily fluctuation percent $\left(=A D / P_{a} \times 100\right)$

Now that some theory has been developed and demonstrated, it remains to apply the theory to some actual power plant designs. This theory which was developed with several limiting assumptions has been found to be quite useful in calculating the floating power coefficient of performance of many types of cooling systems once the plant characteristics were known. The theory is limited in that many systems such as cooling ponds can not be characterized by the atmospheric temperature alone. The application of the theory requires the determination of the power plant characteristics for several types of cooling systems, the evaluation of these characteristics with Equation 1 using actual atmospheric data, and correlating the results. 


\section{ATMOSPHERIC DATA BASE}

The atmospheric data base was obtained from the National Atmospheric and Oceanic Administration's (NOAA) National Climatic Center in Asheville, N. C. Some temperature statistics have been generated from this data. Approximate solar insolation data was developed for use in cooling systems affected by solar insolation.

\subsection{NOAA Data Tapes}

The NOAA data obtained consists of the airways surface observations from the municipal airports at both Pocatello and Idaho Falls, Idaho. The Pocatello airport represents the closest available data (on magnetic tape) to the Raft River Area. The magnetic tapes (9 track, TDF-14 format) obtained contains digitized hourly averaged data during 1959 through 1964 for Pocatello and 1955 through 1964 for Idaho Falls and contains digitized data averaged over three hour periods for Pocatello during 1965 through 1974. These data tapes contain extensive data including the wet and dry bulb temperature, the relative humidity, the wind velocity, and the atmospheric pressure which are used in these studies. Computer programs were developed to read the tapes, decode the required data, and modify the data as necessary such that the required data was returned to the main program in one day blocks for analytical purposes. Data modification was necessary for conversion to the proper units and for filling in missing data. Missing data was filled with the preceding data point.

\subsection{Temperature Statistics}

Temperature statistics in the form of temperature integrals (defined in Equation (4)) of the order $n$ for $n$ equal to one through seven have been compiled in Tables I and II for Pocatello and Idaho Falls, Idaho, respectively over a one year time period. The integrals have been compiled for both the wet and dry bulb temperatures for year 1959 
TABLE I

TABLE OF TEMPERATURE INTEGRALS* FOR POCATELLO, IDAHO

\begin{tabular}{lllllll}
\hline$n$ & \multicolumn{7}{c}{ Dry Bulb Temperature $\left({ }^{\circ} \mathrm{F}\right)$} \\
\cline { 2 - 7 } & 1959 & 1960 & 1961 & 1962 & 1963 & 1964 \\
\hline 1 & $4.7874+01^{\star \star}$ & $4.7048+01$ & $4.8004+01$ & $4.6739+01$ & $4.7641+01$ & $4.4755+01$ \\
2 & $2.6767+03$ & $2.6833+03$ & $2.7075+03$ & $2.6015+03$ & $2.6780+03$ & $2.4545+03$ \\
3 & $1.6723+05$ & $1.7042+05$ & $1.7120+05$ & $1.5923+05$ & $1.6542+05$ & $1.5127+05$ \\
4 & $1.1351+07$ & $1.1693+07$ & $1.1768+07$ & $1.0478+07$ & $1.0972+07$ & $1.0133+07$ \\
5 & $8.1946+08$ & $8.4741+08$ & $8.5929+08$ & $7.2644+08$ & $7.6695+08$ & $7.2046+08$ \\
6 & $6.1967+10$ & $6.3981+10$ & $6.5579+10$ & $5.2468+10$ & $5.5821+10$ & $5.3545+10$ \\
7 & $4.8540+12$ & $4.9852+12$ & $5.1729+12$ & $3.9133+12$ & $4.1933+12$ & $4.1171+12$
\end{tabular}

\begin{tabular}{lllllll}
\hline$n$ & \multicolumn{7}{c}{ Wet Bulb Temperature $\left({ }^{\circ} \mathrm{F}\right)$} \\
\cline { 2 - 7 } & 1959 & 1960 & 1961 & 1962 & 1963 & 1964 \\
\hline 1 & $3.8984+01$ & $3.7903+01$ & $3.9289+01$ & $3.7994+01$ & $3.9400+01$ & $3.6885+01$ \\
2 & $1.6858+03$ & $1.6398+03$ & $1.7170+03$ & $1.6305+03$ & $1.7493+03$ & $1.5815+03$ \\
3 & $7.8156+04$ & $7.5655+04$ & $8.0646+04$ & $7.3695+04$ & $8.2217+04$ & $7.3256+04$ \\
4 & $3.8178+06$ & $3.6701+06$ & $3.9988+06$ & $3.4806+06$ & $4.0385+06$ & $3.5969+06$ \\
5 & $1.9413+08$ & $1.8458+08$ & $2.0653+08$ & $1.6924+08$ & $2.0463+08$ & $1.8416+08$ \\
6 & $1.0188+10$ & $9.5524+09$ & $1.1001+10$ & $8.4347+09$ & $1.0624+10$ & $9.7399+09$ \\
7 & $5.4832+11$ & $5.0567+11$ & $5.9997+11$ & $4.2843+11$ & $5.6218+11$ & $5.2830+11$
\end{tabular}

* $I_{n}=\frac{l}{\Delta t} \int_{\Delta t} T^{n} d t$ where $\Delta t=1$ year

$\star * 4.7874+01=47.874$ 
TABLE II

TABLE OF TEMPERATURE INTEGRALS* FOR IDAHO FALLS, IDAHO

\begin{tabular}{lllllll}
\hline & \multicolumn{7}{c}{ Dry Bulb Temperature $\left(^{\circ} \mathrm{F}\right)$} \\
\cline { 2 - 7 }$n$ & 1959 & 1960 & 1961 & 1962 & 1963 & 1964 \\
\hline 1 & $4.5062+01^{* \star}$ & $4.3423+01$ & $4.4467+01$ & $4.4026+01$ & $4.4074+01$ & $3.9963+01$ \\
2 & $2.4130+03$ & $2.3779+03$ & $2.4100+03$ & $2.3865+03$ & $2.4282+03$ & $2.1089+03$ \\
3 & $1.4488+05$ & $1.4601+05$ & $1.4814+05$ & $1.4340+05$ & $1.4881+05$ & $1.2536+05$ \\
4 & $9.4641+06$ & $9.7362+06$ & $9.9634+06$ & $9.3118+06$ & $9.8848+06$ & $8.1152+06$ \\
5 & $6.5792+08$ & $6.8786+08$ & $7.1429+08$ & $6.3882+08$ & $6.9526+08$ & $5.5733+08$ \\
6 & $4.7930+10$ & $5.0740+10$ & $5.3639+10$ & $4.5740+10$ & $5.1099+10$ & $4.0019+10$ \\
7 & $3.6191+12$ & $3.8685+12$ & $4.1695+12$ & $3.3859+12$ & $3.8841+12$ & $2.9736+12$ \\
\hline
\end{tabular}

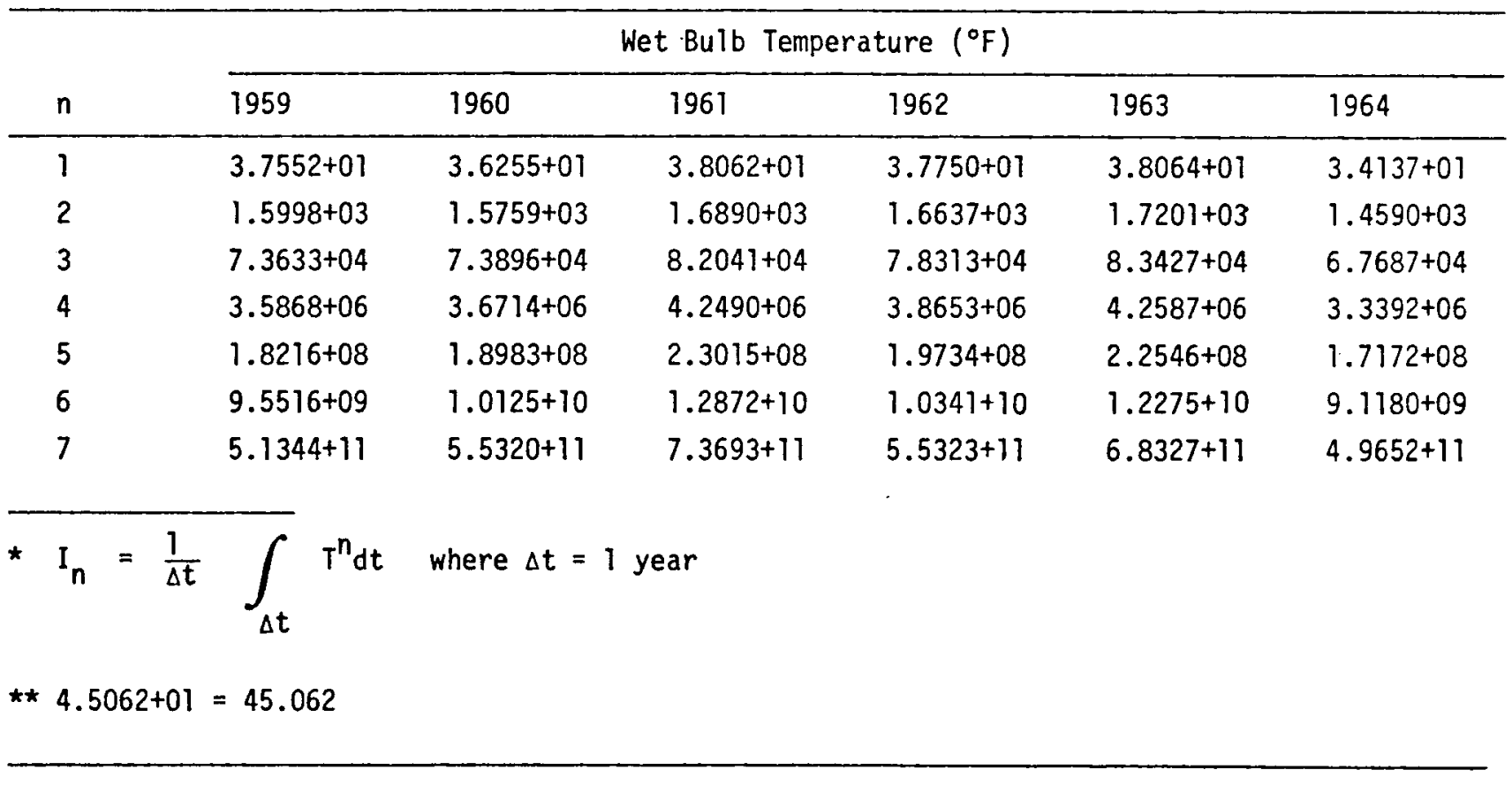


through 1964. The first integrals $(n=1)$ in Tables I and II are the yearly averaged wet and dry bulb temperatures for the respective locations and years. In general, the Pocatello temperature averages are the order of $3.5^{\circ} \mathrm{F}$ for the dry bulb temperature and $1.5^{\circ} \mathrm{F}$ for the wet bulb temperature higher than Idaho Falls temperature. Data for Pocatello during 1959 was chosen for the optimization studies. A sixteen year study using Pocatello data from 1959 to 1974 indicates that the yearly averaged net power output for a geothermal power plant with a wet cooling system (implies that the net power is a function of the wet bulb temperature) varies on the order of $2 \%$ of the sixteen year average between the minimum and maximum net power output. The wet and dry bulb temperature distributions for Pocate110, Idaho during 1959 are tabulated in Table III.

\subsection{Solar Insolation Data Approximation}

Cooling systems affected by solar insolation such as a cooling pond require the use of solar insolation data in the analysis of that system. Detailed solar insolation data as a function of time (hourly averaged digitized data) is needed for realistic calculations. The best data readily available at present for Southeastern Idaho ${ }^{(1)}$ consists of the average daily insolation (averaged over a month time period) for each month on a horizontal surface. Hourly averaged data was approximated by applying seasonal and daily functions to the averaged data.

\section{PRACTICAL ASPECTS OF THE FLOATING POWER CONCEPT}

The evaluation of the practical aspects of the floating power concept includes the analysis of a base case design, a sensitivity study of the base case design, and the comparison of the base case design to other design types. 
TABLE III

WET AND DRY BUI.B TEMPERATURE DISTRIBUTIONS FOR POCATELLO, IDAHO DURING 1959

\begin{tabular}{|c|c|c|c|c|c|}
\hline $\begin{array}{l}\text { Temperature } \\
\left({ }^{\circ} \mathrm{F}\right)\end{array}$ & $\begin{array}{l}\text { Number } \\
\text { of Dry } \\
\text { Bulb Hours }\end{array}$ & $\begin{array}{l}\text { Number } \\
\text { of Wet Bulb } \\
\text { Bulb Hours }\end{array}$ & $\begin{array}{l}\text { Temperature } \\
\left({ }^{\circ} \mathrm{F}\right)\end{array}$ & $\begin{array}{l}\text { Number } \\
\text { of Dry } \\
\text { Bulb Hours }\end{array}$ & $\begin{array}{l}\text { Number } \\
\text { of Wet } \\
\text { Bulb Hours }\end{array}$ \\
\hline $\begin{array}{r}-15 \\
-14 \\
-13 \\
-12 \\
-11 \\
-10 \\
-10 \\
-9 \\
-8 \\
-7 \\
-6 \\
-5 \\
-4 \\
-3 \\
-3 \\
-2 \\
-1 \\
0 \\
1 \\
1 \\
2 \\
3 \\
4 \\
4 \\
5 \\
6 \\
7 \\
8 \\
9 \\
9\end{array}$ & $\begin{array}{r}0 \\
0 \\
0 \\
1 \\
0 \\
1 \\
1 \\
1 \\
0 \\
0 \\
3 \\
2 \\
4 \\
5 \\
5 \\
2 \\
2 \\
1 \\
3 \\
5 \\
4 \\
7 \\
7 \\
4 \\
14 \\
22 \\
26 \\
32 \\
32 \\
31 \\
32 \\
39 \\
49 \\
55 \\
46 \\
71 \\
76 \\
65 \\
83 \\
99 \\
74 \\
119 \\
111 \\
119 \\
124 \\
117 \\
165 \\
147 \\
157 \\
178 \\
177 \\
230 \\
167 \\
217 \\
198 \\
199 \\
236 \\
161 \\
185\end{array}$ & $\begin{array}{r}0 \\
0 \\
1 \\
0 \\
1 \\
1 \\
0 \\
1 \\
0 \\
1 \\
4 \\
3 \\
6 \\
0 \\
2 \\
2 \\
4 \\
4 \\
6 \\
5 \\
7 \\
7 \\
14 \\
23 \\
20 \\
34 \\
32 \\
41 \\
29 \\
39 \\
59 \\
49 \\
59 \\
83 \\
86 \\
104 \\
90 \\
134 \\
106 \\
130 \\
158 \\
131 \\
160 \\
190 \\
185 \\
229 \\
197 \\
317 \\
280 \\
274 \\
237 \\
247 \\
239 \\
258 \\
241 \\
269 \\
195 \\
183\end{array}$ & $\begin{array}{r}43 \\
44 \\
45 \\
46 \\
47 \\
48 \\
49 \\
50 \\
51 \\
52 \\
53 \\
54 \\
55 \\
56 \\
57 \\
58 \\
59 \\
60 \\
61 \\
62 \\
63 \\
64 \\
65 \\
66 \\
67 \\
68 \\
69 \\
70 \\
71 \\
72 \\
73 \\
74 \\
75 \\
76 \\
77 \\
78 \\
79 \\
80 \\
81 \\
82 \\
83 \\
84 \\
85 \\
86 \\
87 \\
88 \\
89 \\
90 \\
91 \\
92 \\
93 \\
94 \\
95 \\
96 \\
97 \\
98 \\
99 \\
100\end{array}$ & $\begin{array}{r}185 \\
154 \\
184 \\
134 \\
143 \\
148 \\
151 \\
153 \\
139 \\
131 \\
139 \\
129 \\
145 \\
142 \\
148 \\
108 \\
102 \\
123 \\
107 \\
107 \\
101 \\
103 \\
131 \\
87 \\
97 \\
81 \\
84 \\
94 \\
79 \\
78 \\
74 \\
76 \\
76 \\
68 \\
77 \\
60 \\
70 \\
51 \\
45 \\
56 \\
42 \\
33 \\
49 \\
45 \\
51 \\
50 \\
38 \\
42 \\
30 \\
30 \\
27 \\
18 \\
22 \\
3 \\
6 \\
5 \\
33 \\
0\end{array}$ & $\begin{array}{r}217 \\
202 \\
213 \\
229 \\
215 \\
243 \\
197 \\
247 \\
186 \\
174 \\
197 \\
150 \\
169 \\
152 \\
145 \\
154 \\
106 \\
122 \\
101 \\
62 \\
38 \\
30 \\
30 \\
29 \\
14 \\
3 \\
2\end{array}$ \\
\hline
\end{tabular}

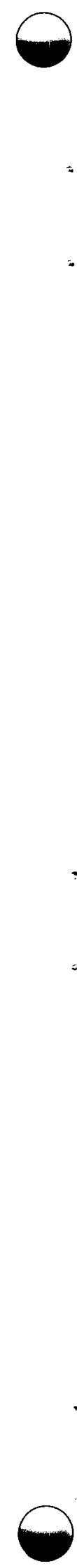




\subsection{Design Base Case}

The analysis of a design base case was done in some detail to understand some of the relationships between components of the power plant cooling system. The design base case used is a conceptual design (2) for a geothermal demonstration power plant utilizing an experimental binary system. This conceptual design produces $10 \mathrm{MW}$ (e) net power from a $300^{\circ} \mathrm{F}$ geothermal heat source such as the source discovered in the Raft River Valley of Southern Idaho, however, this floating power analysis will be applicable to a plant of another size.

\subsubsection{System Configuration. The binary power cycle is shown in} Figure 2 and is a dual boiling isobutane cycle, i.e., isobutane is boiled at two different pressures and the resulting vapors are expanded through separate turbines which are designated as the high and low pressure turbines. The vapors are expanded to a common condenser pressure. The purpose of the dual boiling cycle is to produce better utilization of the geothermal brine. The cooling system design is based upon the use of conventional wet cooling towers operating with a design wet bulb temperature of $61^{\circ} \mathrm{F}$. All preheater, boiler, and condenser heat exchangers are of the tube in shell design.

3.1.2 System Model. The system model for the evaluation of the floating power concept includes; (1) the component models for the turbine, the condenser, the feed pump, and the wet cooling tower and, (2) the necessary relationships to couple the components into a system. The system model requires the input of the temperatures and mass flow rates of both the high and low pressure vapor isobutane flows into the turbines which eliminates the need for component models of the preheaters, boilers, geothermal wells, and etc. It is assumed that the preheaters are capable of handling the variable isobutane subcooling caused by the floating condensing temperature.

The turbine component model calculates the gross electrical power output of the turbine-generator set given: (1) the temperatures (or pressures) and the saturated vapor mass flow rates at the inlet to the turbines, (2) the condenser pressure, (3) the turbine-generator set 


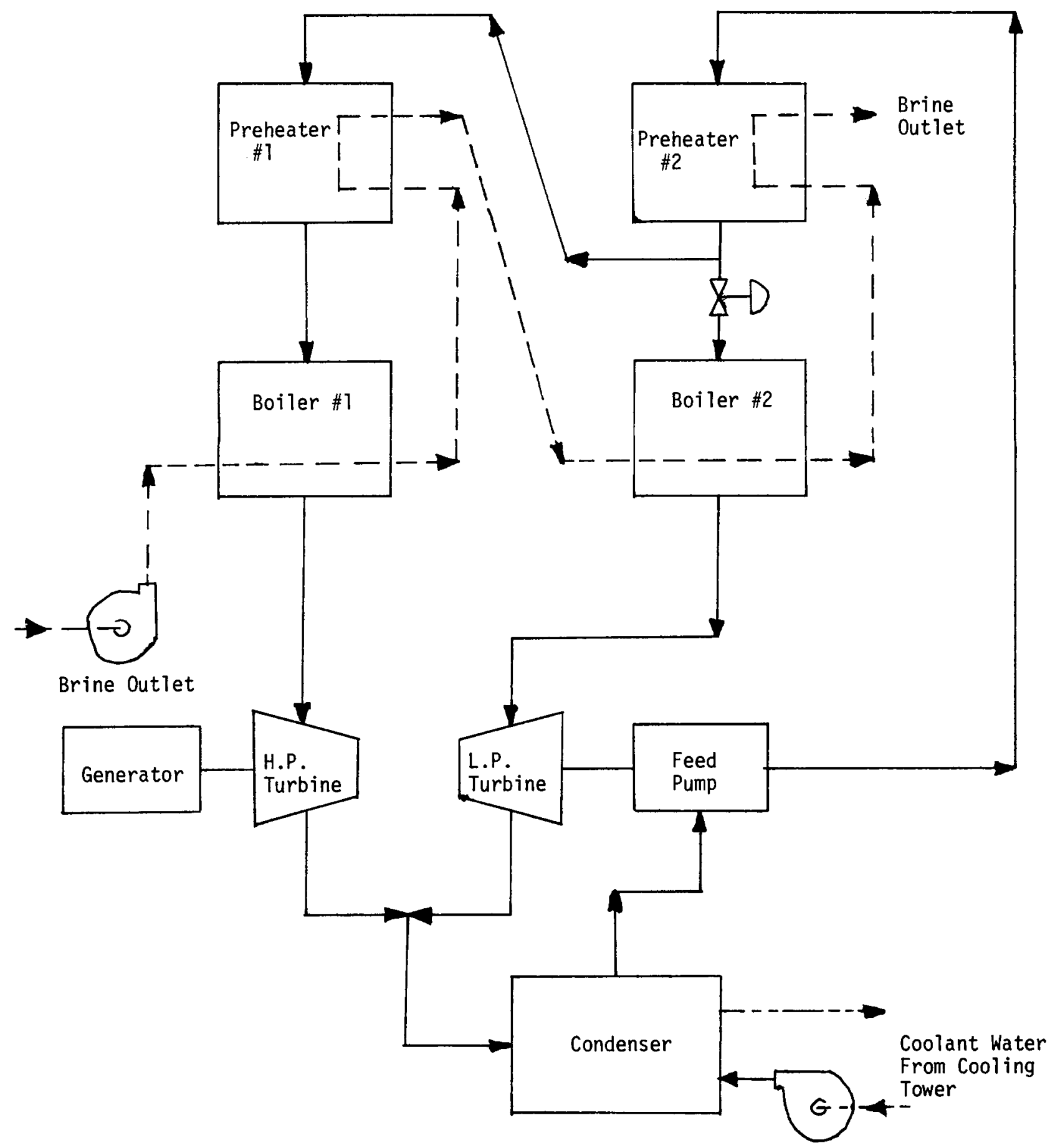

Figure 2. Binary Cycle Geothermal Power Plant 
mechanical efficiency, and (4) the correlation shown in Figure 3 for the turbine isentropic efficiency. The efficiency correlation shown is for an isobutane reaction turbine where the isentropic efficiency is a function of the isentropic enthalpy drop across the turbine. The efficiency is also a function of turbine tip speed but the speed is fixed in these studies. The thermodynamic properties of isobutane were computerized.

The condenser component model relates the cooling water temperature through the condenser to the condensing temperature and pressure using the log-mean temperature difference heat exchanger equations ${ }^{(3)}$. The calculation is treated in two parts, i.e., the isobutane latent heat (constant isobutane temperature) section and the isobutane superheat section. The latent heat transfer is on the order of 10 times greater than the superheat heat transfer. Isobutane exits the turbine in the superheat region. The information given the condenser model are: (1) the total heat transfer area, (2) the overall heat exchanger coefficient for both the latent and superheat sections, (3) the condensing pressure and isobutane flow rates, and (4) the cooling water flow rate.

The feed pump component model assumes that the boiler pressure remains constant at some given pressure (and therefore the feed pump exit pressure). Therefore, the feed pump power requirement is calculated from a given constant power per unit pressure of pumping times the pressure differential between the given feed pump outlet pressure and the condensing pressure.

The wet cooling tower component model calculates the cooling water temperature exiting the cooling tower given: (1) the atmospheric dry bulb temperature, the relative humidity, and the atmospheric pressure, (2) the inlet cooling water temperature, (3) the cooling water flow rate, (4) the air flow rate through the tower, and (5) the cooling tower design parameters. The cooling tower model is described by two equations which are: (1) the mass and energy conservation equation encompassing the entire cooling tower, and (2) an equation which effectively treats the cooling tower as simple tube in shell heat exchanger. The mass and energy conservation equation simply implies that the mass and energy of the inlet water and air flows are equal to the mass and energy of the outlet water and air flows. The mass and energy equation when the inlet flow conditions are given results in two unknowns (assuming that 


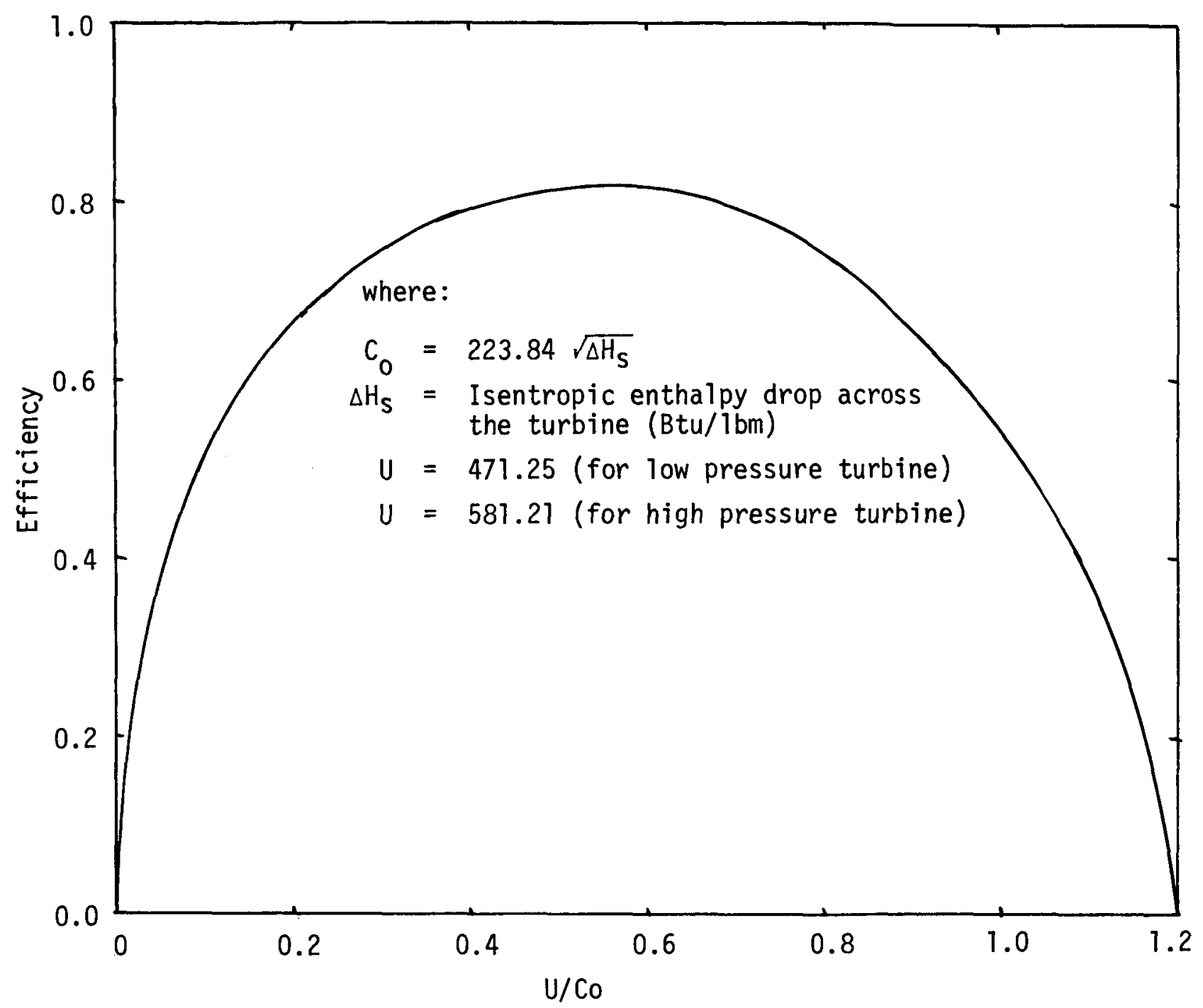

Figure 3: Reaction Turbine Efficiency 
the outlet air flow exits at one hundred percent relative humidity) which are the outlet temperatures of the air and water flows. An effective tube in shell heat exchanger equation was assumed to apply to the cooling tower in order to provide a second equation with the same two unknown temperatures such that the solution of these two equations provide a cooling tower model.

The heat exchanger equation says that the heat removed from the exit cooling water flow (the inlet cooling water flow minus the evaporation) is equal to some effective overall heat transfer coefficient heat transfer area product times the log-mean temperature difference. The log-mean temperature difference is defined by the inlet and outlet cooling water temperatures and air inlet and outlet wet bulb temperatures. The effective overall heat transfer coefficient-area product is determined from the design cooling tower operating conditions, i.e., all the temperatures are known at the design operating condition so that the effective heat exchanger equation can be solved for the effective overall heat transfer coefficient-area product. This product is then assumed constant for all operating conditions.

The justification of the assumptions applied in this cooling tower model is the models ability to predict cooling tower performance. Although not strictly theoretically accurate this model does an adequate job of predicting the cooling tower performance for the purpose of these studies. The model was varified by comparing model predictions to cooling tower operational data. The model was found to predict the data for exit cooling water temperature within the order of 2 percent through the range of use for published cooling tower data (cooling tower data will frequently vary this much from one source of data to another).

The cooling system component models are solved simultaneously through a numerical iterative procedure in order to determine the power plant operation characteristics. The numerical iterative procedure starts by assuming a condenser pressure and then solves around the cooling system loop until the parameters converge on the correct solution. Then the power plant net power output can be calculated. A sensitivity study of the power plant model to the parameters describing the atmospheric heat sink results in the power plant characteristics which can then be used to determine the floating power performance.

The input parameters for the design base case are listed in Table IV. 
Geothermal Brine

1. Brine mass flow rate

$2.8 \times 10^{6} \mathrm{lbm} / \mathrm{hr}$

2. Total brine pumping power

$1210 \mathrm{kw}$

Turbine

3. High pressure isobutane mass flow rate

$2.13 \times 10^{6} \mathrm{lbm} / \mathrm{hr}$

4. Low pressure isotubane mass flow rate

$8.11 \times 10^{5} 1 \mathrm{bm} / \mathrm{hr}$

5. High pressure boiler temperature $230^{\circ} \mathrm{F}$

6. Low pressure boiler temperature $160^{\circ} \mathrm{F}$

7. Turbine-generator set mechanical efficiency

0.95

Isobutane Feed Pump

8. Feed pump exit pressure

396 psia

9. Feed pump specific power

$4.39 \mathrm{kw} / \mathrm{psia}$

\section{Condenser}

10. Cooling water mass flow rate

11. Condenser heat transfer area

12. Overall heat transfer coefficient

$2.13 \times 10^{7} \mathrm{Tbm} / \mathrm{hr}$

$1.67 \times 10^{5} \mathrm{ft}^{2}$

$170 \mathrm{Btu} / \mathrm{hr}-\mathrm{ft}^{2}-{ }^{\circ} \mathrm{F}$

Cooling Tower

13. Air flow rate

$1.62 \times 10^{7} \mathrm{lbm} / \mathrm{hr}$

14. Fan power

$600 \mathrm{kw}$

15. Design dry bulb temperature

$88^{\circ} \mathrm{F}$

16. Design wet bult temperature

$61^{\circ} \mathrm{F}$

17. Design relative humidity

0.23

18. Design atmospheric pressure

12.5 psia

19. Design range

$20^{\circ} \mathrm{F}$

20. Design approach

$15.5^{\circ} \mathrm{F}$

21. Cooling water pumping power

$750 \mathrm{kw}$

22. Make-up water specific pumping power

$7.5 \times 10^{-5} \mathrm{kw} / 7 \mathrm{bm} / \mathrm{hr}$

23. Make-up water temperature $75^{\circ} \mathrm{F}$

Other

24. Miscellaneous electrical

$750 \mathrm{kw}$ 
3.1.3 Design Base Case Power Plant Characteristics. The design base case power plant characteristics are shown in Figures 4 through 10. The power plant characteristics are computed by varying the atmospheric wet bulb temperature while all the power plant flow rates remain constant. The varying atmospheric wet bulb temperature causes the cooling water temperature and therefore the condensing temperature and turbine back pressure to vary which varies the net power output. Figures 4 through 9 show (1) the net electrical power, (2) the condensing temperature, (3) the condensing pressure, (4) the condenser cooling water exit temperature, (5) the condenser cooling water inlet temperature, and (6) the make-up flow rate, respectively, as a function of the atmospheric wet bulb temperature. Figure 10 shows the net electrical power as a function of the condenser cooling water inlet temperature. Figures 4 through 9 show data calculated at $20^{\circ} \mathrm{F}$ intervals from $-40^{\circ} \mathrm{F}$ to $120^{\circ} \mathrm{F}$ wet bulb temperature with the data points connected by straight lines. Figure 10 was constructed from data shown in Figures 4 and 8.

The net electrical power shown in Figure 4 shows that the base case design produces a nominal $10 \mathrm{MW}$ net electrical power at approximately $61^{\circ} \mathrm{F}$ wet bulb temperature. A study of six years of wet bulb data for the Pocate110, Idaho area shows that the $61^{\circ} \mathrm{F}$ wet bulb temperature was exceeded $2.1,1.2,2.3,0.03,1.0$, and 2.8 percent of the year for years 1959 through 1964 (this is an average of 1.6 percent). The maximum recorded wet bulb temperature for Pocatello during these same six years was $70^{\circ} \mathrm{F}$.

Condenser cooling water inlet temperature (approximately equal to the coolint tower exit water temperature) is shown in Figure 8 to decrease below the freezing of water $\left(32^{\circ} \mathrm{F}\right)$ when the wet bulb temperature goes below about $-24^{\circ} \mathrm{F}$. The year 1959 which was chosen for the floating power plant studies had as its lowest wet bulb temperature a $-13^{\circ} \mathrm{F}$ and in fact the wet bulb temperature for Pocatello rarely goes below $-24^{\circ} \mathrm{F}$. Although some freezing problems could occur at wet bulb temperatures less than $32^{\circ} \mathrm{F}$ (the condenser cooling water inlet temperature is about $57^{\circ} \mathrm{F}$ at a wet bu $1 \mathrm{~b}$ temperature of $32^{\circ} \mathrm{F}$ ), this floating power plant study assumes that no freezing occurs until the condenser cooling water inlet temperature drops to $32^{\circ} \mathrm{F}$.

The isentropic efficiency for both turbines will vary as condensing pressure varies due to the changing atmospheric wet bulb temperature. The isentropic efficiency for the reaction turbines of the base case design 


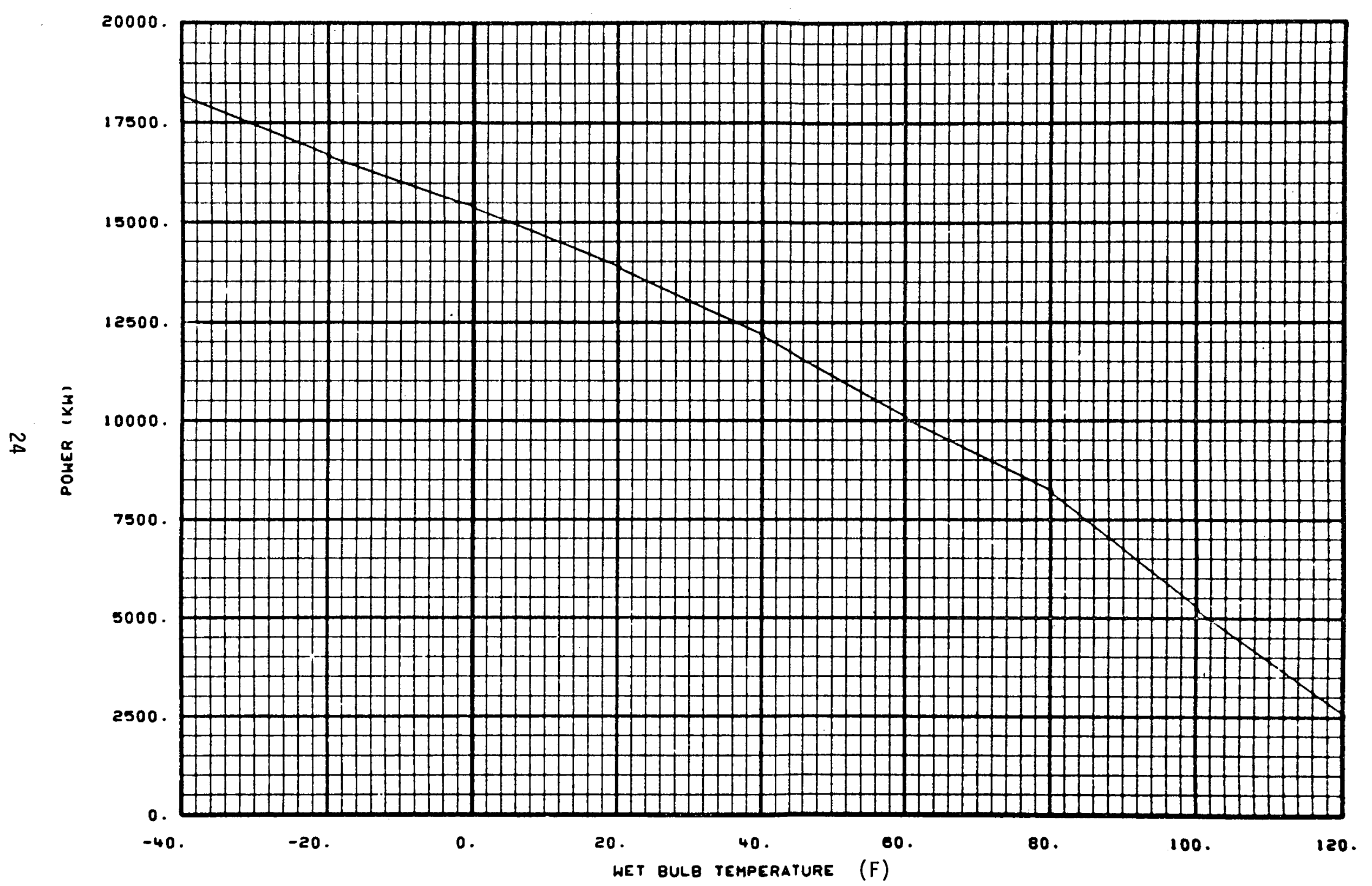

Figure 4. Base case net electrical power vs. the atmospheric wet bulb temperature. 



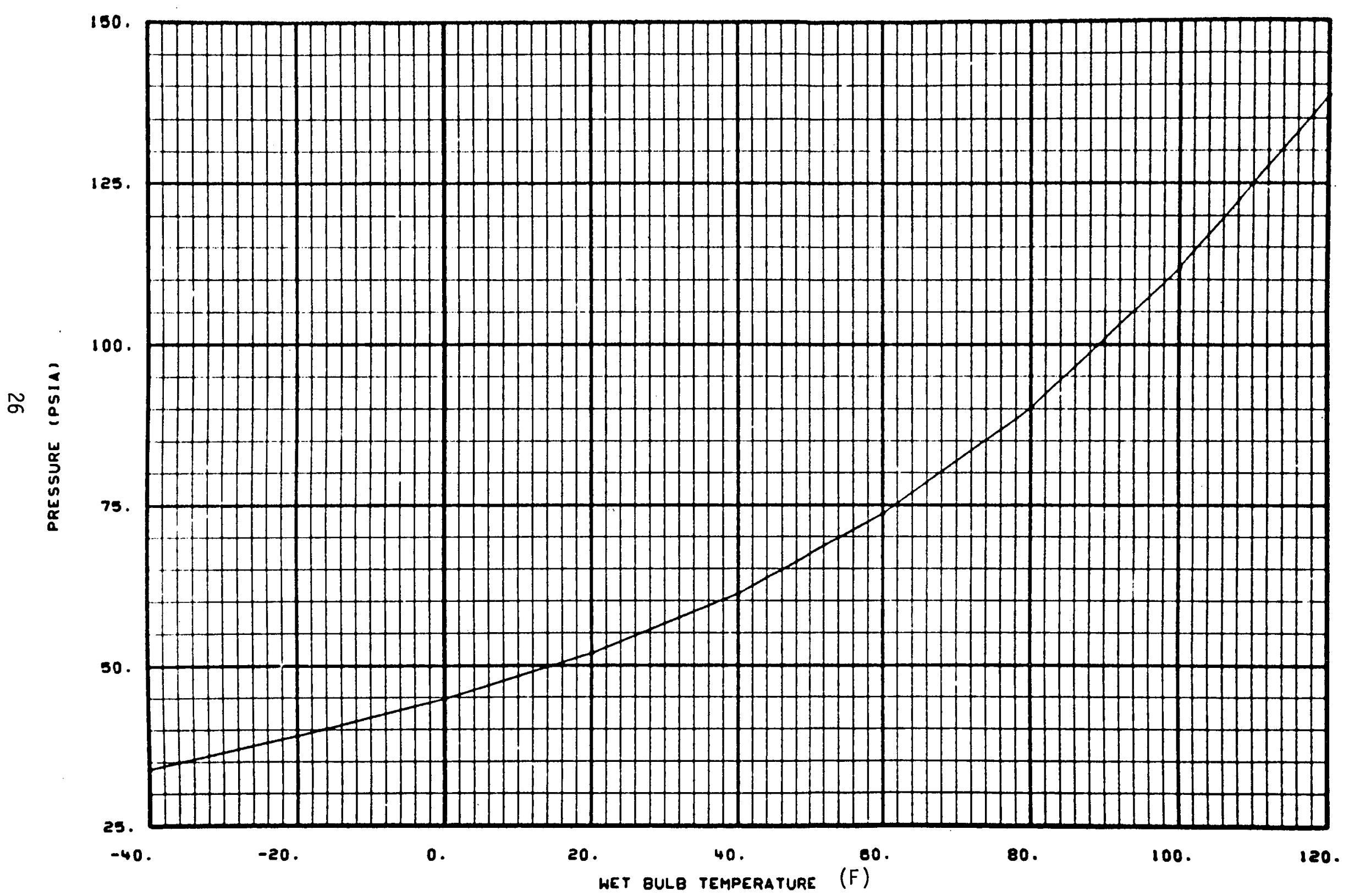

Figure 6. Base case condensing pressure vs. the atmospheric wet bulb temperature. 



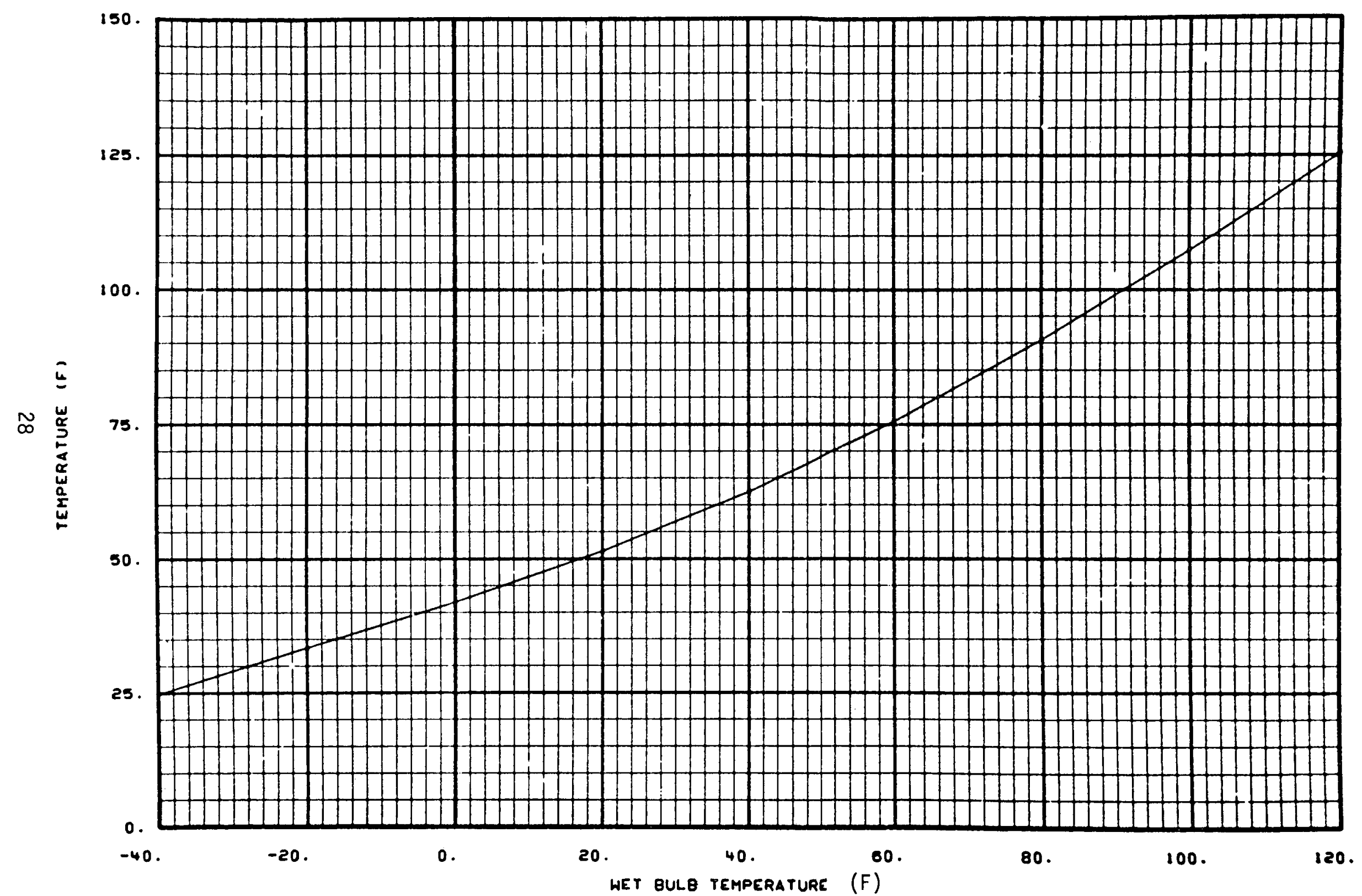

Figure 8. Base case condenser cooling water inlet temperature vs, the a tmospheric wet bulb temperature. 


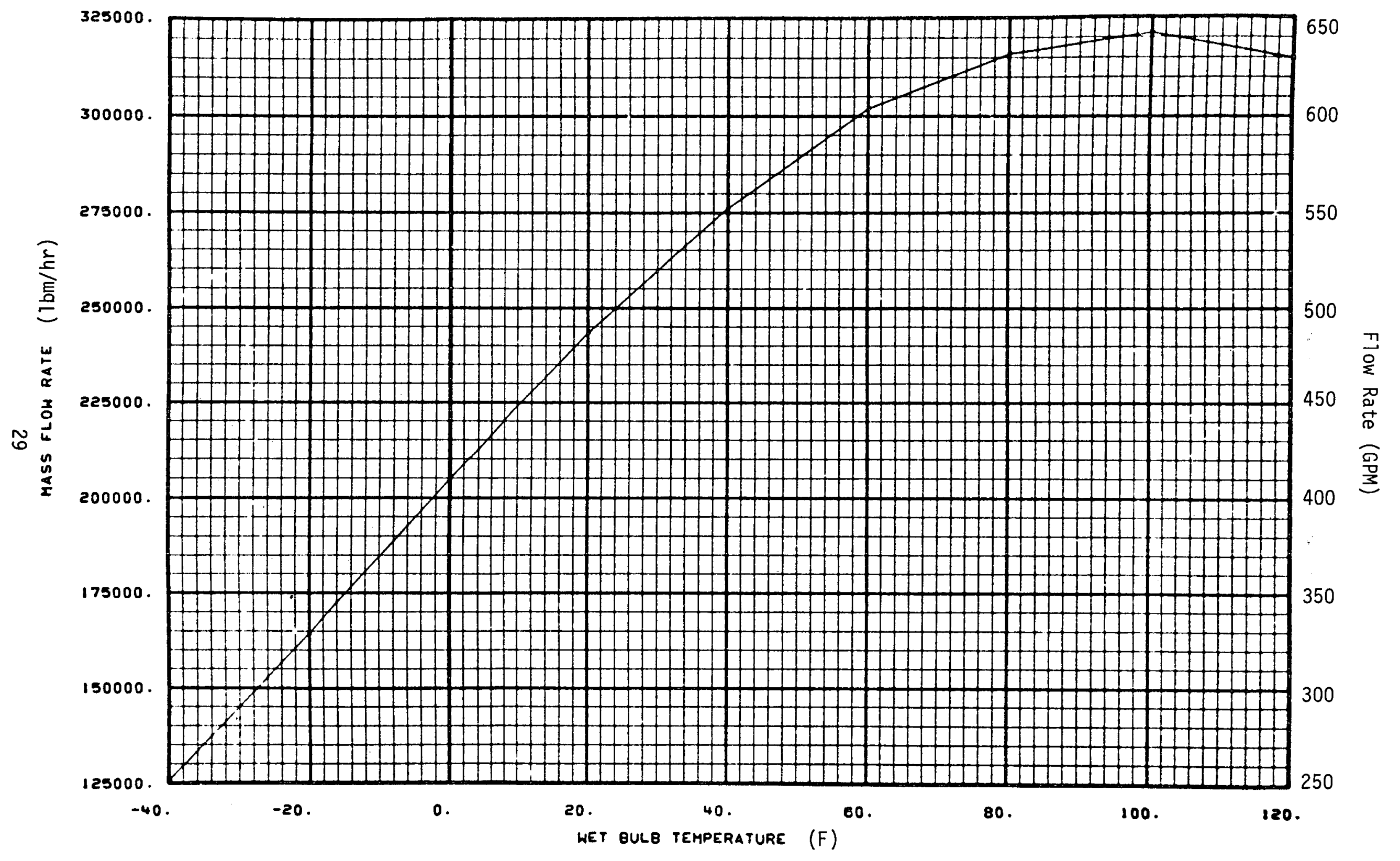
Figure 9. Base case make-up water flow rate vs. the atmospheric wet bulb
temperature. 


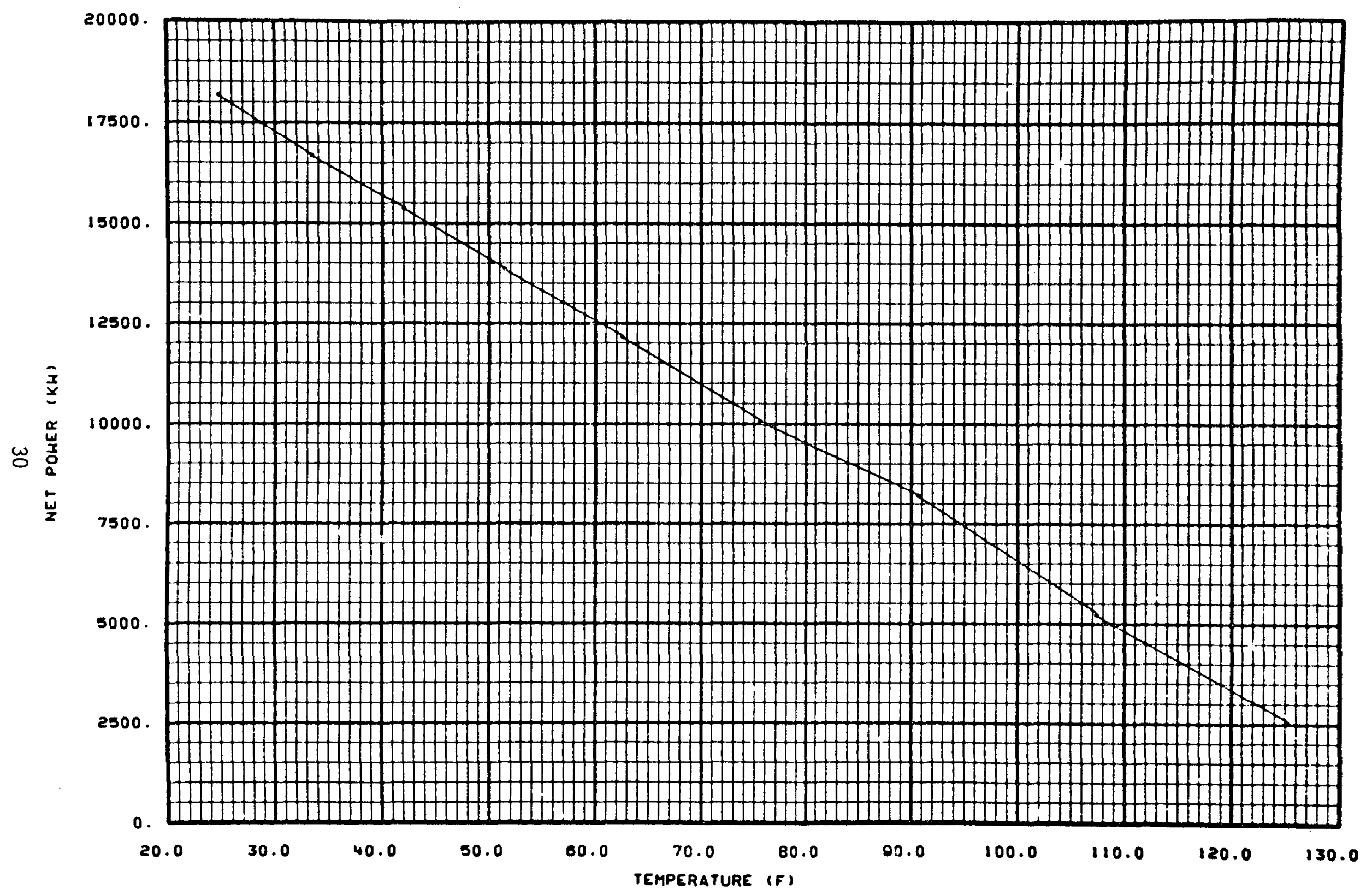

Figure 10. Base case net electrical power vs. the condenser cooling water inlet temperature. 
is shown in Figure 3 as a function of the isentropic enthalpy drop across the turbine. Table $V$ lists the isentropic efficiencies for both the high and low pressure turbines as a function of the atmospheric wet bulb temperature. Table $V$ shows the efficiencies to remain very close to peak of the curve which peaks at 0.82 except for the low pressure turbine at very high wet bulb temperatures, however, these very high wet bulb temperatures are not encountered for the Southern Idaho area. In conclusion, as the atmospheric conditions change, the turbine isentropic efficiencies float between about 0.80 to 0.82 .

The polynomial constants of the design base case power plant characteristics for input into Equation (4) which is used to calculate the average floating power from the temperature integrals were obtained using a least squares polynomial fit of the data shown in Figure 4 . These polynomial constants for a fourth order polynomial are:

$$
\begin{aligned}
& c_{0}=15321.183 \\
& c_{1}=-70.930291 \\
& c_{2}=-0.10945287 \\
& c_{3}=-2.6648878 \times 10^{-3} \\
& c_{4}=8.9847849 \times 10^{-6}
\end{aligned}
$$

3.1.4 The Design Base Case Floating Power Parameters. The design base case floating power parameters, i.e., the yearly averaged net power, the floating power coefficient of performance, and the plant reduction percentage, can be computed from the polynomial constants and temperature integrals (from Table I for Pocatello during 1959) using Equations (4), (8), and (11). The yearly averaged net power, the floating power coefficient of performance, and the plant reduction percentage are $12200 \mathrm{~kW}, 1.22$, and $18 \%$, respectively. This means that this power plant designed to produce $10,000 \mathrm{~kW}$ net electrical power at wet bulb temperature of $61^{\circ} \mathrm{F}$ will produce a yearly average of $12,200 \mathrm{~kW}$ or $22 \%$ more if that power plant is allowed to float with the atmospheric conditions. This power plant if allowed 
TABLE V

FLOATING TURBINE EFFICIENCIES

\begin{tabular}{lll}
$\begin{array}{l}\text { Atmospheric } \\
\text { Wet Butb } \\
\text { Temperature }\left({ }^{\circ} \mathrm{F}\right)\end{array}$ & $\begin{array}{l}\text { High Pressure } \\
\text { Turbine Efficiency }\end{array}$ & $\begin{array}{c}\text { Low Pressure } \\
\text { Turbine Efficiency }\end{array}$ \\
\hline-40 & 0.800 & 0.799 \\
-20 & 0.804 & 0.805 \\
0 & 0.809 & 0.811 \\
20 & 0.811 & 0.813 \\
40 & 0.813 & 0.817 \\
60 & 0.816 & 0.820 \\
80 & 0.820 & 0.807 \\
100 & 0.819 & 0.690 \\
120 & 0.800 & 0 \\
\hline
\end{tabular}


to float could produce a yearly average net electrical power of $10,000 \mathrm{~kW}$ using roughly 18 percent less capital investment.

3.1.5 The Design Base Case Floating Power Fluctuations. The floating power concept has the disadvantages of a fluctuating net electrical power output. The floating point fluctuation parameters (defined in Section 1.5) for the design base case are given in Table VI.

The net electrical floating power fluctuations for the design base case during 1959 are shown in Figures 11 through 13. Figure 11 shows the daily averaged power over the year, i.e., the average power for each day of the year is plotted versus the day of the year. Figure 11 illustrates both the seasonal power fluctuation and the weather systems fluctuations (i.e., the high and low pressure areas, fronts, etc.). As can be seen the daily averages can vary appreciably from day to day. Figure 12 shows the monthly averaged power over the year, i.e., the average power for each month of the year is plotted versus the month of the year. Figure 13 shows the average day for 1959 versus the hour of the day. The average day is defined by averaging each hour of the day over the year (i.e., the first hour between midnight and 1 A.M. for each day of the year is averaged and so forth through all 24 hours). The average days for each month in 1959 are shown in Appendix A.

\subsection{Base Case Sensitivity Studies}

Sensitivity studies of the design base case cooling system illustrates possible design optimizations. Sensitivity studies were performed on the condenser area and the cooling water flow rate by separately varying these parameters in the design base case.

\subsubsection{Condenser Area Sensitivity. The sensitivity of the yearly} average net power to the condenser area is shown in Figure 14 . The sensitivity is shown as a percent increase or decrease from the base case power as the condenser area varies as a percent increase or decrease from the base case. This figure shows that the slope of the curve is leveling off at higher condenser areas, i.e., the power return (per unit of condenser area) 
TABLE VI.

BASE CASE POWER FLUCTUATION PARAMETERS

\begin{tabular}{rlrl}
\hline$G Y$ & $=7330 \mathrm{~kW}$ & $\mathrm{GY} \%$ & $=60.1 \%$ \\
$\mathrm{GM}=$ & $4640 \mathrm{~kW}$ & $\mathrm{GM} \%$ & $=38.0 \%$ \\
$\mathrm{GD}$ & $=2760 \mathrm{~kW}$ & $\mathrm{GD} \%$ & $=22.6 \%$ \\
$\mathrm{AD}$ & $=940 \mathrm{~kW}$ & $\mathrm{AD} \%$ & $=7.7 \%$
\end{tabular}





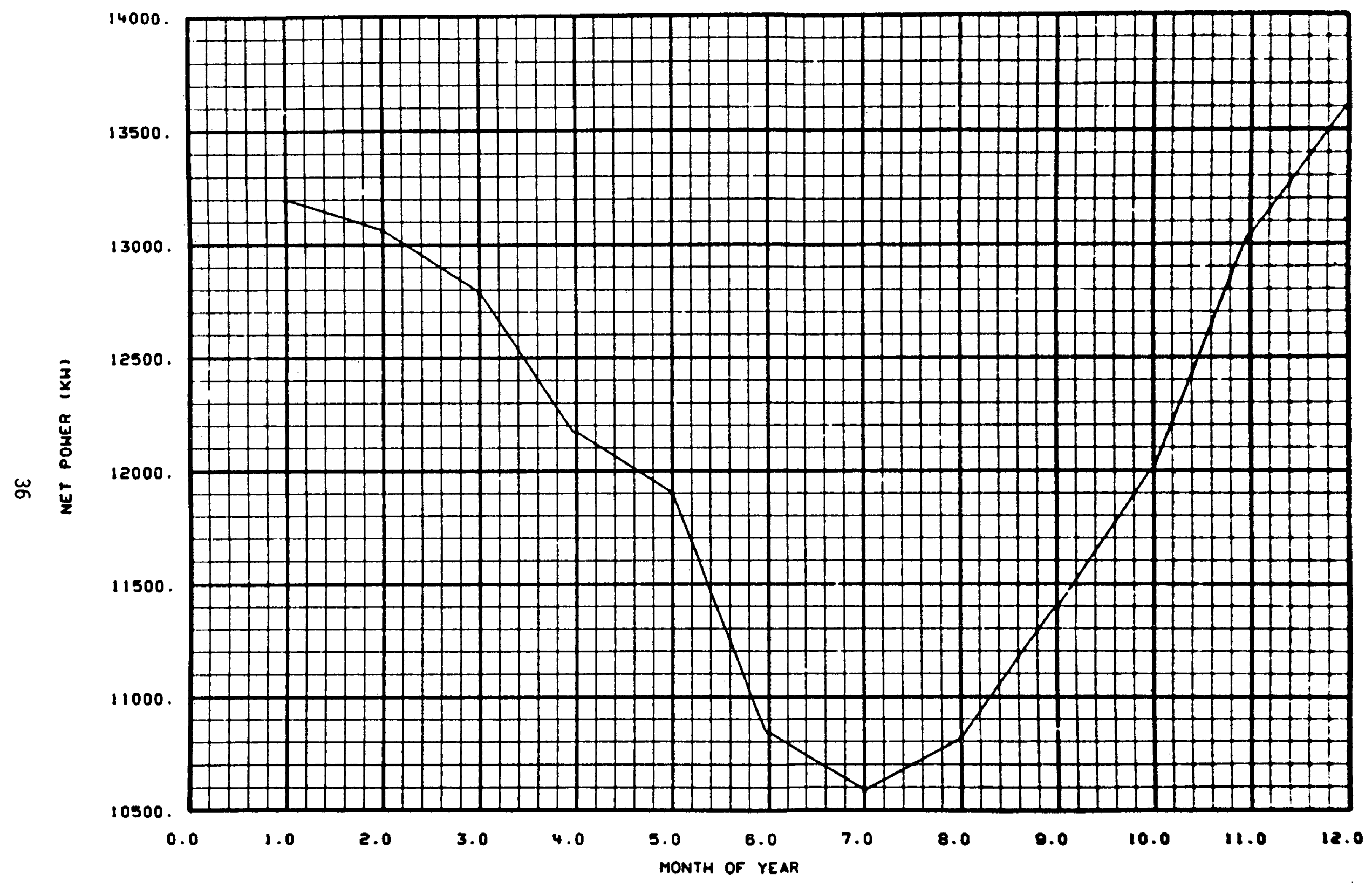

Figure 12. The monthly averaged net electrical floating power for 1959. 


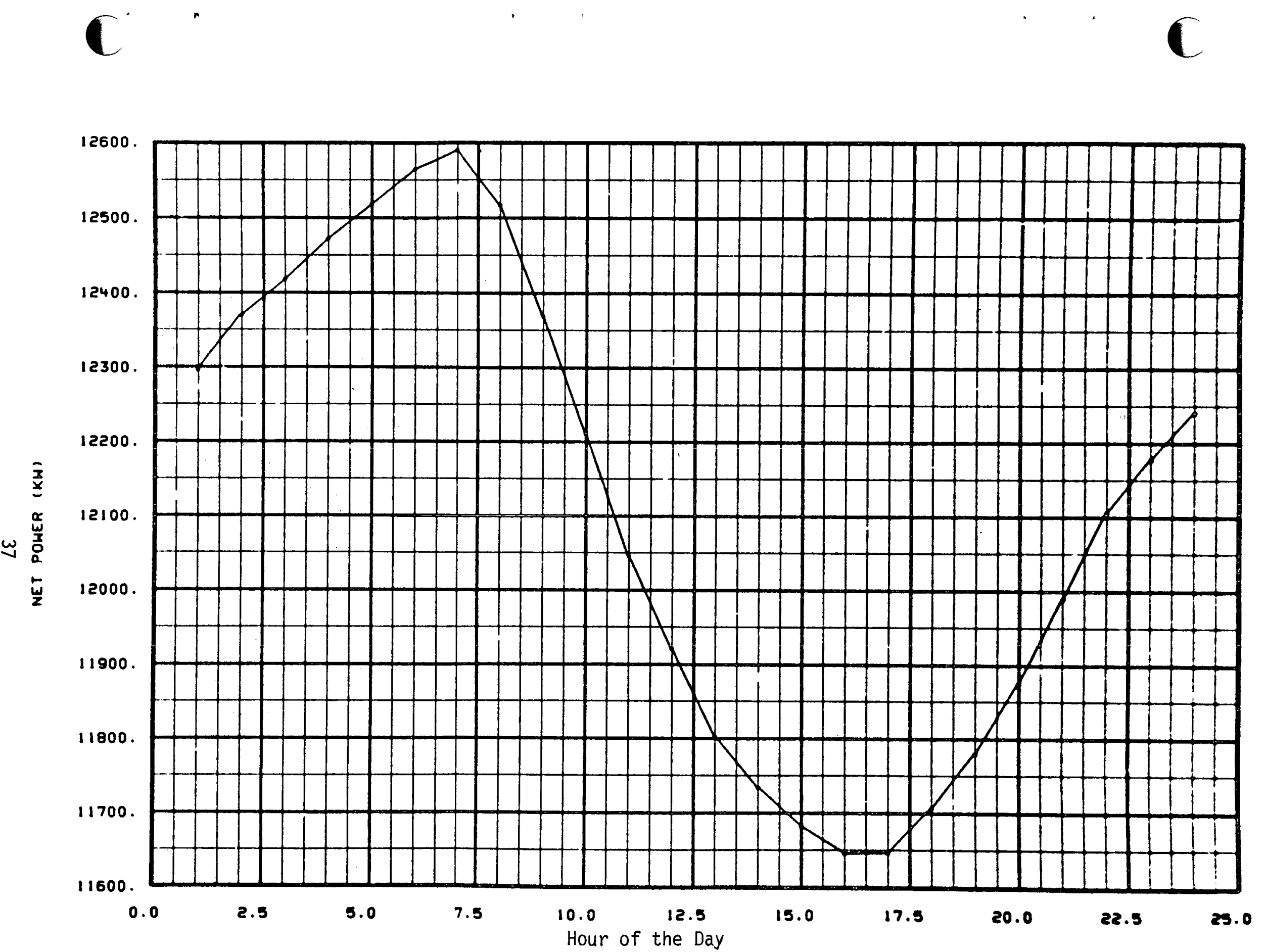

Figure 13. The net electrical floating power for the average day in 1959. 


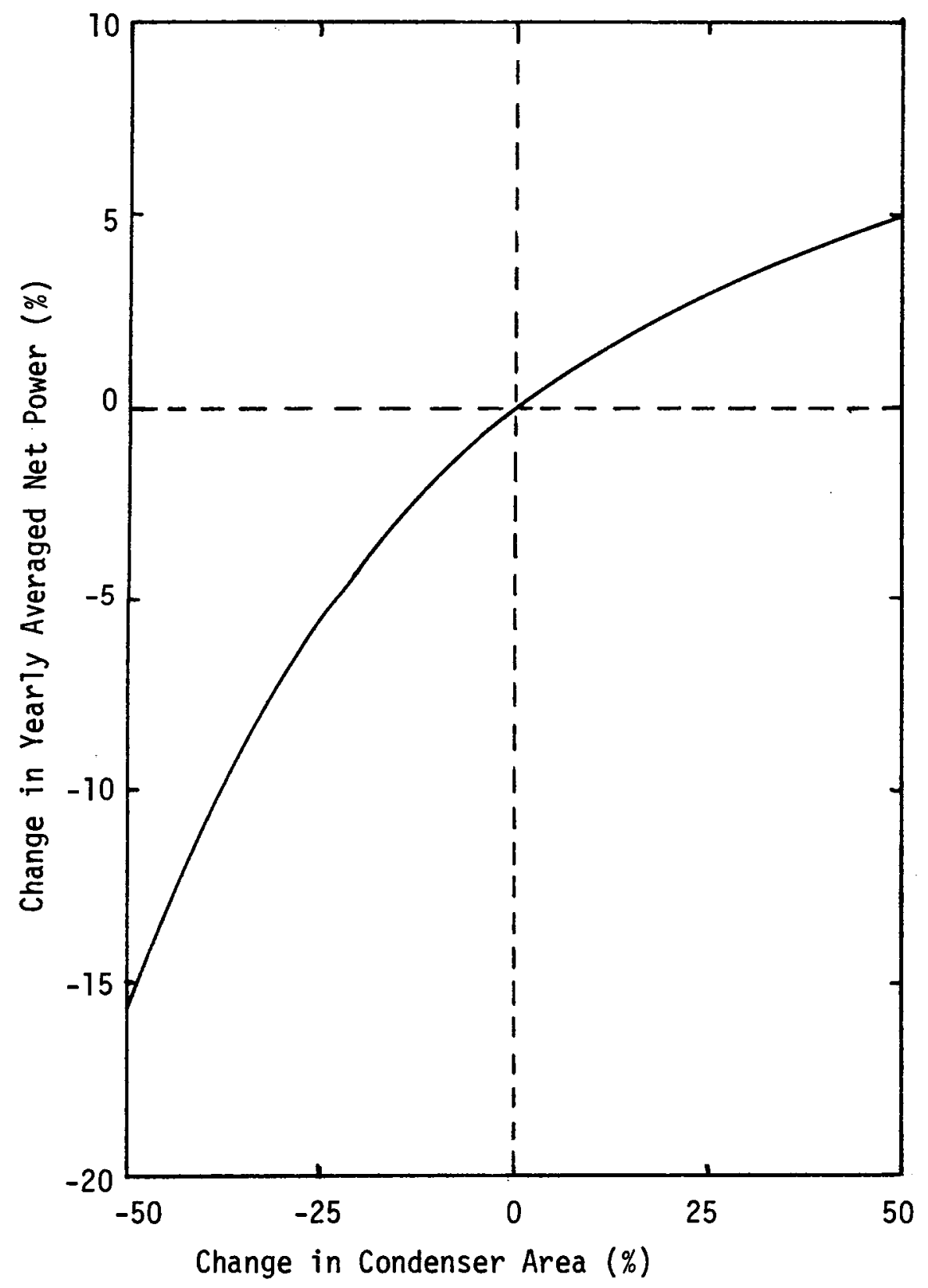

Figure 14. Sensitivity of the Yearly Averaged Net Power to the Condenser. Area 
for increased condenser area decreases. This implies that the optimum condenser area is probably around the knee of the curve where the base case condenser area is located. The sensitivity of the condenser overall heat-transfer coefficient is also shown by Figure 14 since the coefficient and the area are directly multiplied together in the model, i.e., a 5 percent percentage change in the overall heat-transfer coefficient would yield the same change in power as does a 5 percent change in condenser area.

3.2.2 Cooling Water Flow Rate Sensitivity. The sensitivity of the yearly averaged net power to the cooling water flow rate is shown in Figure 15. The sensitivity is shown as a percent increase or decrease from the base case power as the cooling water flow rate varies as a percent increase or decrease from the base case. The slope of this curve levels off at the higher cooling water flow rates implying that the optimum cooling water flow rate is probably in the region about where the base case is located along the knee of the curve. Roughly speaking, this cooling water sensitivity curve applies to the cooling tower size as well as the cooling water flow rate.

\subsection{Comparison of the Design Base Case with Other System Types}

The base case design was compared to several other types of designs including dry cooling towers, direct cooling, wet and dry hybrid cooling towers, natural draft towers and ideal cooling which utilizes the full cooling potential of the atmosphere. (Cooling ponds are considered under a later section on stored cooling.) Each of these cooling system types are modeled assuming the same basic power plant as the base case design, i.e., all equipment from the geothermal brine to the condenser remains the same.

3.3.1 Dry Cooling Towers. The relative comparison of the performance between the wet and dry cooling tower was made by replacing the wet tower in the base case design by a dry cooling tower. The dry tower was modeled as a single pass tube in shell heat exchanger with the cooling water from 


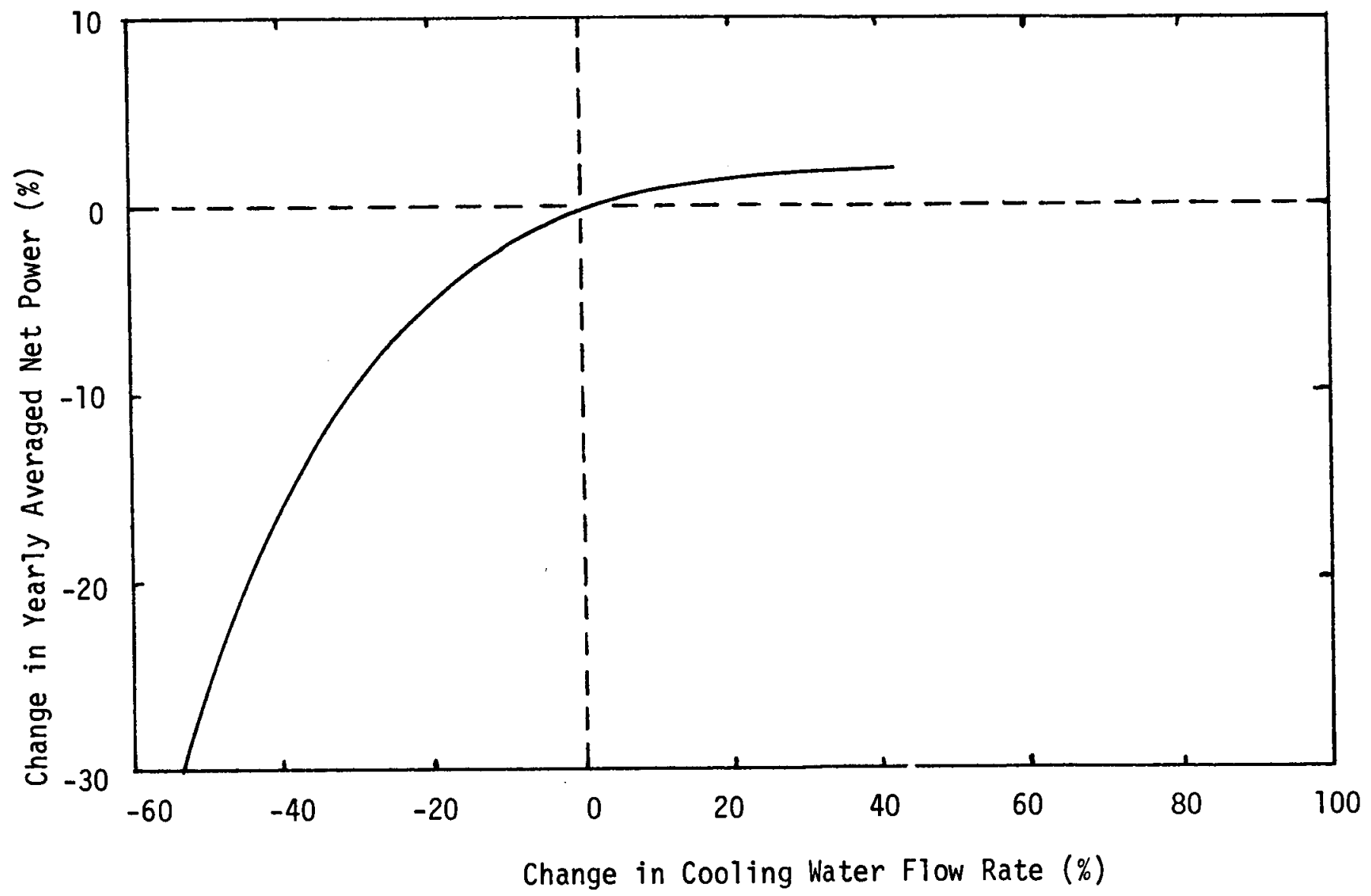

Figure 15: Sensitivity of the Yearly Averaged Net Power to the Cooling Water Flow Rate 
the condenser flowing through finned tubes and air forced over the outside fins. Calculations were made on dry cooling tower systems for two heat trarisfer areas of 3.5 and 5.0 million square feet. The overall heattransfer coefficient was assumed at $10 \mathrm{Btu} / \mathrm{hr}-\mathrm{ft}^{2}-{ }^{\circ} \mathrm{F}$. The mass flow rate of air through the cooling tower was set at $90 \mathrm{million} 1 \mathrm{bm} / \mathrm{hr}$ requiring a fan power of $3300 \mathrm{kw}$. The cooling water flow rate and pumping power were held constant.

The power plant characteristics for the dry cooling tower cooling system are shown in Figure 16 in a comparison with the wet cooling tower cooling system. Figure 16 shows the power plant characteristics as a function of the wet and dry bulb atmospheric temperatures for the wet and dry cooling tower systems, respectively. The dry cooling tower system is shown to produce less power than the wet cooling tower system at the higher temperatures and more power at the lower temperatures. The relative sizes of the wet and dry cooling towers are on the same rough order of magnitude (in terms of heat-transfer area), however, the greater power produced by the dry cooling tower system (at the lower temperatures) is due to the larger air mass flow rate in the dry cooling tower model. A larger air flow rate through the wet cooling tower will raise the characteristics curve for the wet system but most of the increase will be at the lower temperatures instead of the higher temperatures, i.e., the wet cooling system is approximately optimized for the design temperature of $61^{\circ} \mathrm{F}$ wet bulb but not for the lower temperatures. This suggests that a variable air flow rate would provide significantly greater floating power than the constant air flow tower of the base case but in practice the cooling water exiting the cooling tower will freeze at about the $17 \mathrm{MW}$ power level limiting the power to $17 \mathrm{MW}$. Since the dry cooling tower system is a close system, an antifreeze could be added to the cooling water in order to prevent the freezing allowing the cooling temperature to decrease below the freezing point and therefore increasing the net power output as shown in Figure 16.

The dry cooling tower system is not capable of producing as much power as the wet system for the base case design conditions of $61^{\circ} \mathrm{F}$ and $88^{\circ} \mathrm{F}$ wet and dry bulb temperatures, respectively due to the dry bulb temperature being higher than the wet bulb temperature. The dry cooling system shown in Figure 16 has been roughly optimized as demonstrated by the small increase in net power of the order of 6 percent when the 


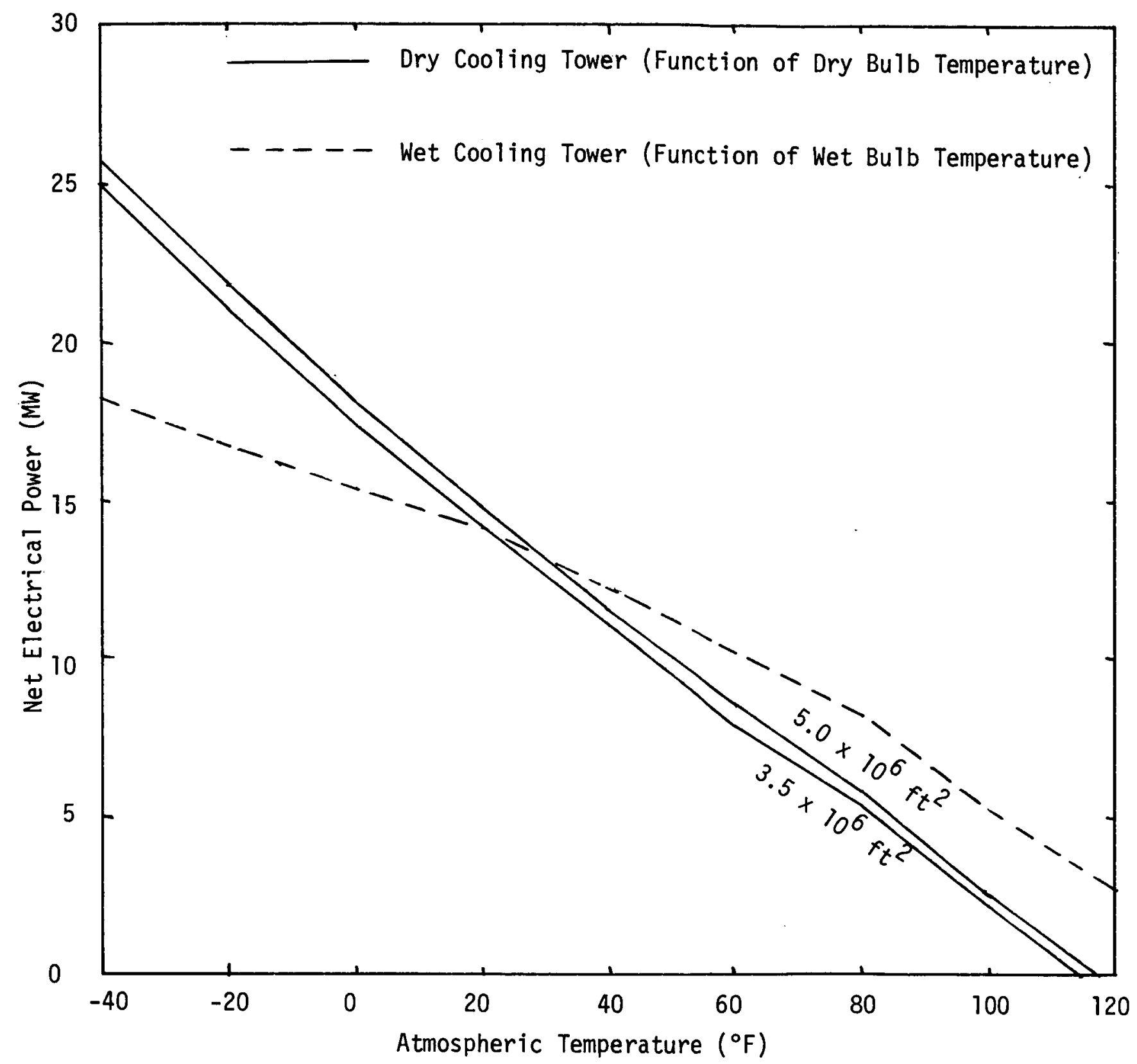

Figure 16: Dry-Wet Cooling Tower Power Plant Characteristics Comparison 
heat-transfer area was increased by 43 percent. In other words, the basic plant (preheaters, boilers, brine flow, and etc.) will need to be enlarged in order to produce on nominal design power of say $10 \mathrm{MW}$ at $88^{\circ} \mathrm{F}$ dry bulb temperature.

The dry cooling tower system floating power parameters and power fluctuation parameters are listed in Table VII in comparison with the base case design. The yearly averaged power for the dry cooling tower systems are on the order of 15 to 20 percent less than the wet cooling tower system which reflects the difference in the power plant characteristics shown in Figure 16 at the portion of the curves around the yearly mean temperatures. The coefficients of performance and therefore the plant reduction percentages for the dry cooling towers are greater than those for the wet cooling tower due to the greater slopes for the dry cooling tower curves. For instance, the dry cooling tower with 3.5 million square feet can produce about 2.56 times as much power if allowed to float than it would produce if it was restricted to the $3830 \mathrm{kw}$ it was designed to produce at $88^{\circ} \mathrm{F}$ dry bulb temperature.

The power fluctuations of the dry cooling tower system as seen in Table VII are much larger than for the wet cooling tower system. This is because the atmospheric dry bulb temperature varies much more rapidly than does the atmospheric wet bulb temperature. For instance, the day with the greatest variation (in the 3.5 million square feet dry cooling tower case) as seen in Table VII (data for Pocatello, Idaho during 1959) was for September 10 and the power varied from $10650 \mathrm{kw}$ down to $3270 \mathrm{kw}$ for a difference of $7380 \mathrm{kw}$ or $75.3 \%$ of the yearly averaged net power. This variation corresponds to a dry bulb temperature variation from $92^{\circ} \mathrm{F}$ to $42^{\circ} \mathrm{F}$ for a difference of $50^{\circ} \mathrm{F}$ where as the wet bulb temperature for the same day only varied from $60^{\circ} \mathrm{F}$ to $36^{\circ} \mathrm{F}$ for a difference of $24^{\circ} \mathrm{F}$.

3.3.2 Direct Dry Cooling. The direct dry cooling concept is one in which the primary working fluid, isobutane, is condensed in air-cooled finned tubes. This concept eliminates the intermediate water loop and consequently decreases the temperature difference between the condensing temperature and the atmospheric dry bulb temperature which increases the cycle thermal efficiency and power output. 
TABLE VII

FLOATING POWER PARAMETER FOR THE DRY COOLING TOWER SYSTEM

\begin{tabular}{|c|c|c|c|}
\hline Parameter & $\begin{array}{l}\text { Wet Tower } \\
\text { (Base Case) }\end{array}$ & $\begin{array}{l}\text { Dry Tower } \\
\left(3.5 \times 10^{6} \mathrm{ft}^{2}\right)\end{array}$ & $\begin{array}{l}\text { Dry Tower } \\
\left(5.0 \times 10^{6} \mathrm{ft}^{2}\right)\end{array}$ \\
\hline $\begin{array}{l}\text { Yearly Averaged } \\
\text { Net Power (kw) }\end{array}$ & 12200 & 9800 & 10400 \\
\hline $\begin{array}{l}\text { Coefficient of } \\
\text { Performance }\end{array}$ & 1.22 & 2.56 & 2.32 \\
\hline $\begin{array}{l}\text { Plant Reduction } \\
\text { Percentage }(\%)\end{array}$ & 18.0 & 61.0 & 56.9 \\
\hline \multicolumn{4}{|l|}{ Fluctuations: } \\
\hline GY (kw) & 7330 & 17270 & 17350 \\
\hline GM $(k w)$ & 4640 & 10630 & 10620 \\
\hline GD (kw) & 2760 & 7380 & 7340 \\
\hline$A D(k w)$ & 940 & 3100 & 3050 \\
\hline GY\% (\%) & 60.1 & 176.3 & 166.7 \\
\hline GM\% (\%) & 38.0 & 108.5 & 102.0 \\
\hline GD\% (\%) & 22.6 & 75.3 & 70.6 \\
\hline$A D \%(\%)$ & 7.7 & 31.6 & 29.3 \\
\hline $\begin{array}{l}\text { Power at } \\
\text { Design Conditions * }(\mathrm{kw})\end{array}$ & 10000 & 3830 & 4480 \\
\hline
\end{tabular}


The direct dry cooling model consists of a single pass tube in shell heat exchanger that can be described by a log-mean temperature difference equation. The log-mean temperature difference equation is solved by an iterative scheme in two parts for the latent and superheat sections of the condenser. The calculations were done for three direct dry cooling cases which differ in the product of the heat-transfer area and the overall heat-transfer coefficient. These coefficient-area products were $2.8 \times 10^{7}, 1.0 \times 10^{8}$, and $2.0 \times 10^{8} \mathrm{Btu} / \mathrm{hr}-{ }^{\circ} \mathrm{F}$. A cooling air mass flow rate of $90 \mathrm{million} 1 \mathrm{bm} / \mathrm{hr}$ requiring $3300 \mathrm{kw}$ of fan power was used for all three cases. An additional benefit of the direct dry cooling system (over the indirect dry cooling system) is that the $750 \mathrm{kw}$ required to pump the cooling water of the other system is not needed.

The power plant characteristics for the direct dry cooling are shown in Figure 17 as a comparison with the design base case wet cooling tower. The direct dry cooling case using a coefficient-area product of $2.0 \times 10^{8}$ $\mathrm{Btu} / \mathrm{hr}-{ }^{\circ} \mathrm{F}$ is not shown in Figure 17 since it is only slightly larger than the $1.0 \times 10^{8} \mathrm{Btu} / \mathrm{hr}-{ }^{\circ} \mathrm{F}$ case. This shows that the $1.0 \times 10^{8} \mathrm{Btu} / \mathrm{hr}-{ }^{\circ} \mathrm{F}$ case is at least approximately optimized in regard to power production. Figure 17 shows the direct dry cooling power to be greater than the wet tower cooling over the medium and low atmospheric temperatures but at the high temperatures the wet tower cooling is greater. For instance, at the design conditions of $61^{\circ} \mathrm{F}$ wet bulb temperature and $88^{\circ} \mathrm{F}$ dry bulb temperature the net powers are $10,000 \mathrm{kw}, 6180 \mathrm{kw}$, and $7430 \mathrm{kw}$ for the wet cooling tower and the $2.8 \times 10^{7}$ and $1.0 \times 10^{8} \mathrm{Btu} / \mathrm{hr}-{ }^{\circ} \mathrm{F}$ direct dry cooling cases, respectively, i.e., when the two curves are compared the relative humidity must be considered.

The direct dry cooling system floating power parameters and power fluctuation parameters are listed in Table VIII. The yearly averaged net power for the direct dry cooling ranges on the order of 10 to 15 percent greater than the design base case wet cooling tower. The steep slope of the direct dry cooling characteristics curves yield large floating power coefficients of performance and large plant reduction percentages but not as large as the dry cooling tower (indirect) system. The floating power fluctuations are large for the direct dry cooling system but the fluctuation percentage numbers for direct dry cooling systems are somewhat smaller than for the dry cooling tower system. 


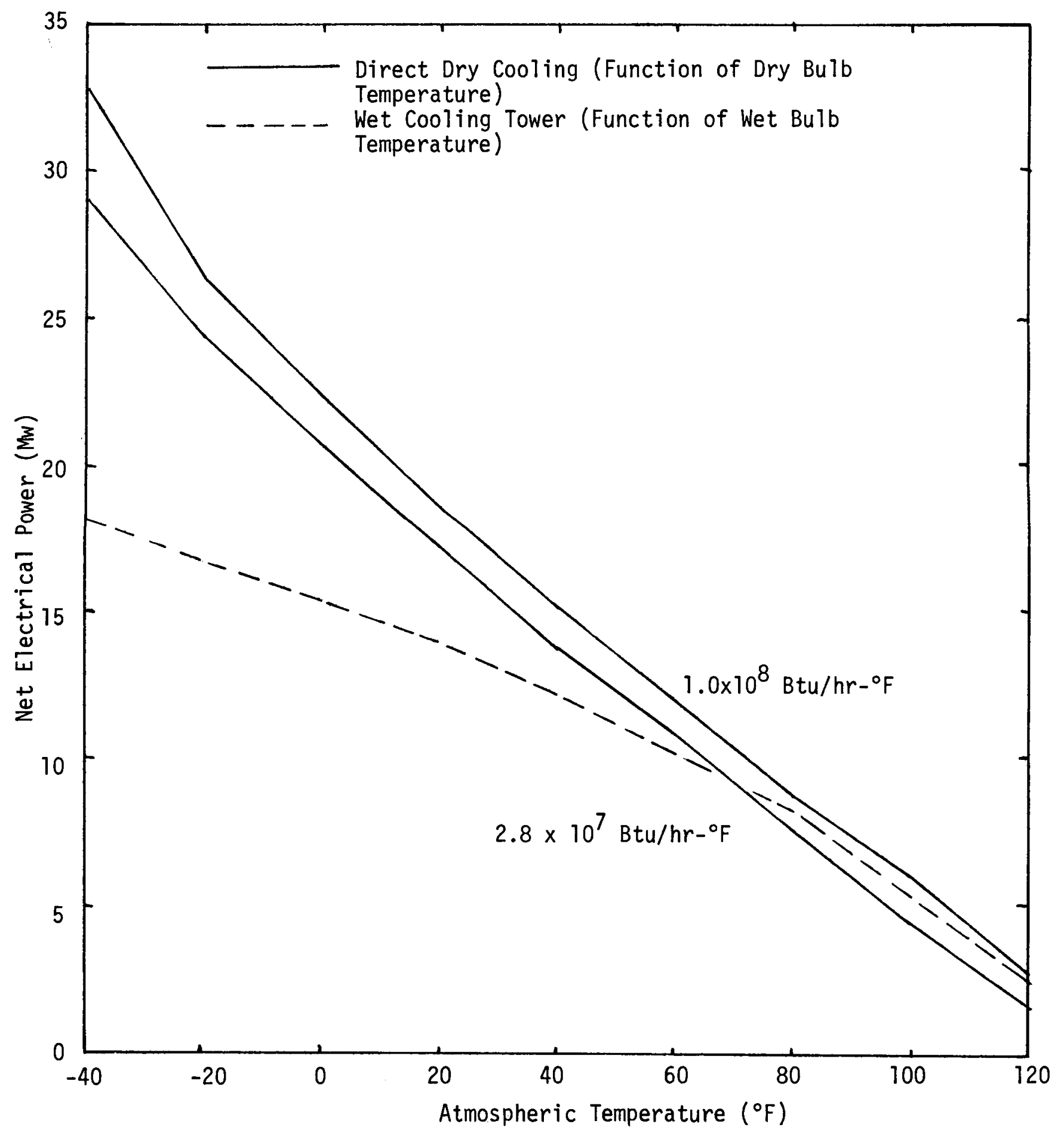

Figure 17: Comparison of Power Plant Characteristics for the Direct Dry Cooling and the Wet Cooling Towers 
TABLE VIII

FLOATING POWER PARAMETERS FOR THE DIRECT DRY COOLING SYSTEM

\begin{tabular}{|c|c|c|c|}
\hline \multirow[b]{2}{*}{ Parameter } & \multicolumn{3}{|c|}{ Coefficient-Area Product $\left(B t u / h r-{ }^{\circ} \mathrm{F}\right)$} \\
\hline & $2.8 \times 10^{7}$ & $1 \times 10^{8}$ & $2 \times 10^{8}$ \\
\hline $\begin{array}{l}\text { Yearly Averaged } \\
\text { Net Power (kw) }\end{array}$ & 12590 & 13820 & 13890 \\
\hline $\begin{array}{l}\text { Coefficient of } \\
\text { Performance }\end{array}$ & 2.04 & 1.82 & 1.82 \\
\hline $\begin{array}{l}\text { Plant Reduction } \\
\text { Percentage }(\%)\end{array}$ & 50.9 & 45.1 & 45.1 \\
\hline Fluctuation: & & & \\
\hline GY (kw) & 18270 & 18890 & 18500 \\
\hline GM $(k w)$ & 11030 & 11760 & 11680 \\
\hline GD $(k w)$ & 7950 & 7880 & 7710 \\
\hline$A D(k w)$ & 3260 & 3320 & 3310 \\
\hline GY\% (\%) & 145.2 & 136.7 & 133.2 \\
\hline GM\% $(\%)$ & 87.6 & 85.1 & 84.1 \\
\hline GD\% $(\%)$ & 63.2 & 57.0 & 55.5 \\
\hline$A D \%(\%)$ & 25.9 & 24.0 & 23.8 \\
\hline $\begin{array}{l}\text { Power at } \\
88^{\circ} \mathrm{F} \text { d.b. (kw) }\end{array}$ & 6180 & 7580 & 7620 \\
\hline
\end{tabular}


3.3.3 Direct Wet Cooling and Hybrids. The direct wet cooling systems concept is where the primary working fluid, isobutane, is condensed in air-cooled finned tubes as does the direct dry cooling but in this concept the air flowing over the finned tubes is wetted with evaporating water in sufficient quantity that the air is kept cooled to the wet bulb temperature. Hybrid systems combine certain aspects of the wet and dry systems in order to produce a more practical design. The direct wet cooling system will basically improve over the wet cooling tower system in much the same way the direct dry cooling system improved over the dry cooling tower system by removing the cooling water loop.

The direct wet cooling system model consists of a single pass tube in shell heat exchanger as does the direct dry cooling system model except that the air temperature of the air flowing through the heat exchanger will be the wet bulb temperature and as the air is heated up evaporation maintains the air at one hundred percent relative humidity and inhances the heat removal capability of the air. Effectively, the evaporation increases the specific heat capacity of the air. The model is solved by using the logmean temperature difference equation in two parts for the latent and superheat sections of the condenser by an iterative numerical scheme. The hybrid model simply means that at some limiting lower wet bulb temperature, the evaporation water is turned off and the solution reverts back to the dry cooling model. The input to the model is the same as the base case design, i.e., the cooling air mass flow rate is $16.2 \mathrm{million} 1 \mathrm{bm} / \mathrm{hr}$ requiring $600 \mathrm{kw}$ of fan power, the overall heat-transfer coefficient is $170 \mathrm{Btu} / \mathrm{hr}-\mathrm{ft}^{2}-{ }^{\circ} \mathrm{F}$, and the heat-transfer area is 167 thousand square feet (the coefficient-area product is then $2.8 \times 10^{7} \mathrm{Btu} / \mathrm{hr}-{ }^{\circ} \mathrm{F}$ ).

The power plant characteristics for the direct wet cooling system and hybrid system are shown in Figure 18. The net power characteristics for the direct wet cooling are on the order of 15 to 20 percent greater than the characteristics for the base case design using a wet cooling tower system. A comparison of the characteristics for the direct wet cooling system, the dry cooling tower and the direct dry cooling systems shows the dry systems produce greater power than the direct wet system at the lower atmospheric temperatures (which is due to the greater heat exchanger areas and air mass flow rates of the dry systems). The relative importance of 


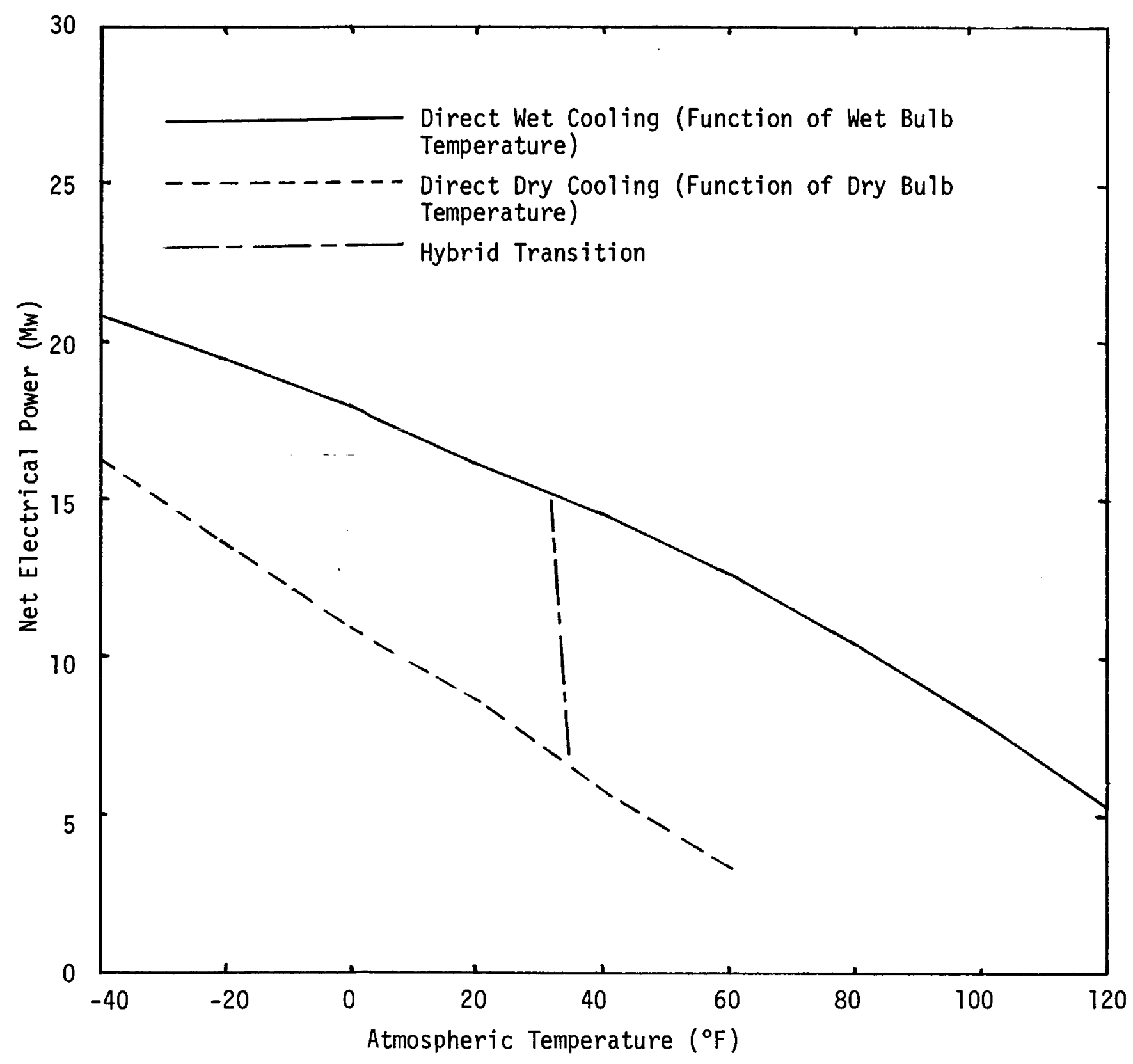

Figure 18: Direct Wet Cooling and Hybrid Power Plant Characteristics 
the evaporation to heat exchanger area decreases as the atmospheric temperature decreases. In a comparison of wet and dry systems which have equivalent heat exchanger areas and air mass flow rates, the wet system will produce the greater power at all atmospheric temperatures as shown in Figure 18. When the evaporation process of the direct wet cooling is turned off, the resulting lower power is equal to using a direct dry system of the same heat transfer area and air flow rate.

A hybrid system is demonstrated in Figure 18 by the vertical dashed 1ine. In this hybrid system the evaporation water of the direct wet cooling is turned off whenever the atmospheric wet bulb temperature drops below $32^{\circ} \mathrm{F}$ in order to prevent any possible freezing problems, but when this is done the net power drops to that of the direct dry cooling curve at $35^{\circ} \mathrm{F}$ dry bulb temperature. (this assumes a 75 percent relative humidity.) The hybrid system then suffers a loss in the yearly averaged net power over the yearly averaged net power of the total direct wet cooling system. A trade off between the wet and dry systems designs is needed in order to determine the optimum hybrid design. If the hybrid was designed with the heat exchanger area and air mass flow rate of the dry systems, then the higher net power at the lower atmospheric temperatures of the dry systems could be coupled with the higher net power of the wet systems at higher atmospheric temperatures. The hybrid design optimization must include economics because as the heat exchanger area and air mass flow rate increases so does the cost of the cooling system.

Another facet of a hybrid cooling system is an additional power plant control system, i.e., the power output of the plant can at least partially be controlled by varying the evaporation water flow. This type of control could be practical in a siting situation in which the plant has limited amounts of water. The evaporation water could be stored at times when the atmospheric temperatures are low and power is high and used when the temperatures are higher in order to level out the power of a floating power plant. For example, consider the direct wet cooling system illustrated in Figure 18. The net power at $61^{\circ} \mathrm{F}$ wet bulb temperature is $12460 \mathrm{kw}$. The net power at any temperature could be maintained at constant $12460 \mathrm{kw}$ by simply reducing the evaporation water flow rate until the atmospheric dry bulb dropped below about $-11^{\circ} \mathrm{F}$, where the evaporation water flow rate is completely turned off. 
The direct wet cooling and hybrid systems floating power parameters and power fluctuation parameters are listed in Table IX. The yearly averaged net power for the direct wet cooling system is about 19 percent larger than the yearly averaged net power for the base case wet cooling tower system and about 5 percent more than the $1.0 \times 10^{8} \mathrm{Btu} / \mathrm{hr}-{ }^{\circ} \mathrm{F}$ direct dry cooling system case. The coefficient of performance and the plant reduction percentage for the direct wet cooling system are on the same order of magnitude as the base case but those for the hybrid case are considerably different. The coefficient of performance for the hybrid case is 0.99 resulting in a $\mathrm{plant}$ reduction percentage of $-1.3 \%$ which means that floating this particular cooling system results in less power production than if it were operated at the design conditions. The power fluctuations for the direct wet cooling system are of about the same magnitude as the base case but the power fluctuations for the hybrid system are greater due to the transition from wet to dry operation.

A more complete study of the hybrid system in context with the operating environment should be performed before concluding the merits of the system. One conclusion is certain and that is that given the heat exchanger area and air mass flow rate, more cooling can be obtained by a wet system than a dry system.

\subsubsection{Natural Draft Cooling Systems. The natural draft cooling} systems are defined as those cooling systems in which the air flows through the system by means of some form of natural convection. The natural draft cooling system therefore require less parasitic power losses and can produce a greater net power output. The power plant characteristics of the natural draft versions of the wet and dry systems discussed above are determined by adding the fan power of $600 \mathrm{kw}$ and $3300 \mathrm{kw}$ for the wet and dry systems, respectively, to the characteristics of the forced air systems.

The floating power parameters for four natural draft cooling systems are listed in Table $X$. The natural draft cooling systems, in general, have greater yearly averaged net power output, smaller coefficients of performance, and smaller plant reduction percentages than the forced air systems. The floating power fluctuations for the natural draft and 
TABLE IX

FLOATING POWER PARAMETERS FOR THE DIRECT

WET COOLING AND HYBRID SYSTEMS

\begin{tabular}{lcc}
\hline Parameter & Direct Wet Cooling & Hybrid \\
\hline Yearly Averaged Net Power (kw) & 14560 & 12290 \\
Coefficient of Performance & 1.17 & 0.99 \\
Plant Reduction Percentage (\%) & 14.5 & -1.3 \\
Fluctuations: & & 9950 \\
GY (kw) & 7420 & 9950 \\
GM (kw) & 4890 & 9950 \\
GD (kw) & 2600 & 1040 \\
AD (kw) & 940 & 80.9 \\
GY (\%) & & 80.9 \\
GM\% (\%) & 50.9 & 80.9 \\
GD\% (\%) & 33.6 & 8.5 \\
AD\% (\%) & 17.8 & \\
Power at Design & 6.4 & \\
\hline $67^{\circ} \mathrm{F}$ and $88^{\circ} \mathrm{F}$ for wet and dry & & \\
\hline
\end{tabular}


TABLE $X$

NATURAL DRAFT COOLING FLOATING POWER PARAMETERS

\begin{tabular}{|c|c|c|c|c|}
\hline \multirow{2}{*}{ Parameter } & \multicolumn{2}{|c|}{ Indirect } & \multicolumn{2}{|c|}{ Direct } \\
\hline & Wet $^{(i)}$ & Dry ${ }^{(i \mathbf{i})}$ & Wet $^{(i i i)}$ & Dry $(i i i i)$ \\
\hline $\begin{array}{l}\text { Yearly Averaged } \\
\text { Net Power (kw) }\end{array}$ & 12800 & 13100 & 15160 & 17120 \\
\hline $\begin{array}{l}\text { Coefficient of } \\
\text { Performance }\end{array}$ & 1.21 & 1.84 & 1.16 & 1.57 \\
\hline $\begin{array}{l}\text { Plant Reduction } \\
\text { Percentage }(\%)\end{array}$ & 17.2 & 46.6 & 13.9 & 36.5 \\
\hline \\
\hline GY (kw) & 7330 & 17270 & 7420 & 18890 \\
\hline GM $(k w)$ & 4640 & 10630 & 4890 & 11760 \\
\hline $\mathrm{GD}(\mathrm{kw})$ & 2760 & 7380 & 2600 & 7880 \\
\hline$A D(k w)$ & 940 & 3100 & 940 & 3320 \\
\hline GY\% (\%) & 57.3 & 131.8 & 48.9 & 110.3 \\
\hline GM\% $(\%)$ & 36.3 & 81.2 & 32.2 & 68.7 \\
\hline GD\% $(\%)$ & 21.6 & 56.3 & 17.1 & 46.0 \\
\hline$A D \%(\%)$ & 7.3 & 23.7 & 6.2 & 19.4 \\
\hline $\begin{array}{l}\text { Power at Design } \\
\text { Condition* (kw) }\end{array}$ & 10600 & 7130 & 13060 & 10880 \\
\hline $\begin{array}{ll}\text { (i) } & \text { Base case } \\
\text { (ii) } & \text { Dry coolin } \\
\text { (iii) } & \text { Direct wet } \\
\text { (iiii) } & \text { Direct dry } \\
\text { * } & 61^{\circ} \mathrm{F} \text { and } 8\end{array}$ & $\begin{array}{l}\text { t coolin } \\
\text { tower wi } \\
\text { ooling. } \\
\text { ool ing w } \\
\text { F for we }\end{array}$ & $\begin{array}{l}\text { million s } \\
10^{8} \text { Btu/ } \\
\text { ry system }\end{array}$ & $\begin{array}{l}\text { feet heat } \\
\text { product. } \\
\text { pectively. }\end{array}$ & fer area. \\
\hline
\end{tabular}


forced systems are of the same magnitude but are a smaller percentage of the yearly average net power. The natural draft cooling systems due to the lack of fan power definitely perform better than the forced draft systems but are larger and more costly to build.

\subsubsection{Systems Comparison to the Atmospheric Cooling Potential. This} section presents a composite comparison of the different types of cooling systems that have been presented here. The comparison will compare both the power production and the power fluctuations but first the concept of atmospheric cooling potential will be developed as a vehicle for the comparisons.

The concept of atmospheric cooling potential illustrates an ideal maximum power that could be produced from the basic power plant of the base case design if an idealized cooling system was used. This idealized cooling system is defined as a cooling system which is capable of maintaining the condensing temperature of the isobutane at the atmospheric temperature (wet or dry bulb temperature) and with zero parasitic power losses by the cooling system. The characteristics of such an idealized system are shown in Figure 19 as the net electrical power output as a function of the condensing temperature with zero parasitic power losses by the cooling system (Figure 19 is a characteristic of a natural draft version of the base case design). The floating power parameters for idealized system are listed in Table XI for both the wet and dry bulb systems, i.e., the condensing temperature is set equal to either the wet or the dry bulb temperature during the entire year.

The cooling systems comparisons are shown in Figures 20 and 21 and Table XII. Figure 20 shows the specific net power (i.e., the net power divided by the brine mass flow rate of $2.8 \mathrm{million} 1 \mathrm{bm} / \mathrm{hr}$ ) as a function of the greatest yearly fluctuation percent (GY\%) for each of the test cases and the wet and dry bulb atmospheric potentials. Similar figures could be generated using monthly or daily fluctuation percentages but would only show the same comparisons. The dry type of systems are al1 shown to have greater power fluctuations than the wet type of systems so Figure 20 was divided into two regions by a dashed line. The dry systems have greater power fluctuations than the wet systems 


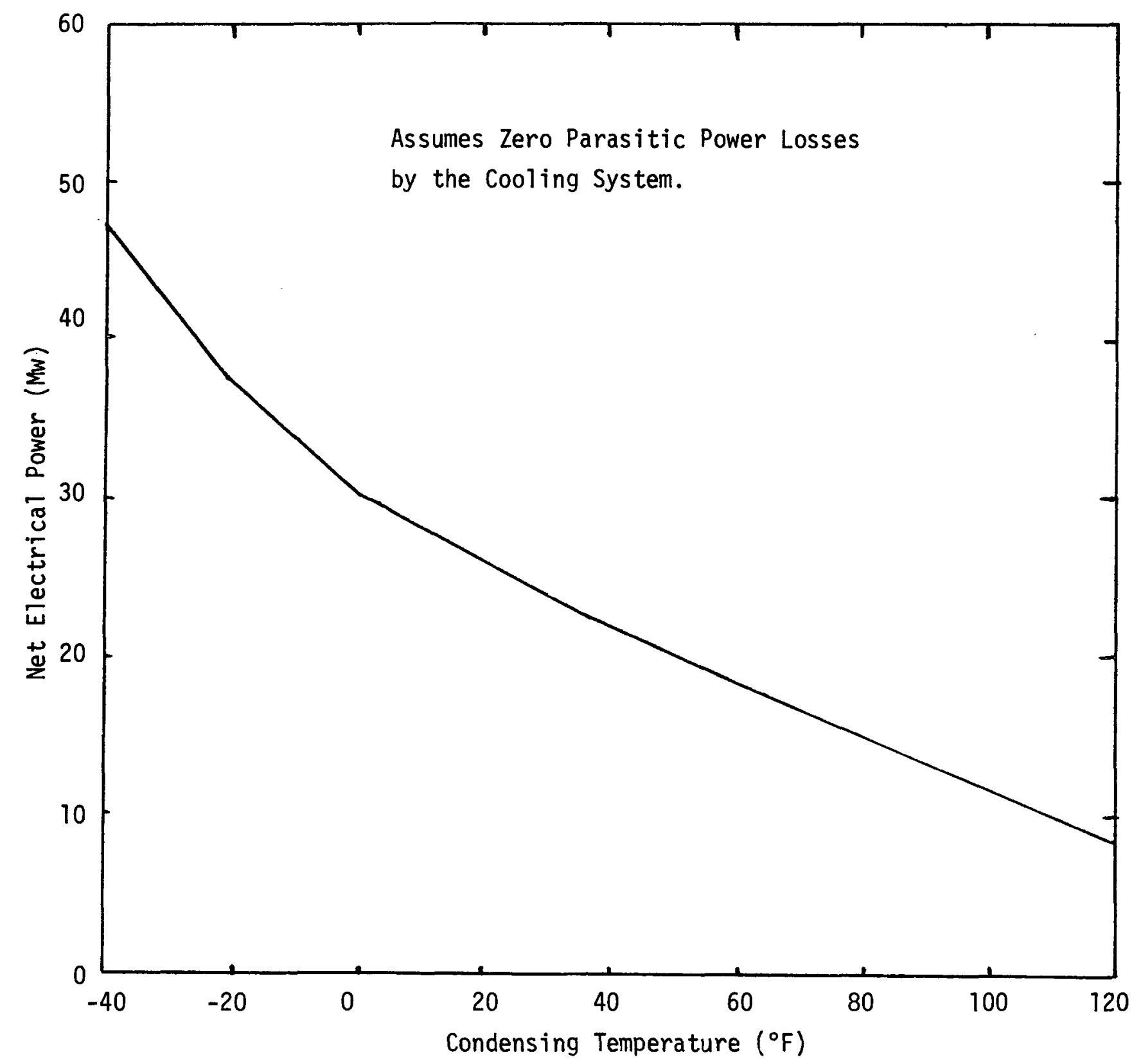

Figure 19: Net Electrical Power as a Function of Condensing Temperature 
TABLE XI

FLOATING POWER PARAMETERS FOR THE IDEALIZED SYSTEM

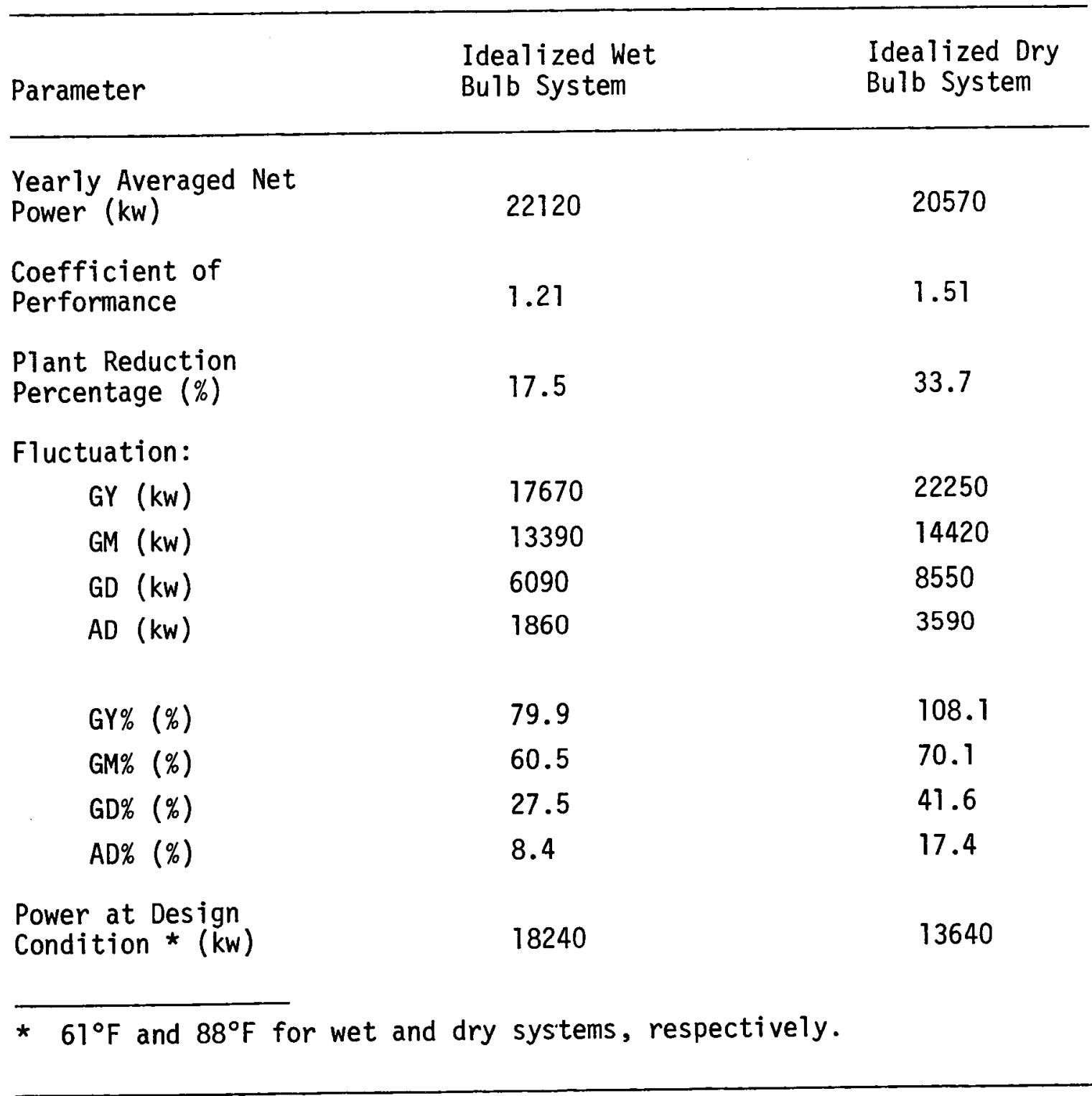




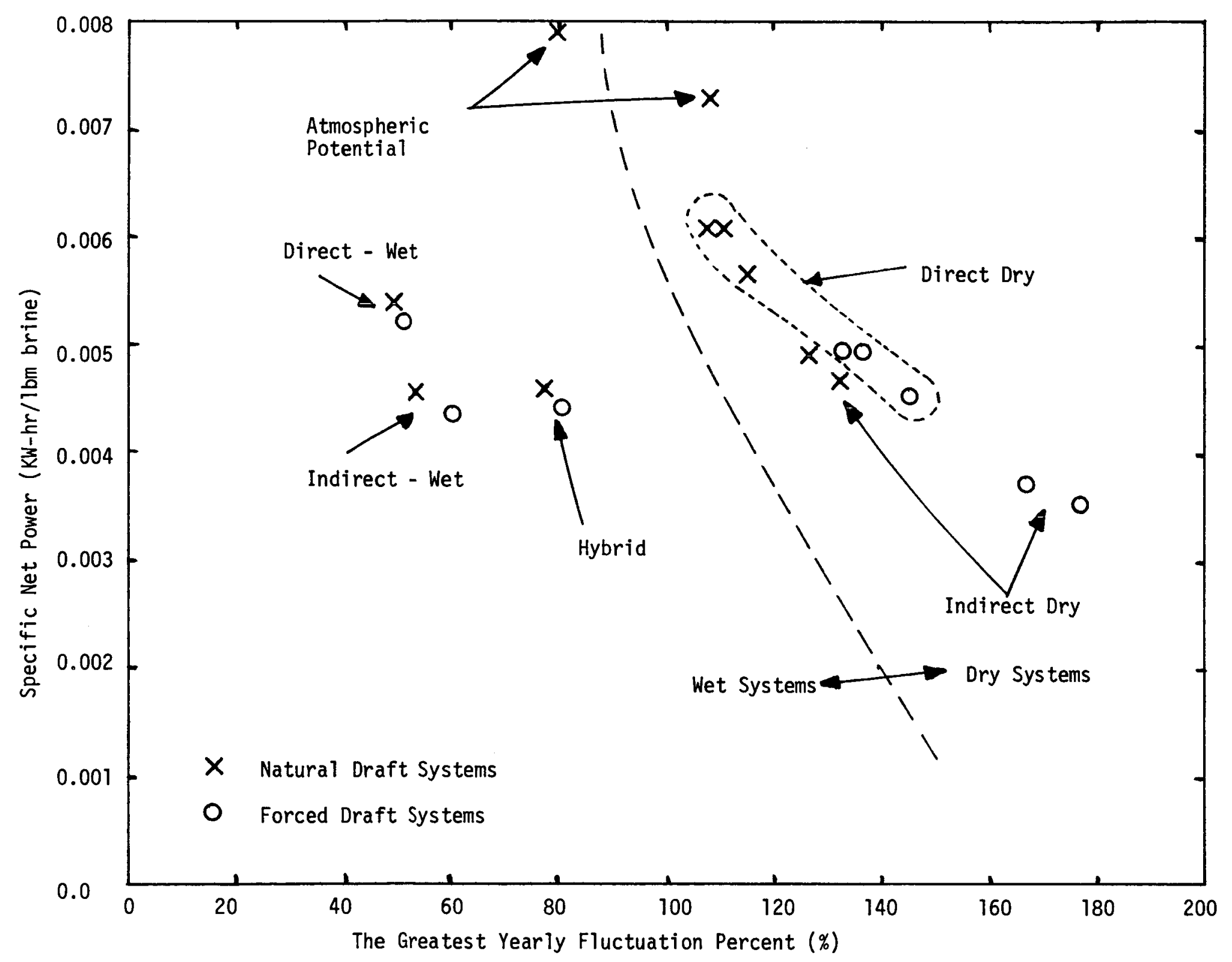

Figure 20: Cooling Systems Comparisons on the Basis of Power and Fluctuations 


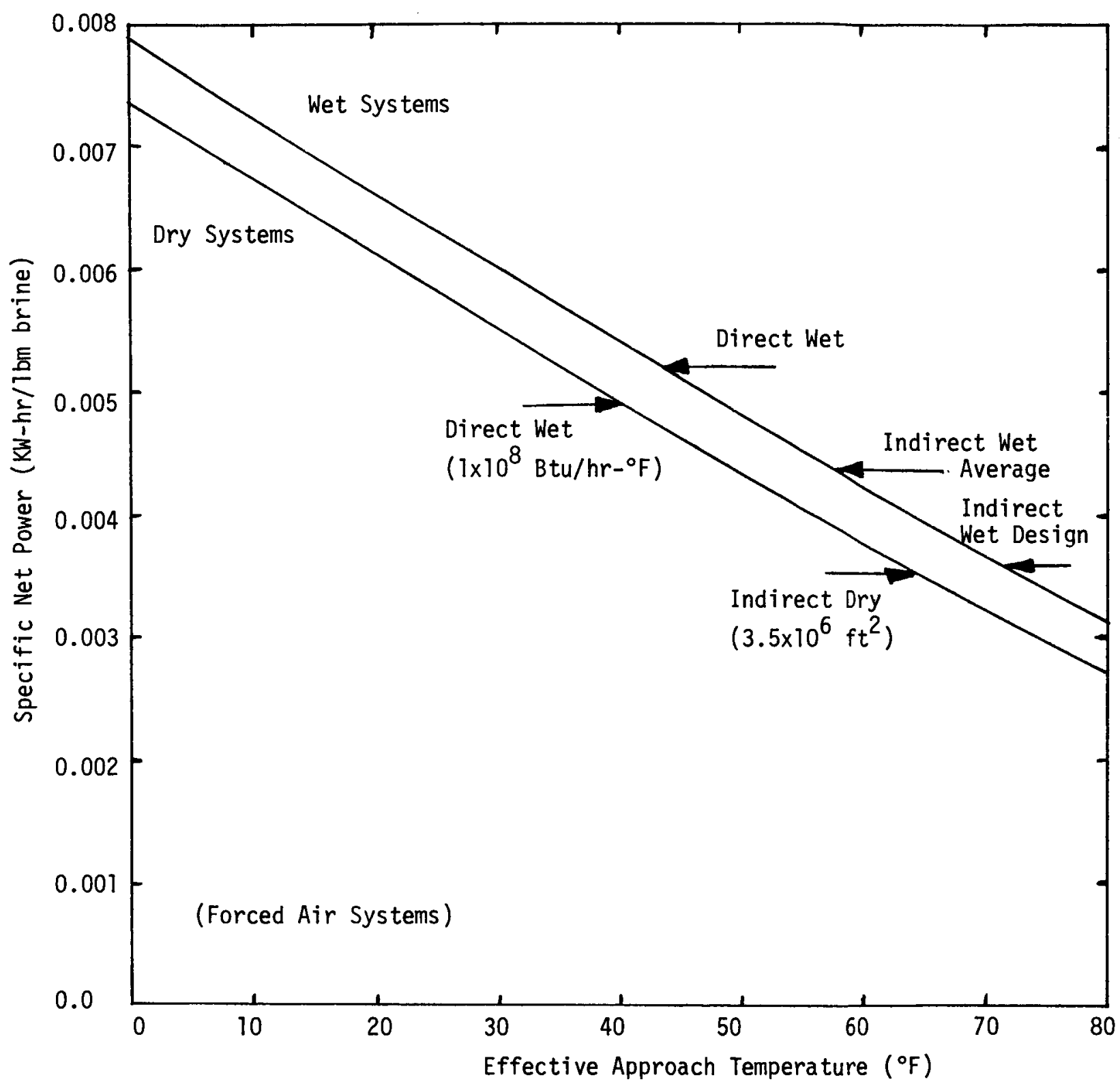

Figure 21: Cooling Systems Effective Approach Temperature 
TABLE XII

COOLING SYSTEMS COMPARISON PARAMETERS

\begin{tabular}{|c|c|c|c|c|c|c|c|c|}
\hline \multirow[b]{2}{*}{ Case } & \multicolumn{4}{|c|}{ Forced Draft } & \multicolumn{4}{|c|}{ Natural Draft } \\
\hline & $\begin{array}{l}\text { Design } \\
\text { SP. Power } \\
\text { (kwh/1bm- } \\
\text { Brine) }\end{array}$ & $\begin{array}{l}\text { Average } \\
\text { SP. Power } \\
\text { (kwh/1bm- } \\
\text { Brine) }\end{array}$ & C.0.P. & $\delta(\%)$ & $\begin{array}{l}\text { Design } \\
\text { SP. Power } \\
\text { (kwh/1bm- } \\
\text { Brine) }\end{array}$ & $\begin{array}{l}\text { Average } \\
\text { SP. Power } \\
\text { (kwh/1bm- } \\
\text { Brine) }\end{array}$ & C.0.P. & $\delta(\%)$ \\
\hline $\begin{array}{l}\text { Atmospheric } \\
\text { Potential Wet }\end{array}$ & --- & --- & -- & $\cdots$ & -- & 0.00790 & --- & -- \\
\hline $\begin{array}{l}\text { Indirect - Wet } \\
\text { (Base Case) }\end{array}$ & 0.00357 & 0.00436 & 1.22 & 18.0 & 0.00379 & 0.00451 & 1.21 & 17.2 \\
\hline Direct Wet & 0.00445 & 0.00520 & 1.17 & 14.5 & 0.00466 & 0.00542 & 1.16 & 13.9 \\
\hline Hybrid & 0.00445 & 0.00439 & 0.99 & -1.3 & 0.00466 & 0.00461 & 0.99 & -1.3 \\
\hline $\begin{array}{l}\text { Atmospheric } \\
\text { Potential Dry }\end{array}$ & --- & --- & --- & --- & --- & 0.00735 & --- & -- \\
\hline $\begin{array}{l}\text { Indirect - Dry } \\
\left(3.5 \times 10^{6} \mathrm{ft}^{2}\right)\end{array}$ & 0.00137 & 0.00350 & 2.56 & 61.0 & 0.00255 & 0.00468 & 1.84 & 46.6 \\
\hline $\begin{array}{l}\text { Indirect Dry } \\
\left(5.0 \times 10^{6} \mathrm{ft}^{2}\right)\end{array}$ & 0.00160 & 0.00372 & 2.32 & 56.9 & 0.00278 & 0.00490 & 1.76 & 43.2 \\
\hline $\begin{array}{l}\text { Direct Dry } \\
\left(2.8 \times 10^{7} \mathrm{Btu} / \mathrm{hr}-{ }^{\circ} \mathrm{F}\right)\end{array}$ & 0.00221 & 0.00450 & 2.04 & 50.9 & 0.00339 & 0.00567 & 1.67 & 40.3 \\
\hline $\begin{array}{l}\text { Direct Dry } \\
\left(1.0 \times 10^{8} \mathrm{Btu} / \mathrm{hr}-{ }^{\circ} \mathrm{F}\right)\end{array}$ & 0.00271 & 0.00494 & 1.82 & 45.1 & 0.00389 & 0.00612 & 1.57 & 36.5 \\
\hline $\begin{array}{l}\text { Direct Dry } \\
\left(2.0 \times 10^{8} \mathrm{Btu} / \mathrm{hr}-{ }^{\circ} \mathrm{F}\right)\end{array}$ & 0.00272 & 0.00496 & 1.82 & 45.1 & 0.00390 & 0.00614 & 1.57 & 36.5 \\
\hline
\end{tabular}


simply because the dry bulb temperature varies much more rapidly and over a wider range than does the wet bulb temperature. The comparison between forced and natural draft system are also shown in Figure 20. The natural draft systems produce more net power than the forced draft systems simply because the natural draft systems use less parasitic power which is also the reason that there is a greater difference (between the natural and forced systems) for the dry than the wet system.

The comparison between the direct wet and dry systems shows the specific net power for the natural draft direct dry cooling systems to be larger than for the natural draft direct wet cooling system. This shows that the direct wet cooling system has not been fully optimized since a wet system can always produce more power than the corresponding dry system because the wet buib temperature is always colder than the dry bulb temperature. The maximum power output of the direct dry system has been approached as is evident by the relatively small increase in net power that was obtained by doubling the heat-transfer area (from 100 to $200 \mathrm{million} \mathrm{Btu} / \mathrm{hr}-{ }^{\circ} \mathrm{F}$ ). An increase in the heat-transfer area and/or the air mass flow rate of the direct wet cooling system will increase the net power output of that system until it approaches some maximum limitation which will be greater than the limitation for the dry system.

The hybrid case shown in the comparisons is shown with the wet cooling systems (when in fact it is both a wet and a dry type) because it uses the same heat-transfer area and air mass flow rate as the direct wet case. The only difference between the direct wet and the hybrid cases is that in the hybrid case the evaporation water is turned off whenever the wet bulb temperature drops below $32^{\circ} \mathrm{F}$. The hybrid cooling system can not be compared by just one data point but an entire parametric study to determine its performance. The hybrid cooling system performance could move around on Figure 20 from the performances of the wet systems to the performances of the dry systems depending upon the relative portions of wet or dry operation, the heat-transfer area, and the cooling air mass flow rate.

Several cooling systems floating power parameters are listed in Table XII for comparison purposes. Table XII lists both the design and average specific net powers, the coefficient of performance, and the 
plant reduction percentage for both the forced and natural draft systems. The design specific powers were computed at the design conditions of $61^{\circ} \mathrm{F}$ and $88^{\circ} \mathrm{F}$ wet and dry bulb temperatures, respectively. This table illustrates the gain in net power produce for each type of cooling system by utilizing the floating power concept over operating the plant at a constant design power. The ratio of the average to design specific net powers is the coefficient of performance. The coefficients of performance and the plant reduction percentages of the dry cooling systems are generally much larger than for the wet cooling systems.

Another useful method of comparing cooling systems performances is through the effective approach temperatures of each system. The effective approach temperature will now be defined. The concept of cooling tower potential was defined such that the condensing temperature was maintained at either the wet or dry bulb atmospheric temperature (depending on whether a wet or dry system is being studied) and the cooling system parasitic losses was zero. An effective approach temperature of say $10^{\circ} \mathrm{F}$ means that the condensing temperature is maintained at $10^{\circ} \mathrm{F}$ warmer than the atmospheric temperature at all times. The cooling system parasitic losses are always zero. The effective approach temperature of a cooling system in general terms is defined as that temperature difference between the condensing temperature and the atmospheric temperature maintained at all times throughout the year which will yield the same net power output as the cooling system. The effective approach temperature is demonstrated in Figure 21. Figure 21 shows a plot of the specific net power as a function of the effective approach temperature for both the wet and dry bulb atmospheric temperatures. Several cooling systems are also shown in Figure 21. For example, the cooling system effective approach temperatures for the average floating net power for the direct wet and the indirect wet (base case) cooling systems are approximately $43^{\circ} \mathrm{F}$ and $58^{\circ} \mathrm{F}$, respectively. This says that effectively there is a $58^{\circ} \mathrm{F}$ temperature differential maintenance between the condensing temperature and the atmospheric wet bulb temperature for the base case design. However, if a constant design power was maintained with the base case design, the effective approach temperature would be approximately $71^{\circ} \mathrm{F}$. This type of comparison clearly illustrates the inefficient use of atmospheric cooling potential by most cooling system designs. 
The concept of stored cooling is used in conjunction with the floating power concept to reduce the magnitude and severity of the power fluctuations inherent in the floating power concept. The stored cooling concept stores the colder cooling water from times of good atmospheric cooling conditions for use when the atmospheric cooling conditions are poor. Both the theoretical and practical aspects of the stored cooling concept are discussed.

\section{THEORETICAL ASPECTS OF THE STORED COOLING CONCEPT}

The stored cooling concept theoretically inserts a thermal capacitor in the cooling water loop between the cooling tower exit and the condenser inlet. The thermal capacitor studied here consists of a volume of water which mixes with the cooling water flow. The thermal capacitor affects the cooling water such that the temperature leaving the capacitor does not vary as rapidly or with as great of a magnitude as does the inlet temperature to the capacitor. Theoretically if a large enough capacitor is used, the floating power fluctuations could be completely damped such that a constant power was produced.

The stored cooling concept under some conditions changes the average floating power production. The change in floating power is due to; 1) changing the operation of the power plant, and 2) heat transfer between the capacitor and the environment. The changing of the operation of the power plant depends upon the shape of the power plant characteristics curve, i.e., the capacitor could keep the power plant operating in a region of the characteristics curve which has a higher thermal efficiency. For example, the turbine efficiency is usually described by a bell shaped curve such as Figure 3 so that as the atmospheric temperature changes sufficiently to cause the turbine efficiency to fall off the bell shaped curve, the power characteristics curve could also fall off. A thermal capacitor could keep the turbine efficiency operating near the peak efficiency much more of the time resulting in a higher average floating power. 
The floating power remains relatively constant with respect to the capacitor size for a floating power plant in which the power characteristics are linear with respect to the cooling water temperature at the inlet to the condenser. The net power of this type of power plant can be described by the following equation:

$$
P=k_{0}+k_{1} T_{C}
$$

where: $P=$ the net power output

$T_{c}=$ cooling water temperature at the condenser inlet

$k_{0}$ and $k_{1}=$ constants

The insertion of Equation (12) into the integral of Equation (1) and simplifying yields Equation (13):

$$
p_{a}=k_{0}+\frac{k_{1}}{\Delta t} \int_{\Delta t} T_{c} d t
$$

Equation (13) says that the average floating power, $P_{a}$, is a function of the average condenser inlet cooling water temperature. The sensitivity of the average condenser inlet cooling water temperature to the capacitor size needs to be determined for each individual case but for the standard wet cooling tower design of the floating power base case, the average temperature is constant for all practical purposes.

The heat transfer between the capacitor and the environment will affect the average floating power. The heat transfer will either increase or decrease the average condenser inlet cooling water temperature depending upon the direction of the heat transfer. If the capacitor is a closed volume, the heat transfer will be by conduction through the container walls but if the capacitor is an open volume such as a pond then the heat transfer will involve evaporative cooling. Heat transfer mechanisms may include conduction, convection, evaporation, condensation, solar insolation, radiation, and the mixing of makeup water. 


\section{PRACTICAL ASPECTS OF THE STORED COOLING CONCEPT}

The major concern and limitation of the stored cooling concept from the practical standpoint is the large quantity of water required for significant fluctuation damping capability. The damping capability (quantified in terms of the power fluctuation parameters) was determined for various sizes of adiabatic and non-adiabatic stored water systems.

\subsection{Adiabatic Stored Water Systems}

An adiabatic stored water system consists of an adiabatic tank of water to perform as a thermal capacitor inserted in the cooling water loop between the cooling tower exit and the condenser inlet. The damping capability of the adiabatic stored water system is shown in Figure 22 as a function of the stored water volume $\left(10^{7} \mathrm{ft}^{3}\right.$ is about 230 acre- $\left.\mathrm{ft}\right)$. Figure 22 shows that the power fluctuations decrease as the water volume increases while the yearly averaged net power is remaining nearly constant. The power plant characteristics for the floating power base case design are approximately linear with respect to the cooling water temperature at the condenser inlet. All the parameters in Figure 22 approach the floating power parameters of the floating power base case design as the volume decreases (approaching zero). The volume of $10^{5}$. cubic feet is for all practical purposes zero. It would require a volume of approximately $10^{8}$ cubic feet ( 2300 acre $\mathrm{ft}$ ) in order to reduce the greatest daily fluctuation down to about $120 \mathrm{kw}$ or one percent of the yearly averaged net power. Figure 22 demonstrates that a rather large water storage volume is needed.

\subsection{Non-Adiabatic Stored Water Systems}

Realistic stored water systems involve heat transfer from the thermal capacitor stored water volume. This heat transfer can have a substantial influence upon the performance of the thermal capacitor. The heat transfer mechanisms include conduction and convection for the closed water 


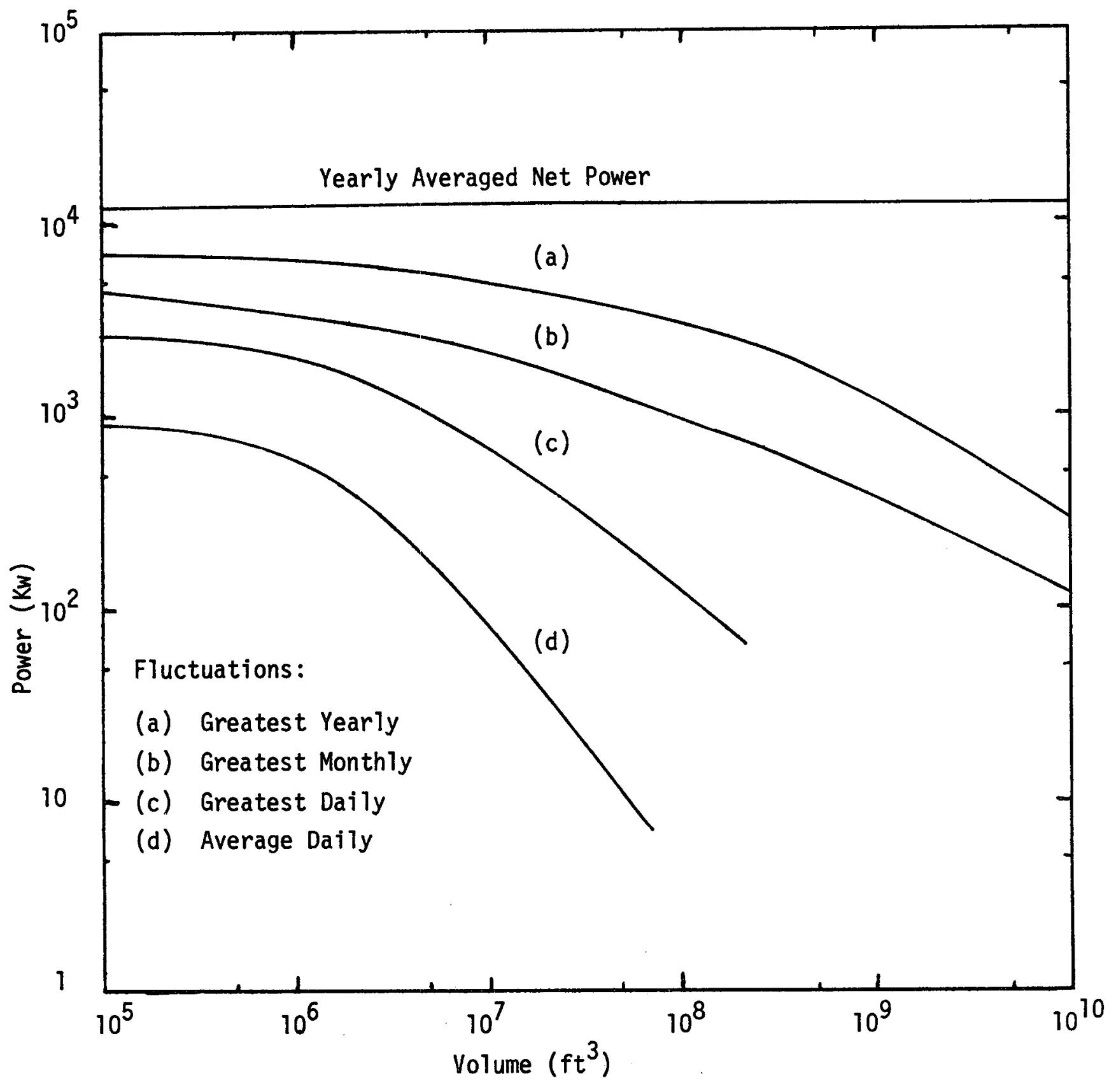

Figure 22. Size Sensitivity of the Adiabatic Stored Water System 
systems and evaporation and condensation for open water systems such as ponds. Ponds could be designed to act primarily as thermal capacitors or as cooling ponds.

2.2.1 Closed Water Storage Systems. Heat transfer from a closed water storage system such as a tank of water includes conduction and convection. The analysis for these types of systems was done as a function of the heat load (Btu/hr- ${ }^{\circ} \mathrm{F}$ ) between the storage water and the environment, i.e., the heat transfer is equal to the heat load times the temperature differential between the stored water temperature and the atmospheric dry bulb temperature. The results of the heat load analysis is shown in Figures 23 and 24 for the stored water volumes of $10^{7}$ and $10^{8}$ cubic feet, respectively. The floating power fluctuation parameters and the yearly averaged net power are shown in Figures 23 and 24 as a function of the heat load for the respective storage volumes. The yearly averaged net power increases with the heat load as seen in both figures which means that more energy is transferred out of the storage volume than into the volume. But, as the average net power increases so does the power fluctuations. Therefore, the stored water acts as a better thermal capacitor if the system is insulated in order to reduce the heat load. Even though the stored water system acts somewhat as a cooling system, it is probabiy not an efficient cooling system and more cooling could be obtained more economically by increasing the cooling tower capacity.

\subsubsection{Open Water Storage Systems. Open water storage systems such} as ponds transfer energy to and from the environment by means of evaporation, condensation, conduction, convection, solar heating, radiative cooling and make-up water mixing. The model used in the analysis of the open water storage systems is a simple one which assumes that; 1) the stored water temperature is always isothermal throughout the volume, and 2) the energy transferred into or out of the stored water is transferred by evaporation, convection and solar heating. The evaporative cooling and convection are handled by a correlation (4) and the solar heating by the solar insolation data of Section II (2.3). This simple model admittedly 


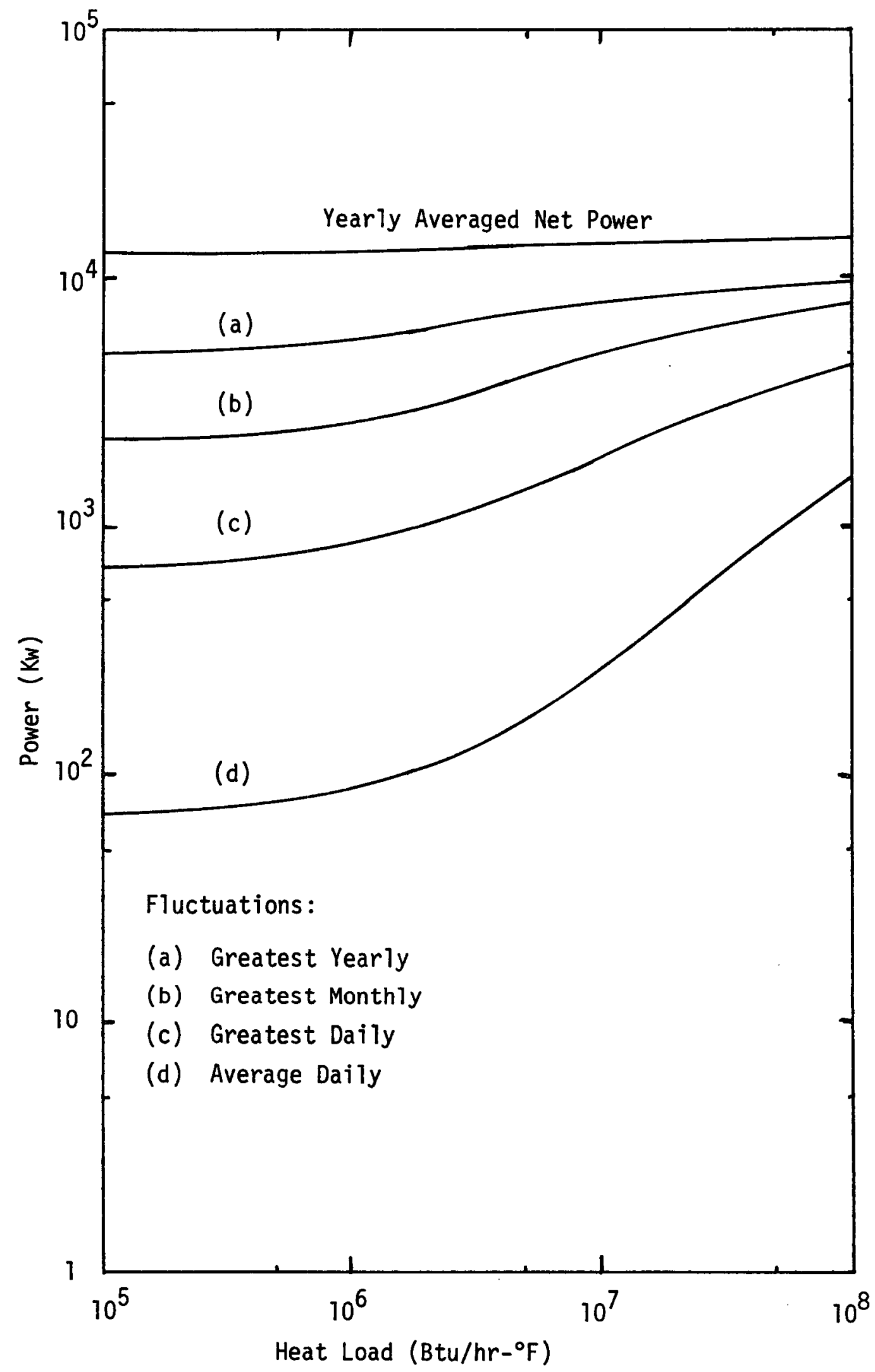

Figure 23. Heat Load Sensitivity of the non-Adiabatic Stored Water System (for a volume of $10^{7} \mathrm{ft}^{3}$ ). 


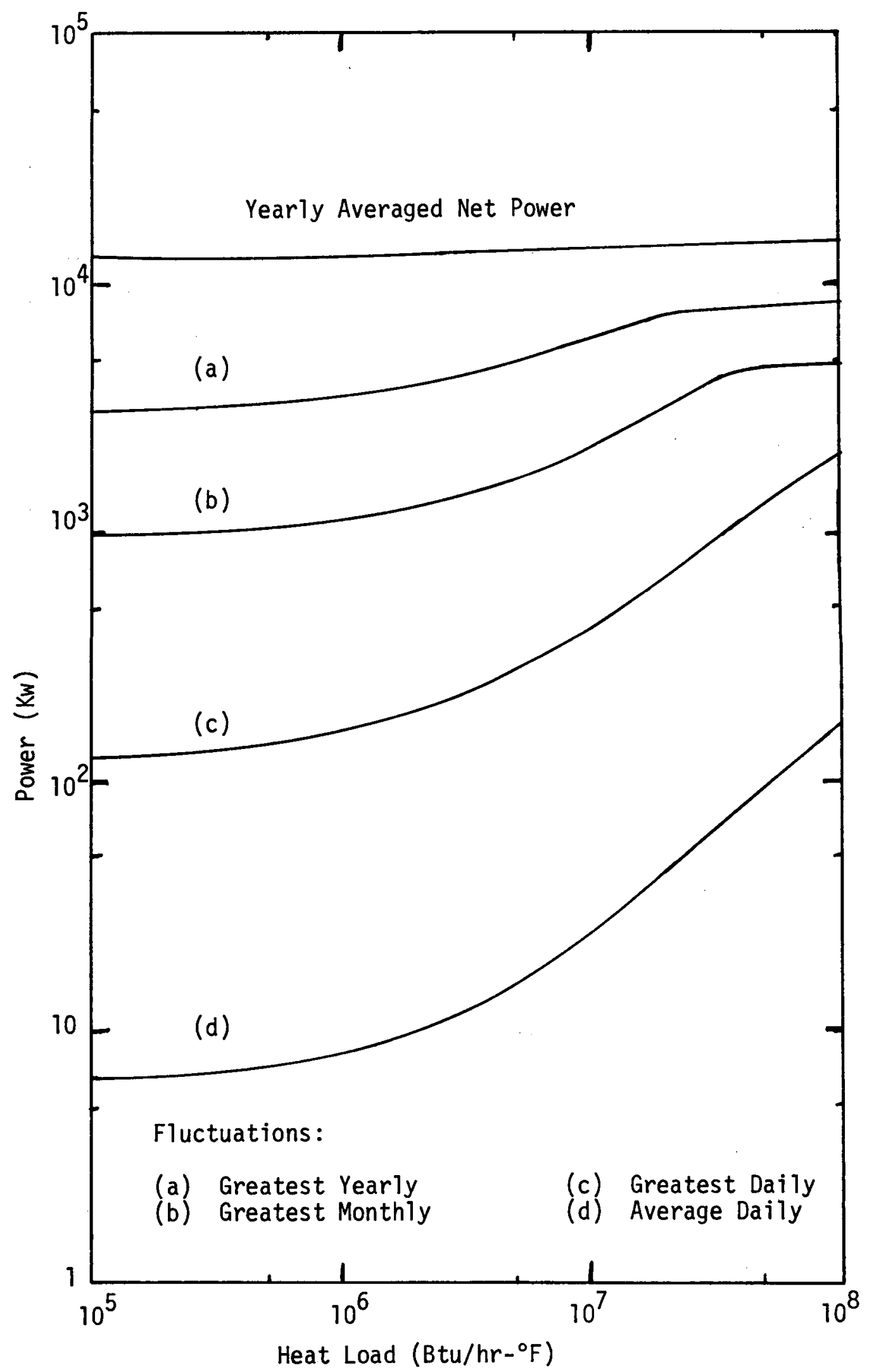

Figure 24. Heat load Sensitivity of the Non-Adiabatic Stored Water System (for a volume of $10^{8} \mathrm{ft}^{3}$ ). 
has shortcomings but still it is able to provide a preliminary type of results. Probably the most serious shortcoming is the isothermal temperature assumption. A stratified temperature distribution at least near the water surface would be more realistic.

The results of several case studies are illustrated in Figure 25 . The resuTts in Figure 25 are shown as the specific net power (i.e., the net power produced per pound mass of brine flow) as a function of the greatest yearly fluctuation percent. Cases shown in the figure include; 1) wet cooling towers with adiabatic water storage of volumes $0,10^{5}, 10^{6}, 10^{7}$, $10^{8}$, and $10^{9}$ cubic feet (the zero volume is the floating power base case), 2) wet cooling towers with non-adiabatic pond water storage of $10^{7}$ cubic feet volume at 3 and 20 feet of depth, 3) cooling ponds of $10^{7} \mathrm{ft}^{3}$ volume at $3 \mathrm{ft}$ depth, $10^{8} \mathrm{ft}^{3}$ volume at 3 and $20 \mathrm{ft}$ of depth, and $10^{9} \mathrm{ft}^{3}$ volume at $20 \mathrm{ft}$ depth, 4) direct and indirect dry cooling systems, and 5) direct wet cooling system.

The volume and depth sensitivities of stored water systems is demonstrated in Figure 25. The performance of the adiabatic and the non-adiabatic stored water systems which are in series with a wet cooling tower is shown relative to the floating power base case design (designated as $V 0$ in Figure 25). The power fluctuations of the adiabatic system is shown to decrease with increasing stored water volume but at a constant specific net power leve1. This adiabatic system parametric study demonstrates the fluctuation leveling potential of the stored water system and also quaritifies the minimum storage volume for a given leveling effect. The adiabatic systems have greater power fluctuation leveling abilities than does the non-adiabatic systems at least in the types of systems presented here. The influence of heat transfer in the non-adiabatic systems is demonstrated by the two cases of wet cooling towers with ponds. Both of these cases have ponds of $10^{7} \mathrm{ft}^{3}$ volume but the ponds have the different depths of 3 and $20 \mathrm{ft}$. These non-adiabatic ponds act as both cooling ponds and thermal capacitors which are greatly influenced by the heat transfer characteristics of the pond. The heat transfer characteristics are determined primarily by the surface area of the pond, i.e., more area will transfer more energy. The pond with a depth of $20 \mathrm{ft}$ tends to act 


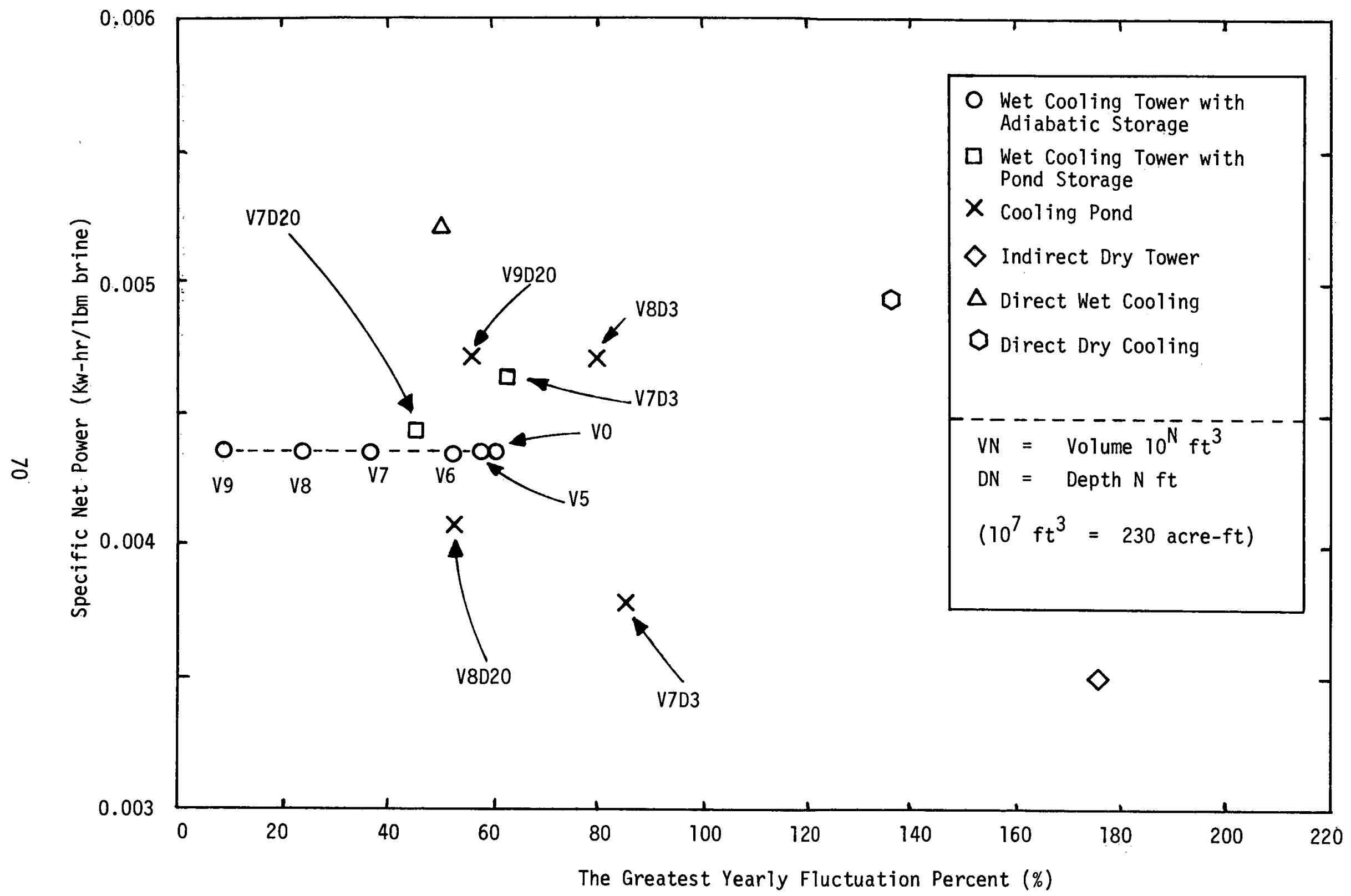

Figure 25. Storage Cooling Systems Comparisons 
more as a thermal capacitor than as a cooling pond where as the pond with a depth of $3 \mathrm{ft}$ tends to act more as a cooling pond than as a thermal capacitor due to its greater surface area. The pond with the $3 \mathrm{ft}$ depth increases the specific net power but does not decrease the power fluctuations for which it was designed.

Cooling ponds as a cooling system (without any cooling towers) were studied and four cases are presented in Figure 25. These four cases vary in volume and depth. Again it can be seen that shallow ponds perform better for cooling than deep ponds and deep ponds make better thermal capacitors. A volume on the order of 50 million cubic feet (375 million gallons or 1150 acre-ft) for 3 feet deep pond is needed to yield the same specific net power as the floating base case design which has a wet cooling tower but with a greater power fluctuation. It should be noted that the results of the deep ponds $(20 \mathrm{ft})$ are not as accurate as the shallow ( $3 \mathrm{ft}$ ) ponds due to the isothermal assumption in the model used but these results will still yield reliable trends.

Figure 25 also contains data points for direct and indirect dry cooling towers, and for direct wet cooling towers (these data points are also contained in Figure 20). The cooling ponds are a type of wet cooling system and have power fluctuations much less than the fluctuations of dry systems. Large volumes of water are required for a cooling pond to reach the specific net power of the direct wet system or to significantly reduce the power fluctuations.

\subsection{Phase Stored Cooling}

A few words about phase stored cooling should be said to complete the discussion on the stored cooling concept. Phase stored cooling is defined as a cooling system which is divided into two or more distinct phases. One such phase cooling system which is designed to reduce the evaporation losses of a wet cooling system cools and stores enough additional water at night to last during the day. The evaporation losses are greater at higher atmospheric temperatures than at lower atmospheric temperatures as shown in Figure 9 for the floating power base case design. A system of this type incorporated into the floating power base case design would require 
two storage ponds of the order of 30 million gallons each as well as additional night time cooling capacity. This type of system can result in some increase in average floating power (partially due to evaporation cooling of ponds) with some reduction in evaporation losses and properly designed can reduce the power fluctuations some but the expense of two ponds and the additional cooling capacity could be extremely costly.

Another type of phase stored cooling system designed to reduce the floating power fluctuations consists of a hot and a cold storage pond and operation such that the cooling water temperature remains constant. This is done by bleeding water out of the coolant loop and replacing it with water of a different temperature so that the cooling temperature at the condenser inlet remains constant. For instance, during the warmer part of the day when the cooling water from the cooling tower is warmer than the mean temperature, some of the warm water is bleed out of the cooling loop and stored in the warm pond while some water from the cold water is feed into the loop to maintain a constant cooling water temperature. In practice, it would be very difficult to balance out the warm and cold water storages since the atmospheric temperature varies so much from one day to another and each day varies differently. If one had a nice standard day which say varied from $11600 \mathrm{kw}$ to $12600 \mathrm{kw}$ (see Figure 13) in a relatively smooth sinusoidal manner the fluctuating power during that day could be leveled out with two storage ponds of the order of 15 million gallons each. But since days are seldom very standard and differ greatly from day to day, the storage volumes to significantly reduce floating power fluctuations will be much greater. The magnitude of these storage volumes was not calculated but will most probably be on the same order as the volumes depicted in Figure 22 for the adiabatic stored water system if not larger due to heat transfer effects and the fact that this phase cooling system requires two ponds instead of one. 


\section{CONCLUSIONS AND RECOMMENDATIONS}

The floating power concept is a viable concept for realizing a significant power increase in power plants cooled by the atmosphere. Floating power coefficients of performance (ratio of the yearly averaged floating power to the design power) calculated were on the order of 1.2 for the wet cooling systems and the order of 1.5 to 2.5 for the dry cooling systems. This clearly illustrates the inefficient use of the atmospheric cooling potential of most cooling system designs.

The stored cooling concept has the capacity of dampening the floating power fluctuations but only with the use of relatively large volumes of stored water. The cost effectiveness of stored cooling will have to be evaluated for each individual power plant design. A cost effectiveness evaluation must trade off the increased power production of the floating power concept with the disadvantage of the floating power fluctuations on the power grid or the cost of dampening the fluctuations.

Additional studies into advanced cooling systems are recommended. Advanced systems such as direct air condensers (both wet and dry types) have promise in that the temperature differential between the condensing temperature and the atmospheric temperature is reduced. Floating power studies on other types of power plants and studies of the effects of floating power fluctuations on power grids should be made. 


\section{REFERENCES}

1. C. J. Buchenauer, Solar Radiation Flux and Insolation Data for Southern Idaho, ANCR-1269, (November 1975).

2. I. J. Ingvarsson and W. W. Madsen, Determination of the $5 \mathrm{MW}$ Gross Nominal Design Case Binary Cycle for Power Generation at Raft River, Idaho, TREE-1039, (December 1976).

3. J. P. Holman, Heat Transfer, New York: McGraw-Hill Book Company, 1968.

4. J. W. Langhaar, "Cooling Pond May Answer Your Water Cooling Problem", Chem. Engr. 60 (8) (1953), pp. 194 - 198. 
Page 1 of 13

APPENDIK A

THE MONTHLY AVERAGE DAYS FOR THE BASE CASE DESIGN 


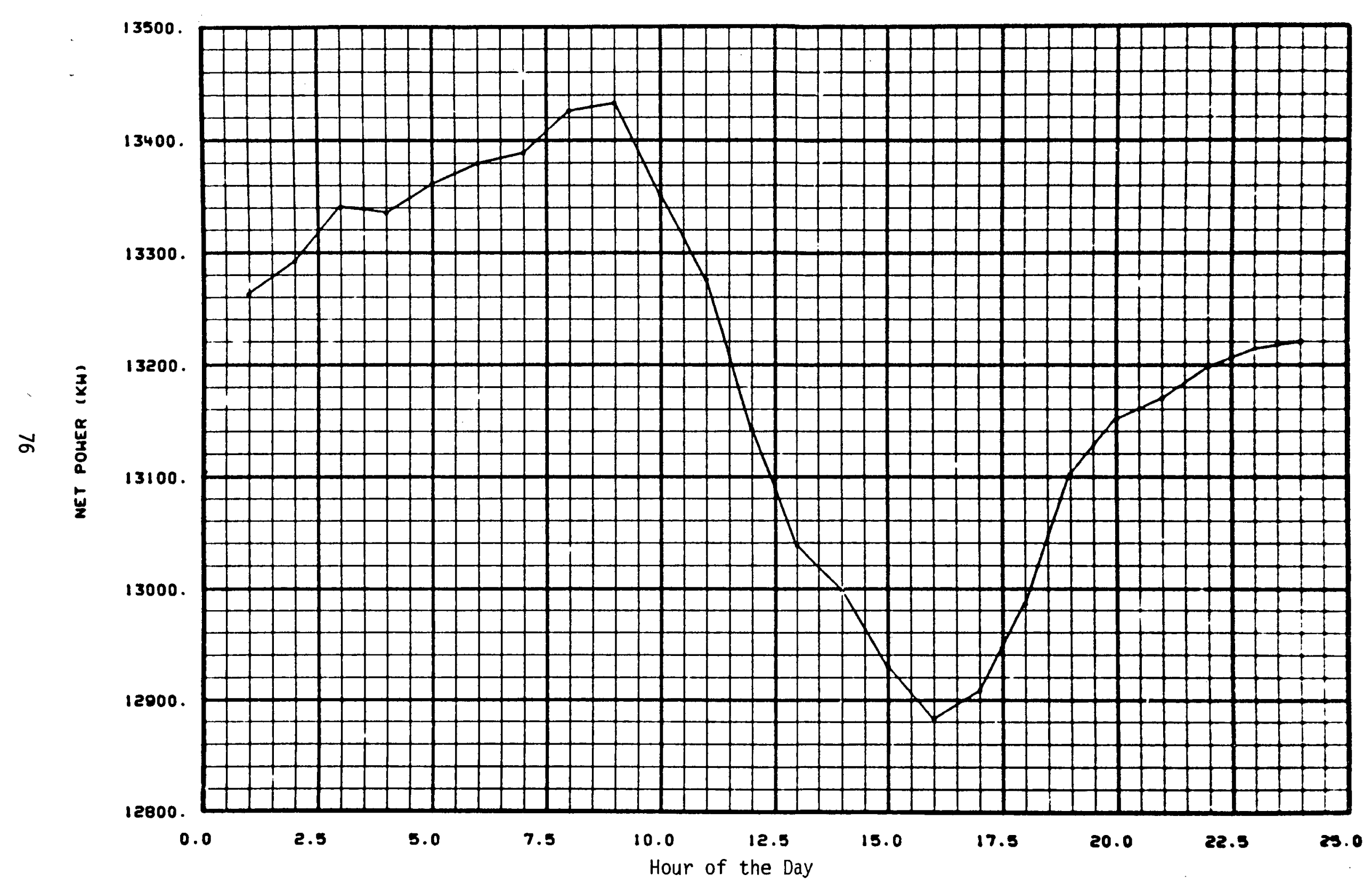

Figure A1: The net electrical floating power for the average day in January, 1959. 


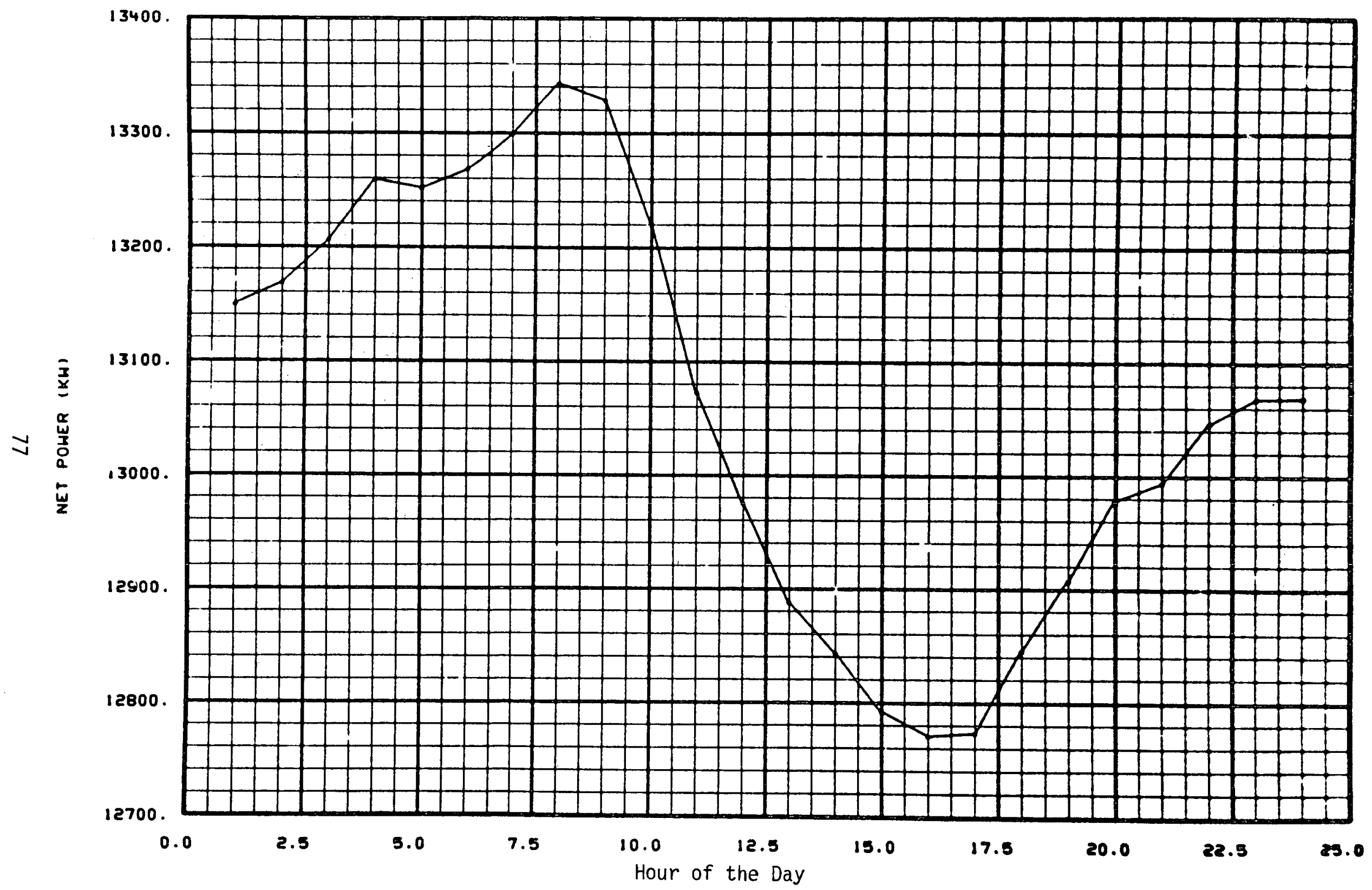

Figure A2: The net electrical floating power for the average day in February, 1959. 


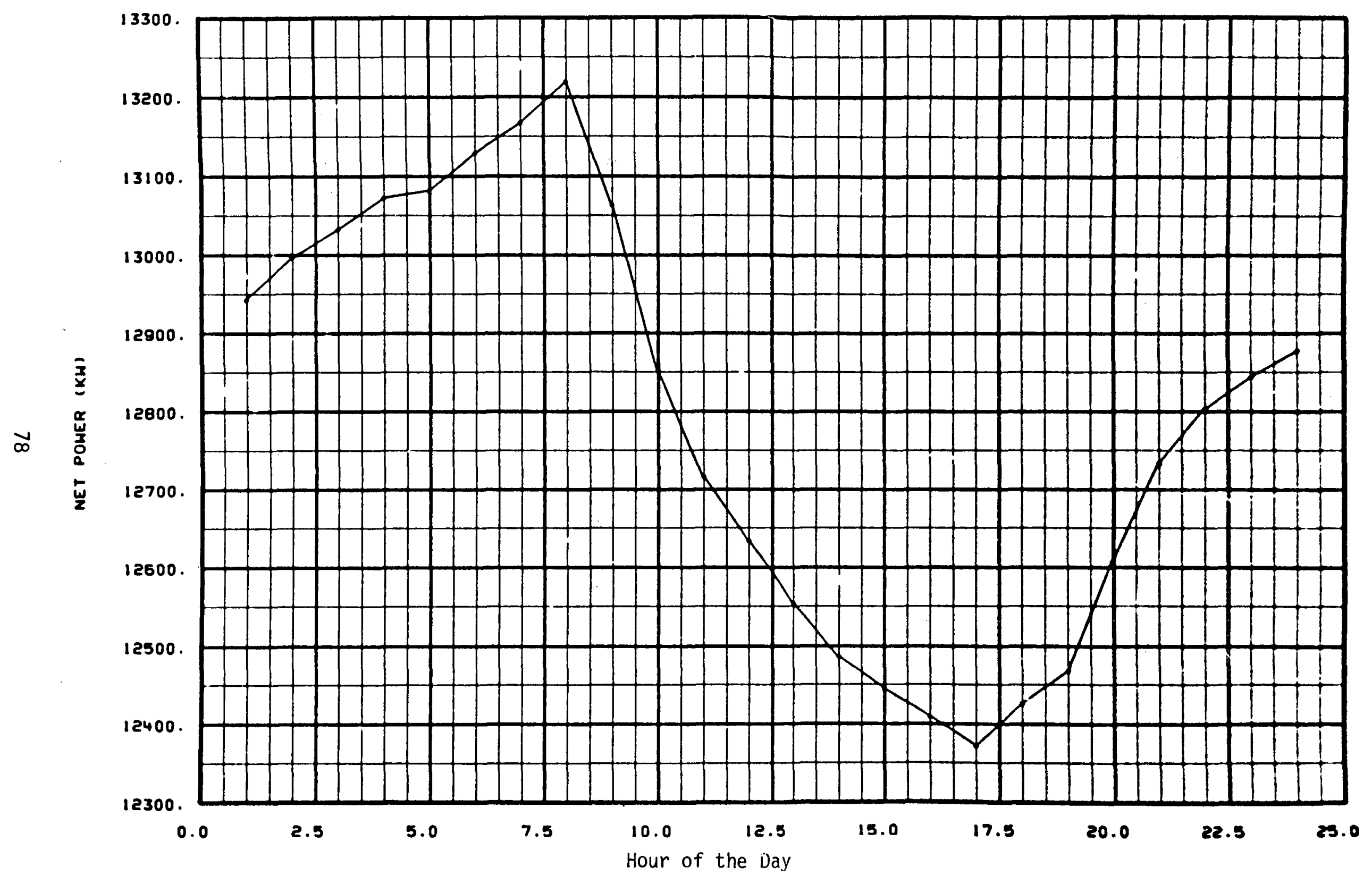

Figure A3: The net electrical floating power for the average day in March, 1959. 



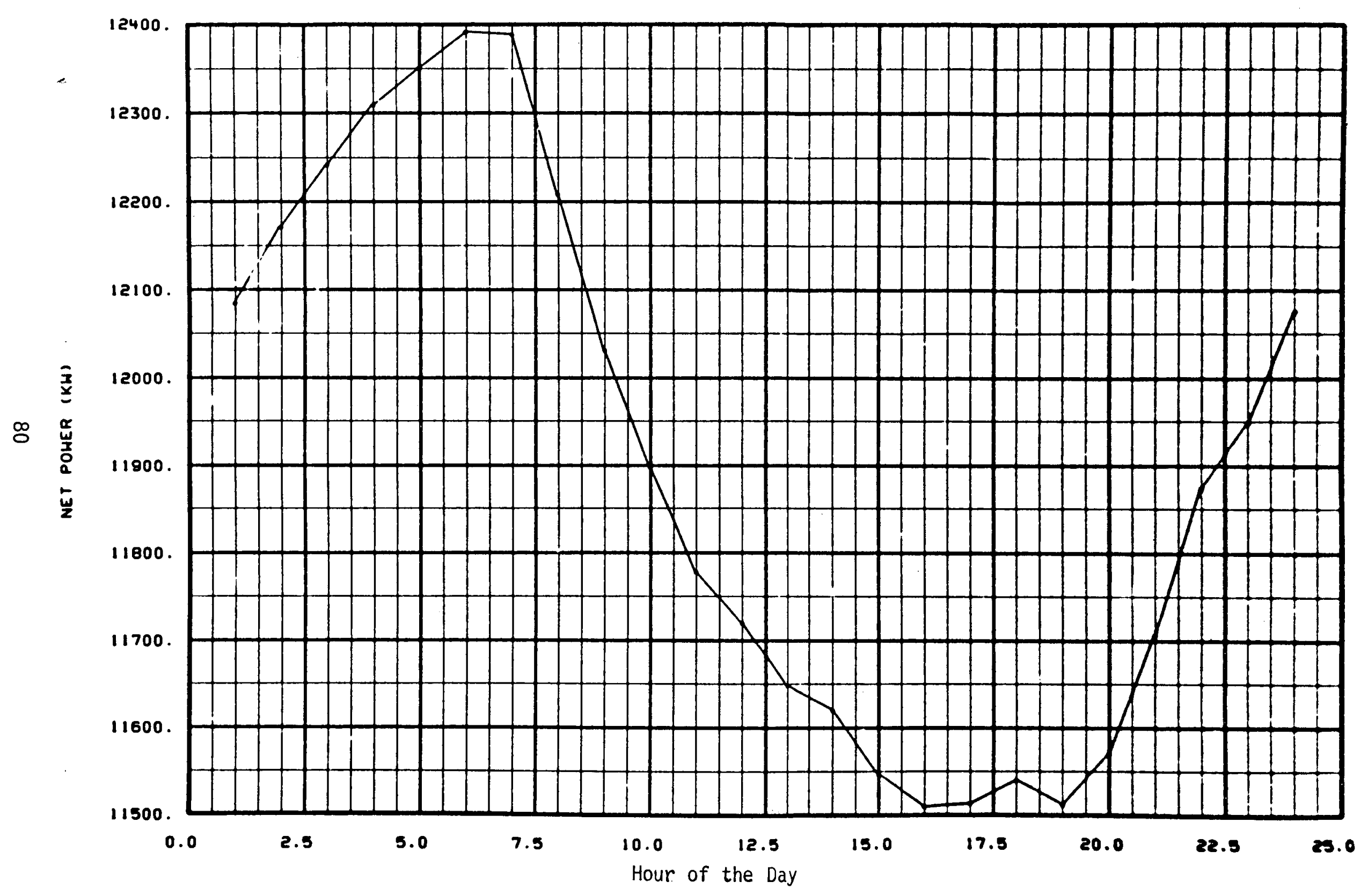

Figure A5: The net electrical floating power for the average day in May, 1959. 


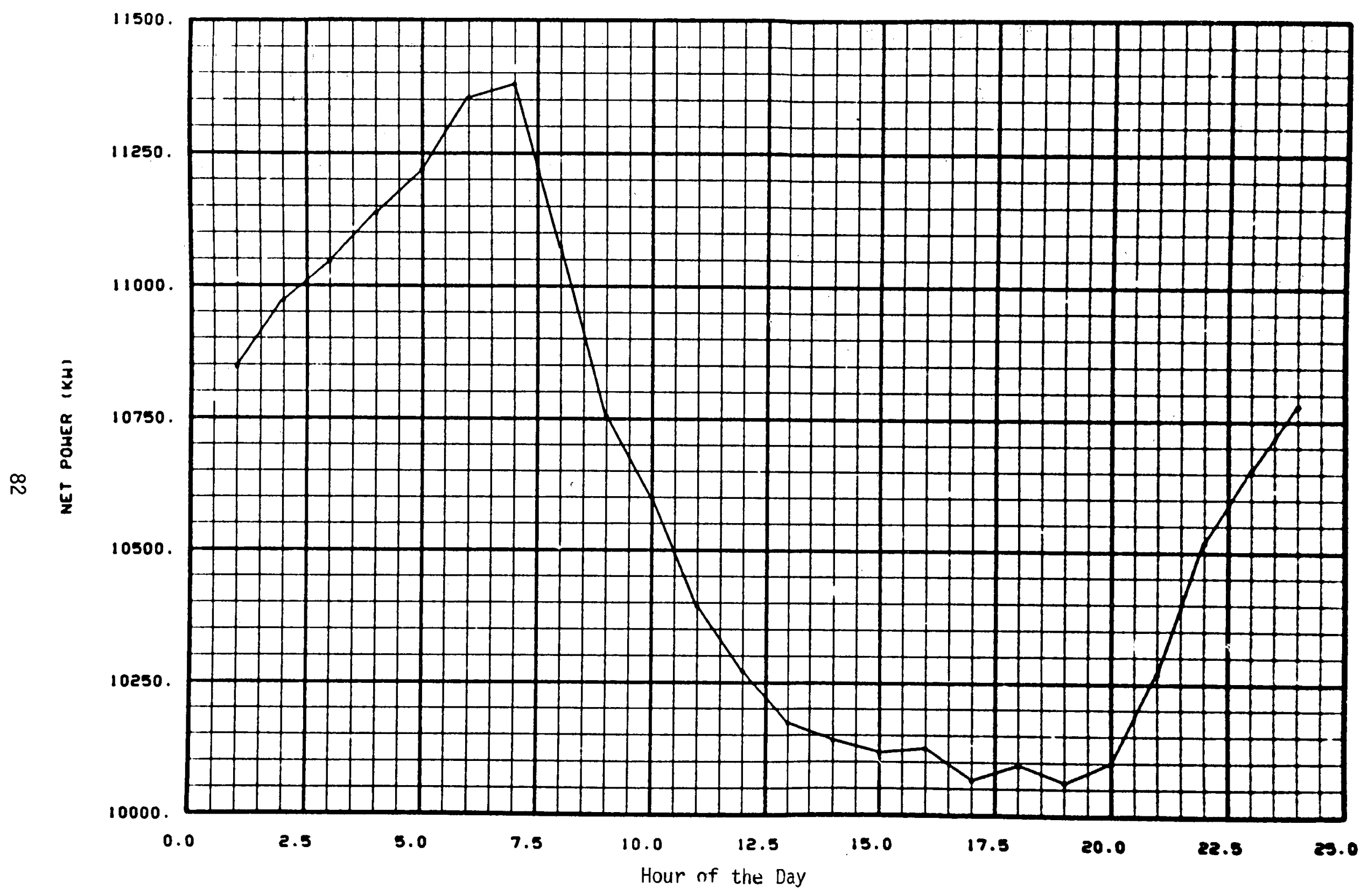

Figure A7: The net electrical floating power for the average day in July, 1959. 


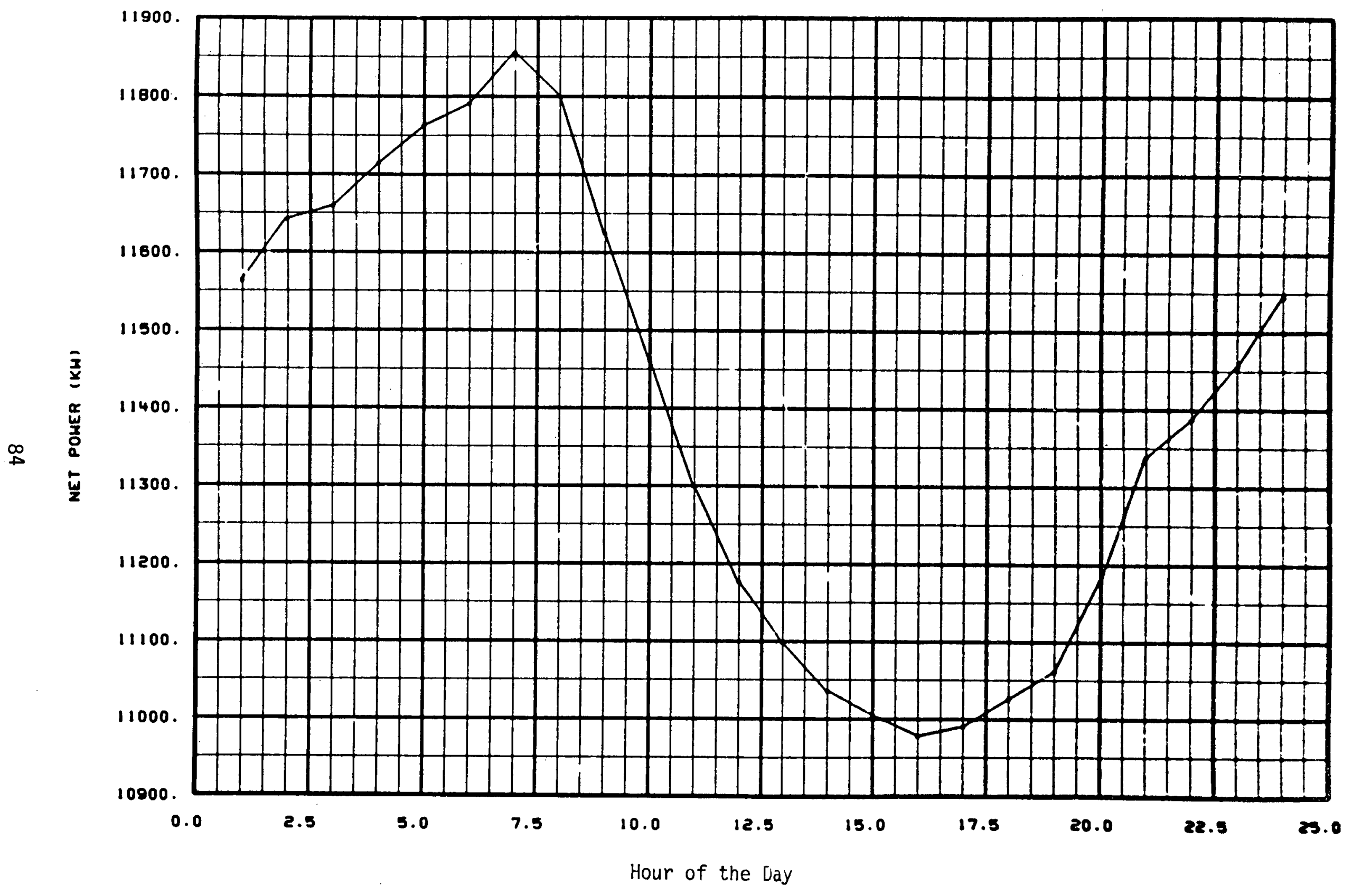

Figure A9: The net electrical floating power for the average day in September, 1959. 


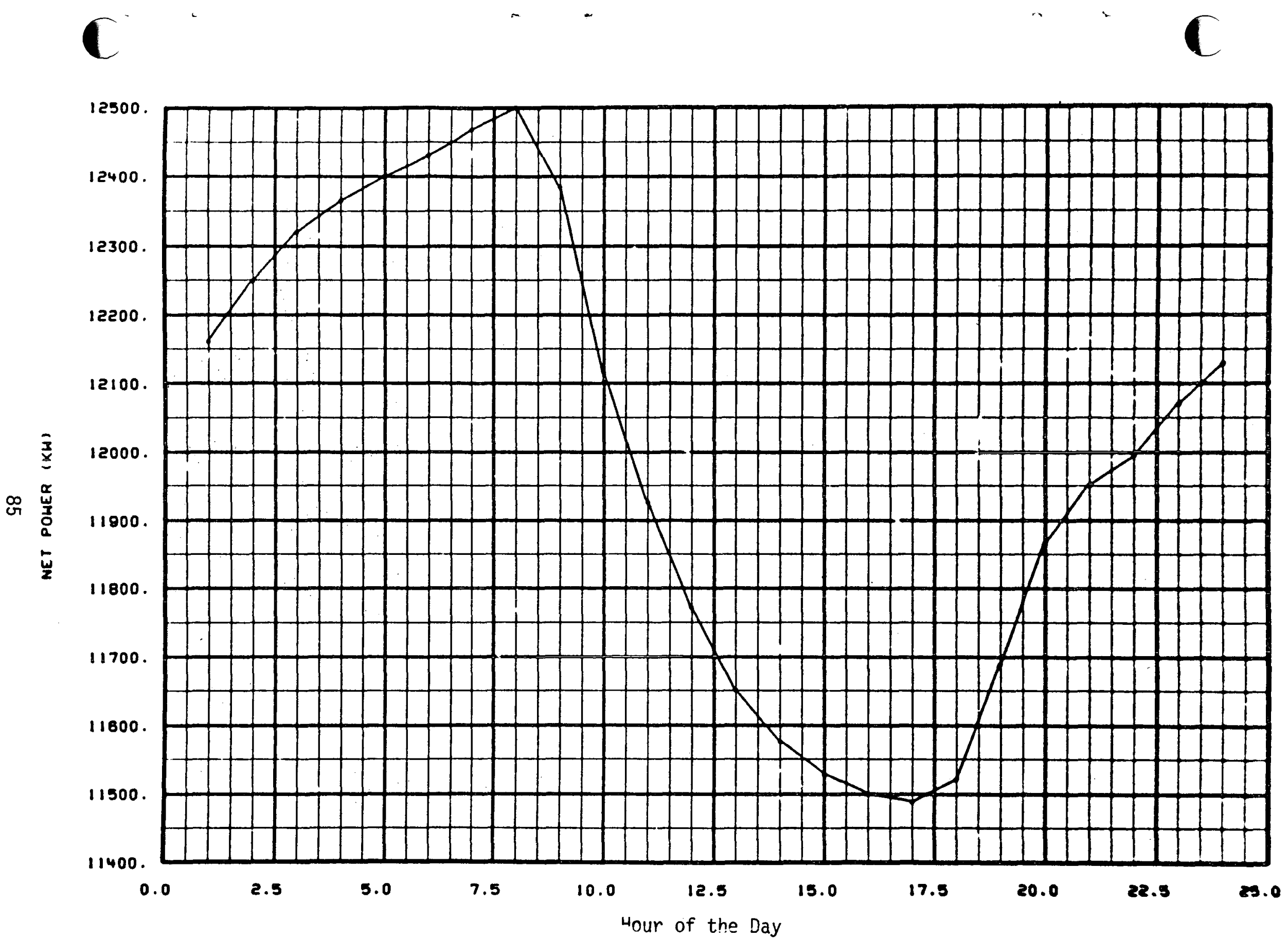

Figure A10: The net electrical floating power for the average day in October, 1959. 


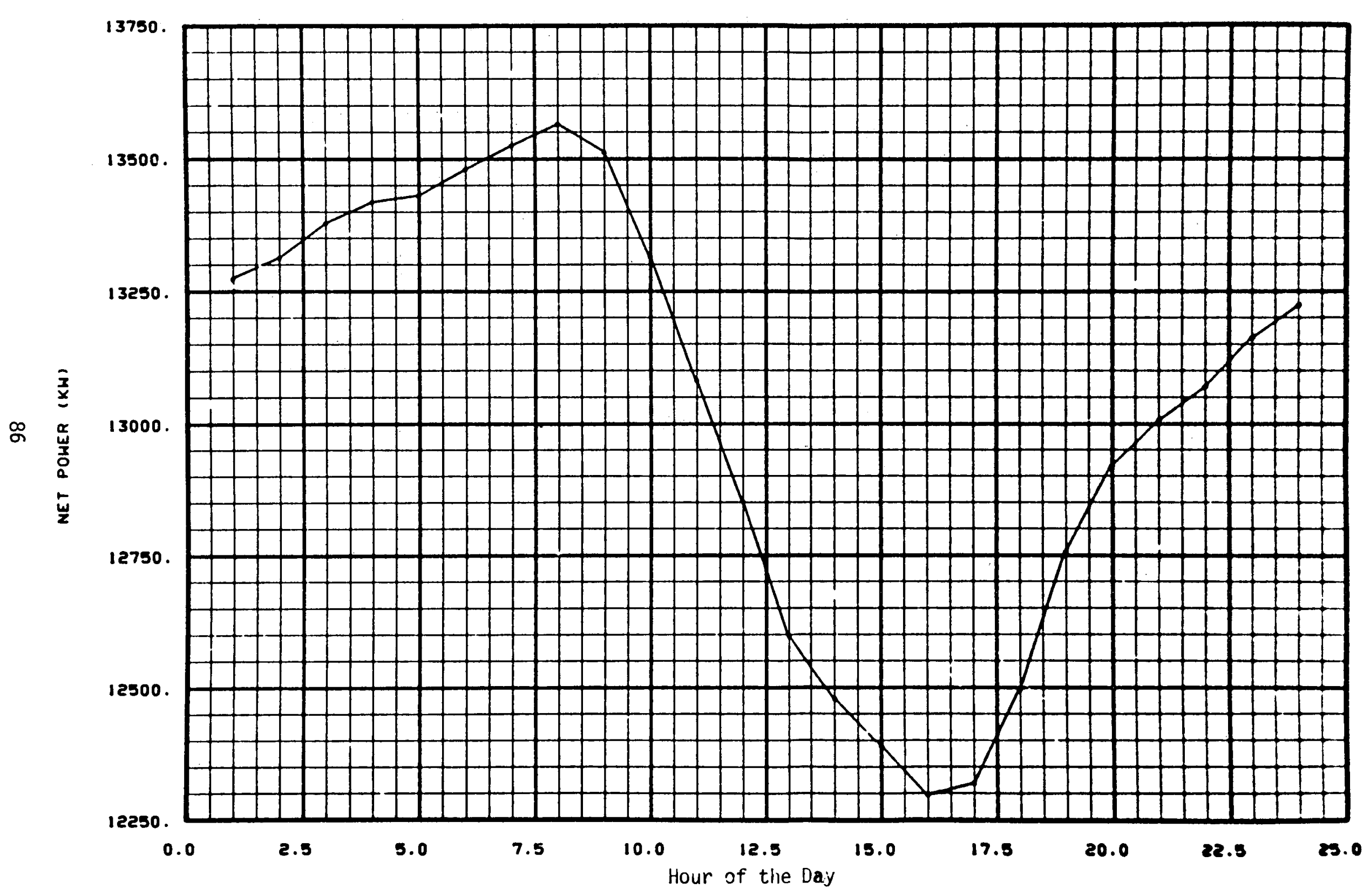

Figure A11: The net electrical floating power for the average day in November, 1959. 


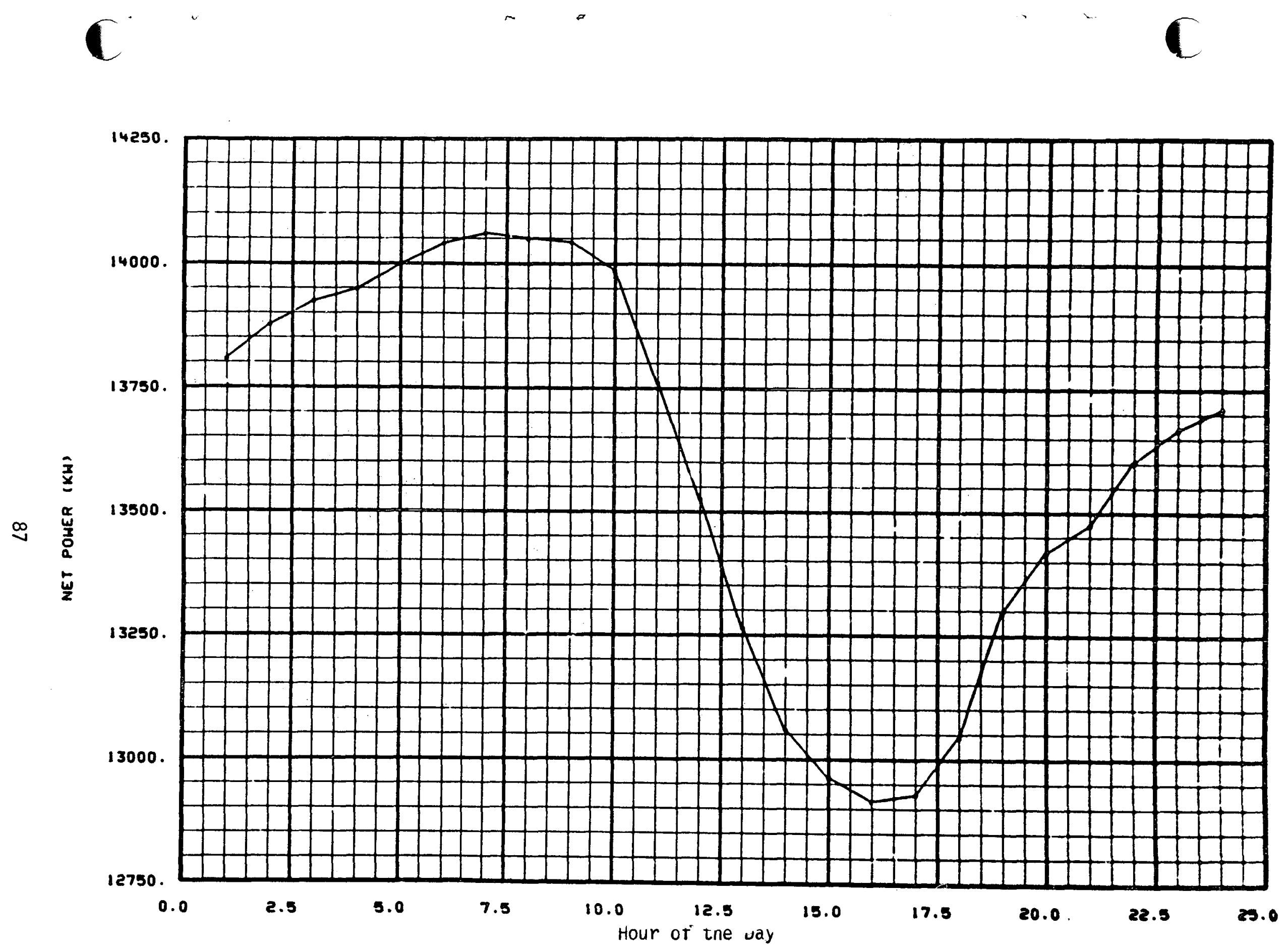

Figure A12: The net electrical floating power for the average day in December, 1959. 


\section{DISTRIBUTION RECORD FOR TREE-1164}

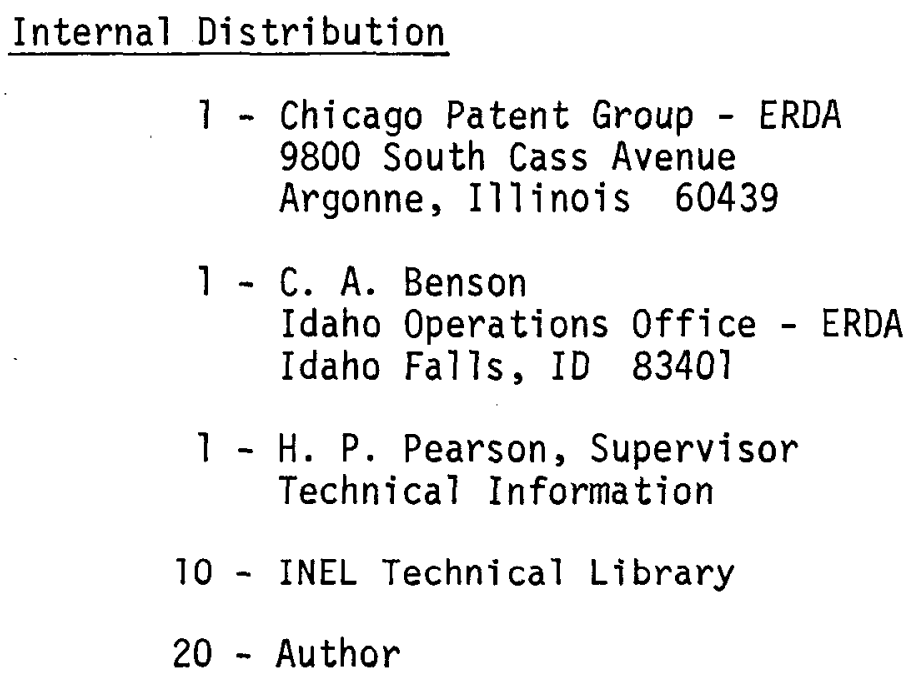

External Distribution

419 - UC-66 - Geothermal Energy, TID-4500, R65 